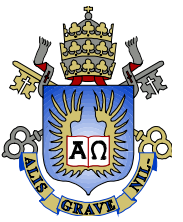

Gil Capote Mastrapa

\title{
Estudo da incorporação de fósforo em grafeno crescido por CVD usando trifenilfosfina como precursor
}

Dissertação de Mestrado

Dissertação apresentada como requisito parcial para obtenção do título de Mestre pelo Programa de PósGraduação em Física da PUC-Rio.

Orientador: Prof. Fernando Lázaro Freire Júnior 
Gil Capote Mastrapa

\section{Estudo da incorporação de fósforo em grafeno crescido por CVD usando trifenilfosfina como precursor}

Dissertação apresentada como requisito parcial para obtenção do grau de Mestre pelo Programa de Pós-Graduação em Física do Departamento de Física do Centro Técnico Científico da PUC-Rio. Aprovada pela Comissão Examinadora abaixo assinada.

Prof. Fernando Lázaro Freire Júnior Orientador Departamento de Física - PUC-Rio Prof. André Santarosa Ferlauto UFMG

Prof. Pedro Paulo de Mello Venezuela UFF

Prof. José Eugenio Leal Coordenador Setorial do Centro

Técnico Científico - PUC-Rio

Rio de Janeiro, 30 de maio de 2014. 
Todos os direitos reservados. É proibida a reprodução total ou parcial do trabalho sem autorização da universidade, da autora e do orientador.

\section{Gil Capote Mastrapa}

Graduou-se em Engenharia em Tecnologias Energéticas y Nucleares pelo Instituto Superior de Tecnologias y Ciencias Aplicadas (Havana, Cuba-2008).

Ficha Catalográfica

Mastrapa, Gil Capote

Estudo da incorporação de fósforo em grafeno crescido por CVD usando trifenilfosfina como precursor / Gil Capote Mastrapa; orientador: Fernando Lázaro Freire Júnior. - Rio de Janeiro: PUC, Departamento de Física, 2014.

$$
\text { v., } 77 \text { f : il. ; 29,7 cm }
$$

Dissertação (Mestrado) - Pontifícia Universidade Católica do Rio de Janeiro, Departamento de Física, 2014.

Inclui referências bibliográficas.

1. Física - Tese. 2. Grafeno; Fósforo; CVD; 3. Raman; XPS; MEV. I. Freire Júnior, Fernando Lázaro. II. Pontifícia Universidade Católica do Rio de Janeiro. Departamento de Física. IV. Título. 
À minha mãe e noiva. 


\section{Agradecimentos}

À minha mãe, minha irmã e família por todo o apoio, agora e sempre.

À minha noiva, por estar ao meu lado desde o começo, em bons e maus momentos, por todo o amor e a compreensão.

Ao Prof. Fernando Lázaro Freyre Júnior por acreditar em mim e me ajudar sempre que precisei, pela paciência e pela amizade.

Ao doutor Dunieskys Roberto González Larrudé, grande amigo, por toda sua ajuda oferecida na realização deste trabalho e por estar sempre presente.

Aos meus colegas da pós-graduação Cesar Diaz Mendoza e Neileth Stand, Eric Cardona, Cinthya Blois, Erika Ochoa, Stefania Nardecchina. Pelas discussões e por todo o que tenho aprendido nestes dois anos. Não teria conseguido sem vocês.

Ao Prof. Marcelo Eduardo Huguenin Maia da Costa pelas boas ideias e por todas as discussões sobre o XPS.

À Giza, por me ajudar tanto e tão seguido.

Aos técnicos e funcionários Carlos Augusto, Edson, Nilton, ao engenheiro Sérgio e a química Cassia.

Aos professores e funcionários do departamento de física.

À CAPES pelo apoio financeiro sem o qual esse trabalho não seria possível. 


\section{Resumo}

Capote Mastrapa, Gil: Freyre Júnior, Fernando Lázaro. Estudo da incorporação de fósforo em grafeno crescido por CVD usando trifenilfosfina como precursor. Rio de Janeiro, 2014. 77p. Dissertação de Mestrado-Departamento de Física, Pontifícia Universidade Católica do Rio de Janeiro.

Neste trabalho foram obtidos filmes de grafeno usando um precursor sólido, a Trifenilfosfina, num processo de deposição química na fase vapor em alto vácuo (HVCVD). A microscopia eletrônica de Varredura permitiu observar a presença de pequenas regiões inomogêneas na superfície das amostras crescidas. Estas regiões foram observadas na microscopia antes e após o processo de transferência da folha de cobre para o substrato de silício oxidado. Medidas realizadas por XPS permitiram comprovar a incorporação de fósforo no filme crescido. A espectroscopia Raman foi usada para determinar a temperatura de trabalho adequada no sistema de crescimento. A presença de grafeno foi confirmada em todas as amostras, mas observou-se que, em geral, a quantidade de defeitos nas amostras cresceu com o aumento da massa do precursor utilizado no crescimento. Os resultados obtidos são discutidos à luz de recentes trabalhos teóricos que tratam do uso da técnica Raman no estudo de defeitos em grafeno.

\section{Palavras Chaves}

Grafeno; Raman; dopante; fósforo; CVD. 


\section{Abstract}

Capote Mastrapa, Gil: Freyre Júnior, Fernando Lázaro. Phosphorus incorporation into graphene prepared by CVD using triphenylphosphine as precursor. Rio de Janeiro, 2014. 77p. Msc. Dissertation-Departamento de Física, Pontifícia Universidade Católica do Rio de Janeiro.

In this work graphene films were obtained using a solid precursor, Triphenylphosphine, by chemical vapor deposition in high vacuum (HVCVD). Scanning electron microscopy allowed to observe the presence of small inhomogeneus regions on the surface of the grown samples. These regions were observed in the microscopy before and after the transfer process from the copper foil to silicon oxidized wafer. XPS measurements checked the incorporation of phosphorus in the film grown. Raman spectroscopy was used to determine the suitable working temperature in the growth system. The presence of graphene was confirmed in all samples, but it was observed that in general, the amount of defects in the samples increased with increasing the mass of the precursor used in growth. The results are discussed in light of recent theoretical works that address the use of Raman technique in the study of defects in graphene.

\section{Keywords}

Graphene; Raman; dopants; phosphorus; CVD. 


\section{Sumário}

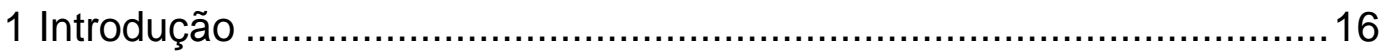

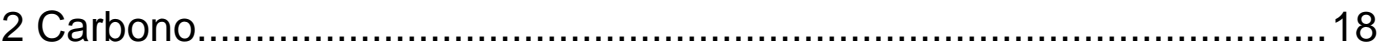

2.1 Estrutura Eletrônica do Grafeno ……………….......................... 19

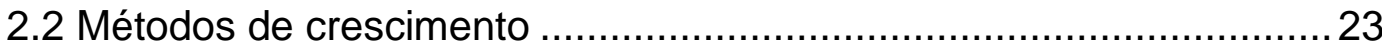

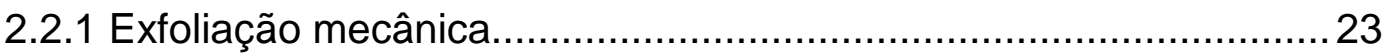

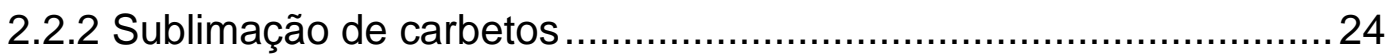

2.2.3 Deposição química na fase vapor (CVD) ……….......................... 25

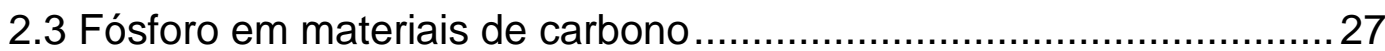

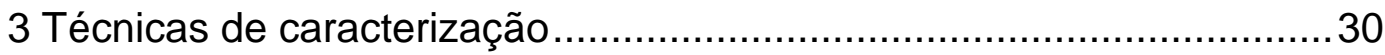

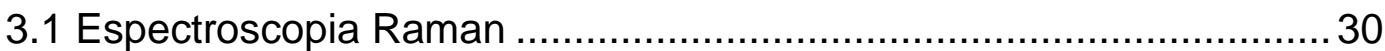

3.1.2 Espectro Raman do grafeno...................................................... 32

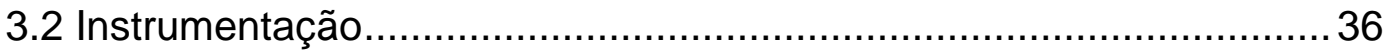

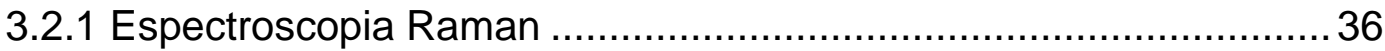

3.2.2 Espectroscopia de fotoelétrons induzida por raios X (XPS) .............38

3.2.3 Microscopia Eletrônica de Varredura (Scanning Electron

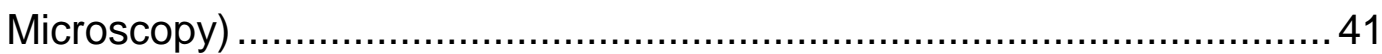

3.2.4 Microscopia Eletrônica de Transmissão (Transmission

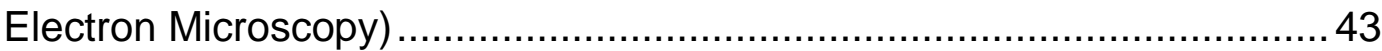

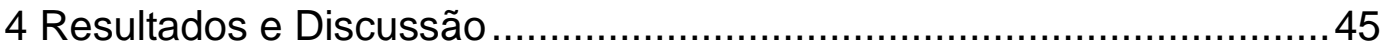

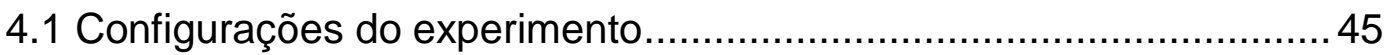

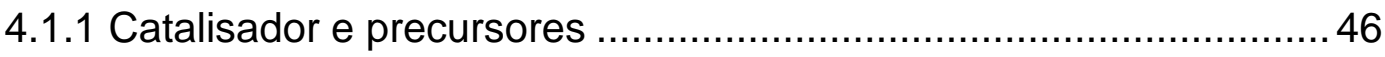

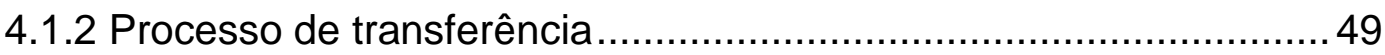

4.2 Caracterização por Microscopia Eletrônica de Varredura

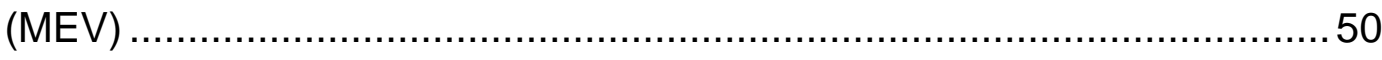


4.3 Caracterização por Microscopia Eletrônica de Transmissão

(MET)

4.4 Caracterização por Microscopia de Força Atômica (AFM) ……….......55

4.5 Caracterização das amostras por Espectroscopia Raman .................. 56

4.6 Espectroscopia por fotoelétrons induzidos por raios X (XPS) ............6 64

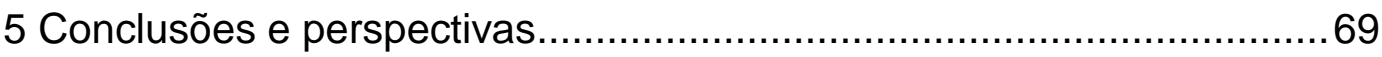

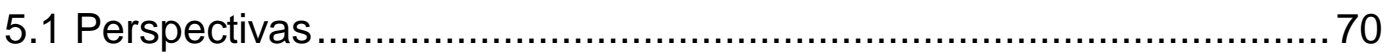

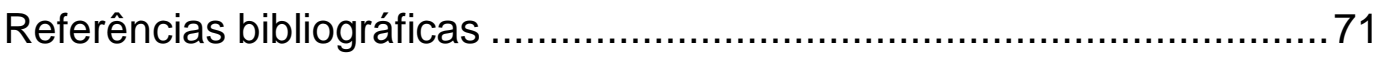




\section{Lista de figuras}

Figura 2.1 Esquema da configuração dos orbitais eletrônicos no grafeno.

Figura 2.2 Alótropos do carbono formados por hibridização sp2[3].

Figura 2.3 Estrutura cristalina do grafeno. a) Célula unitária (losango pontilhado) e vectores primitivos da rede no espaço real, b) Espaço reciproco com seus vetores unitários b1 e b2. A primeira zona de brillouin é mostrada na cor cinza e os pontos de alta simetria nela $(\Gamma, \mathrm{M}$ e K) são representados[4].

Figura 2.4 Curvas de dispersão do grafeno na primeira zona de Brillouin. No insert, se mostra o comportamento linear da dispersão em torno dos pontos de Dirac[5].

Figura 2.5 Imagem ótica de filme de grafeno obtido por exfoliação mecânica de grafite altamente ordenado e transferido para um substrato de oxido de silício. Observasse a diferencia da cor correspondente a uma monocamada de grafeno e varias camadas.(Adaptado de [7]).

Figura 2.6 Microscopia eletrônica de um filme de grafenoobtido por CVD usando um substrato de cobre como catalizador.

Figura 2.7 Estrutura geométrica otimizada do átomo de fósforo no filme de grafeno[38] (distância em $A^{\circ}$ ).

Figura 3.1 Esquema de níveis de energia para o espalhamento elástico a) e inelástico, Stokes b) e Anti-Stokes c). Os níveis de energia são representados pelas linhas horizontais. Observa-se a perda e ganho de energia nos processos Stokes e AntiStokes, indicado pelas setas verticais indicando os fótons incidentes e espalhados.

Figura 3.2 Esquema das relações de dispersão dos fônons para o grafeno para os pontos de alta simetria ГМКГ[46].

Figura 3.3 Espectro Raman de amostras de grafenocrescido por CVD mostrando as principais bandas características. A) amostra com poucos defeitos. B) amostra defeituosa. Energia do laser $2.62 \mathrm{eV}$, Potência $0.15 \mathrm{~mW}$.

Figura 3.4 Exemplos de processos Raman possíveis e correspondência para cada banda do espectro no grafeno. As setas verticais azuis e vermelhas correspondem aos fótons incidentes e espalhados respetivamente. As linhas com traços 
correspondem á emissão de fônons e as linhas pontilhadas horizontais correspondem á dispersão de elétrons em defeitos da amostra. a) Banda G,(b-d) Processos de primeiro ordem (um fônon) na presença de defeitos, intra-vale (banda D') ou inter-vale (banda D). (e-g) Processos de segundo ordem: 2D, 2D', D+D' e D+D"' (Adaptado de [48]).

Figura 3.5 Fotografia do espectrômetro Raman instalado no Laboratório de Revestimentos Protetores e Materiais Nanoestruturados. No insert, o Laser de estado sólido utilizado $(\lambda=473 \mathrm{~nm})$.

Figura 3.6 Desenho de princípio básico do microscópio de força atômica (AFM). Um cantilever, com uma pequena ponta (sonda), move-se ao longo da superfície e experimenta forças atômicas. Laser e fotodiodo são usados para medir as forças. b) Dispositivo de suporte do cantilever. c) Foto da ponta de DLC (NT NSG10_DLC) usada nas medições.

Figura: 3.7 Diagrama para o processo de emissão de XPS (esquerda). Um fóton incidenteprovoca a ejeção do fotoelétron. Processo secundário de relaxamento (direita), resultando na emissão de um elétron Auger.

Figura 3.8 Fotografia da câmara do espectrômetro de fotoelétrons induzido por raios-X (XPS) usado nos experimentos e instalado no Laboratório Van de Graaff.

Figura 3.9 Fotografia do microscópio modelo JSM6701Finstalado no Laboratório de Revestimentos Protetores e Materiais Nanoestruturados.

Figura 3.10 Fotografia do microscópio JEM 2100F usado nas medidas por MET.Laboratório de Nanociência e Nanotecnologia (LABNANO), CBPF.

Figura 4.1 Esquema do sistema de crescimento usado no crescimento.

Figura 4.2 Sistema de crescimento por HVCVD instalado no Laboratório Van de Graaff.b) Detalhe do forno e a placa quente usados. No insert, controlador de fluxo de gás usado.

Figura 4.3 Folha de cobre de $25 \mu \mathrm{m}$ de espessura usada nos crescimentos (Sigma-Aldrich, $99.9 \%$ de pureza). Observam-se as linhas na superfície do cobre na microscopia ótica.

Figura 4.4 Esquema da estrutura da molécula de Trifenilfosfina. O átomo amarelo corresponde ao fósforo, rodeado de três anéis fenilo.b) Trifenilfosfina (Sigma Aldrich, $99 \%$ de pureza) usada nos crescimentos. No insert, pó de Trifenilfosfina no cadinho usado no crescimento. 
Figura 4.5 Diagrama do processo de transferência utilizado.b) Amostras durante e após o processo de transferência para 0 substrato de $\mathrm{SiO}_{2} / \mathrm{Si}$ seguindo o procedimento descrito anteriormente.

Figura 4.6 Imagem obtida por MEV de uma amostra de grafenocrescido por HVCVD com $20 \mathrm{sccm}$ de pressão de $\mathrm{CH}_{4}$. a) Sobre o substrato de cobre, b) Amostra transferida para 0 substrato de oxido de silício.

Figura 4.7 Imagens por microscopia eletrônica de varredura dos filmes crescidos usando Trifenilfosfina como precursore transferidos para lâminas de oxido de silício. As imagens em a), b), c) e d) correspondem ás amostras crescidas com 10, 20, 30 e $40 \mathrm{mg}$ de precursor, respectivamente. Observa-se a presença de pequenas regiões escuras espalhadas nas imagens em todos os casos.

Figura 4.8 Comparação das imagens por microscopia eletrônica de varredura dos filmes crescidos usando $20 \mathrm{mg}$ de Trifenilfosfina como precursor, antes a) e após b) a transferência.

Figura 4.9 Imagens de microscopia eletrônica de transmissão (MET) de grafeno crescido com $20 \mathrm{mg}$ de Trifenilfosfina em modo de imagem de campo claro. b) Ampliação da imagem para a mesma amostra. Microscópio usado: modelo JEOL JEM 2100F, calibrado para uma energia do feixe de elétrons de $100 \mathrm{kV}$.

Figura 4.10 Imagens de microscopia de Força Atômica (AFM) de grafeno crescido com $20 \mathrm{mg}$ de Trifenilfosfina $(8 \mu \mathrm{m}$ quadrados). b) Ampliação de $3 \mu \mathrm{m}$ quadrados para a mesma amostra. c) Gráfico do perfil de altura correspondente à linha em (b). (Modo semi-contato. Ponta de carbono DLC).

Figura 4.11 Espectros Raman normalizados de grafeno obtido para diferentes temperaturas de crescimento. Amostras medidas sobre substrato de cobre obtidas com $20 \mathrm{mg}$ de Trifenilfosfina como precursor.(Energia do laser $2.62 \mathrm{eV}$, potência do laser $0.15 \mathrm{~mW}$, resolução espectral de $3 \mathrm{~cm}^{-1}$ ).

Figura 4.12 Espectros Raman normalizados de filmes de grafeno crescidos por HVCVD para os quatro casos que foi usada a Trifenilfosfina sólida, assim como no caso de referencia crescido com gás metano. b) Bandas $D$ e $G$ dos espectros anteriores. (Energia do laser $2.62 \mathrm{eV}$, potência do laser $0.15 \mathrm{~mW}$, resolução espectral de $3 \mathrm{~cm}^{-1}$ ).

Figura 4.13 Espectros Raman normalizados em diferentes regiões da amostra crescida com $10 \mathrm{mg}$ de Trifenilfosfina, 
correspondendo a a) Regiões sem irregularidades, b) Regiões irregulares escuras, c) Imagem de MEV da linha medida. As localizações aproximadas das medidas na amostra correspondem às pontas das setas. (Energia do laser $2.62 \mathrm{eV}$, potência do laser $0.15 \mathrm{~mW}$, resolução espectral de $3 \mathrm{~cm}^{-1}$ ).

Figura 4.14 Espectros Raman normalizados em diferentes regiões da amostra crescida com $20 \mathrm{mg}$ de Trifenilfosfina, correspondendo a a) Regiões sem irregularidades, b) Regiões irregulares escuras, c) Imagem de MEV da linha medida. As localizações aproximadas das medidas na amostra correspondem às pontas das setas. (Energia do laser $2.62 \mathrm{eV}$, potência do laser $0,15 \mathrm{~mW}$, resolução espectral de $3 \mathrm{~cm}^{-1}$ )

Figura 4.15 Espectros Raman normalizados em diferentes regiões da amostra crescida com $30 \mathrm{mg}$ de Trifenilfosfina, correspondendo a a) Regiões sem irregularidades, b) Regiões irregulares escuras, c) Imagem de MEV da linha medida. As localizações aproximadas das medidas na amostra correspondem às pontas das setas. (Energia do laser $2.62 \mathrm{eV}$, potência do laser $0.15 \mathrm{~mW}$, resolução espectral de $3 \mathrm{~cm}^{-1}$ ).

Figura 4.16 Espectros Raman normalizados em diferentes regiões da amostra crescida com $40 \mathrm{mg}$ de Trifenilfosfina, correspondendo a a) Regiões sem irregularidades, b) Regiões irregulares escuras, c) Imagem de MEV da linha medida. As localizações aproximadas das medidas na amostra correspondem às pontas das setas. (Energia do laser $2.62 \mathrm{eV}$, potência do laser $0.15 \mathrm{~mW}$, resolução espectral de $3 \mathrm{~cm}^{-1}$ )

Figura 4.17 Posição da banda G para o grafeno crescido com massas de precursor diferentes. As barras de erro mostram a variação da posição para diferentes pontos em cada amostra.(Energia do laser $2.62 \mathrm{eV}$, potência do laser $0.14 \mathrm{~mW}$, resolução espectral de $1 \mathrm{~cm}^{-1}$ ).

Figura 4.18 Espectro completo (survey) do grafeno crescido com $20 \mathrm{mg}$ de Trifenilfosfina e transferido para o substrato de oxido de silício. ( $h v=1253.6 \mathrm{eV}$ ) ( $1 \mathrm{eV}$ de passo)

Figura 4.19 Espectro de XPS do Carbono C1s do grafeno crescido com $20 \mathrm{mg}$ de Trifenilfosfina. O ajuste revela a presença de picos relacionados com o oxigênio ligado ao carbono presente na amostra. $(h v=1253.6 \mathrm{eV}) \quad(0.1 \mathrm{eV}$ de passo)

Figura 4.20 Espectro de XPS do Fósforo P2p do grafeno crescido com $20 \mathrm{mg}$ de Trifenilfosfina. $O$ ajuste revela a presença de dois dupletos. ( $h v=1253.6 \mathrm{eV})(0.1 \mathrm{eV}$ de passo) 


\section{Lista de tabelas}

Tabela 4.1 Concentrações relativas estimadas de Fósforo total e Fósforo-Carbono para os casos analisados. 68 
"Se o conhecimento pode criar problemas, não é através da ignorância que podemos solucioná-los.”

Isaac Asimov. 


\section{1 \\ Introdução}

Considerado o bloco base da maioria dos alótropos do carbono, o grafeno foi por muito tempo considerado impossível de se obter experimentalmente. Desde seu descobrimento há 10 anos, o grafeno tem gerado muito interesse na comunidade cientifica.

O grafeno é basicamente um cristal bidimensional formado por átomos de carbono arranjados em hexágonos, numa estrutura chamada de favo de mel (honeycomb). O fato de estar formado por só uma folha de átomos provoca uma mudança nas propriedades com respeito ao grafite, estrutura formada porpilhas ordenadas de milhares de folhas deste tipo.

A imensa popularidade atingida pelo grafeno se deve em grande parte as suas propriedades. É considerado um dos materiais mais resistentes já conhecidos, possuindo índice de rigidez 100 vezes maior do que o aço. Além disso, é extremadamente bom condutor tanto térmico quanto elétrico. Tudo isso sem falar sobre as suas propriedades eletrônicas únicas, com alta mobilidade devido a que seus portadores de carga se comportam como fermíones de Dirac sem massa. Essa mobilidade dos portadores de carga muito alta faz que o grafeno continue sendo intensamente estudado como uma possível alternativa ao silício na indústria eletrônica. No entanto, algumas aplicações ópticas e electrónicas precisam da existência de um gap de energia entre as bandas de valência e de condução. $\mathrm{O}$ grafeno no seu estado intrínseco é um semicondutor de gap zero, pelo qual é necessário o desenvolvimento de estratégias que contornem essa limitação. Um dos métodos é mediante a introdução de heteroátomos ligados no cristal de grafeno. As mudanças resultantes na estrutura eletrônica do material permitem a geração e controle de gaps de energia.

Muito tem mudado desde as primeiras pesquisas feitas na obtenção do grafeno. O método inicial desenvolvido por Geim e Novosselov de exfoliação mecânica usando uma fita adesiva sucessivamente tem sido replicado com êxito ao redor do mundo e ainda hoje é o jeito mais fácil de obter grafeno de alta 
qualidade. A falta de controle neste processo e a dimensão micrométrica das folhas obtidas fez com que novos métodos de crescimentos tenham sido propostos e estudados. Entre eles o mais popular no momento é o crescimento por deposição química na fase vapor, do inglês Chemical Vapor Deposition (CVD).

O processo original de deposição química na fase vapor (CVD) já era altamente conhecido desde a década dos sessentas como um método de recobrimento de metais na presença de um vapor químico precursor. Tem sido aplicado com êxito no caso do grafeno, permitindo a obtenção de filmes homogêneos e de alta qualidade na superfície de uma folha de um metal de transição, sendo o cobre o mais usado neste caso.

O objetivo principal deste trabalho será estudar o crescimento y caracterização de filmes de grafeno obtidos por CVD na presença de um precursor de fósforo. Tenta-se encontrar evidências da incorporação de átomos de fósforo no grafeno usando técnicas diversas, tais como a espectroscopia Raman ressonante e a espectroscopia de fotoelétrons excitados por raios-X (XPS). Além disso, serão usadas na caracterização as técnicas de microscopia eletrônica de varredura (SEM),microscopia eletrônica de transmissão (MET) e microscopia de força atômica (AFM).

Este trabalho está organizado em cinco capítulos. O capítulo 2 apresenta uma descrição básica das propriedades e estrutura cristalina do grafeno, assim como uma explicação dos principais métodos de crescimento e uma visão geral do que tem sido já feito com fósforo em materiais de carbono. No capítulo 3 são discutidos os conceitos e características principais das diversas técnicas utilizadas na caracterização das amostras. O quarto capítulo descreve as condições experimentais utilizadas e os resultados atingidos. A introdução e as conclusões correspondem ao primeiro e último capítulos respectivamente. 


\section{2}

\section{Carbono}

O carbono é um dos elementos mais importantes da tabela periódica. A grande flexibilidade das suas ligações faz dele um elemento muito versátil, apresentando um enorme numero de estruturas e compostos possíveis. Esta versatilidade faz com que muitos sistemas baseados no carbono tenham propriedades físicas muito diferentes. Ainda entre seus alótropos, estruturas compostas somente por átomos de carbono, o arranjo de seus átomos e a dimensionalidade destas provoca mudanças importantes nas propriedades mecânicas e eletrônicas. Um átomo de carbono possui seis elétrons distribuídos igualmente em orbitais $1 \mathrm{~s}, 2 \mathrm{~s}$ e $2 \mathrm{p}$. Os 4elétrons exteriores, responsáveis das ligações químicas no carbono podem se combinar em estados de hibridização dos seus orbitais, seja sp, sp2 ou sp3.

Ainda sendo estudado teoricamente por décadas[1], o grafeno só foi realmente isolado e estudado por Geim e Novosselov em 2004[2], trabalho pelo qual foram premiados com o Nobel em Física no ano 2010.

O grafeno é formado por uma folha de átomos de carbono arranjados em forma hexagonal com elétrons no estado de hibridização $\mathrm{sp} 2$, numa estrutura conhecida como favo de mel (honeycomb). Nesse estado os orbitais S, Px e Py se ligam covalentemente entre eles formando 3 orbitais $\sigma$ arranjados num plano, com ângulo de $120^{\circ}$ entre eles. Estas ligações $\sigma$ são responsáveis pela robustez da estrutura da rede no grafeno. O quarto elétron de valência (orbital $\mathrm{Pz}$ ) não se hibridiza originando o orbital $\pi$, perpendicular ao plano. Ver Figura 2.1. 


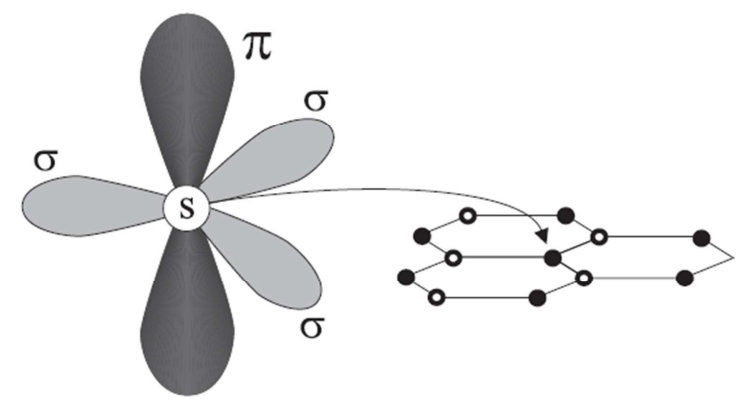

Figura 2.1 Esquema da configuração dos orbitais eletrônicos no grafeno.

Todos os alótropos do carbono formados por hibridização $\mathrm{sp} 2$ são então obtidos a partir das combinações de uma ou mais folhas de grafeno. É possível formar estruturas em 3D como o grafite, 2D como o grafeno, 1D como os nanotubos de carbono ou o chamado OD como os fulerenos, como ilustrado na Figura 2.2.

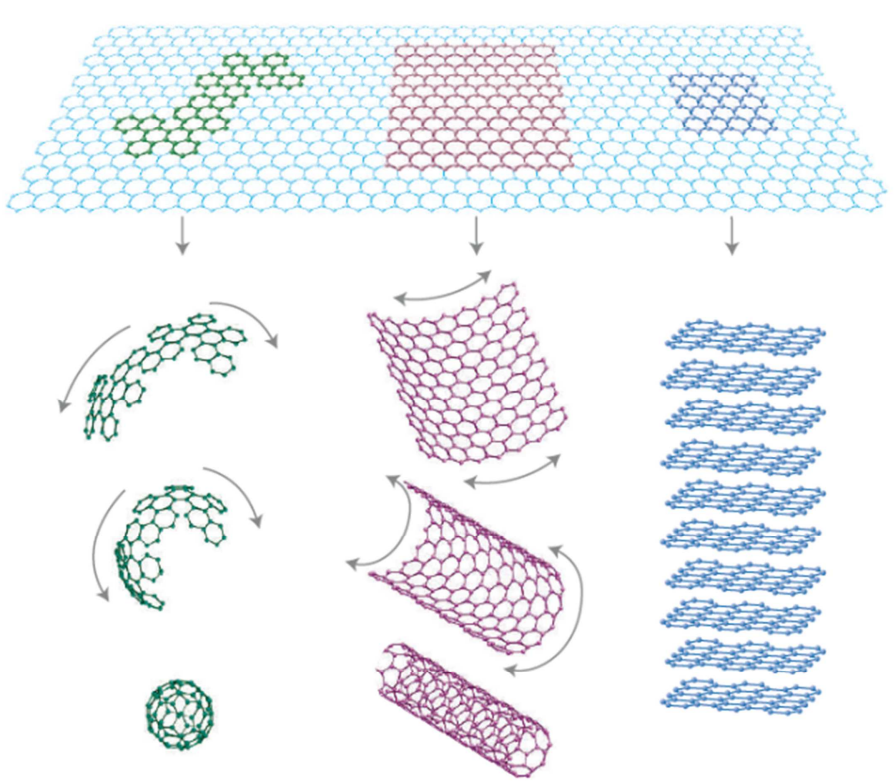

Figura 2.2 Alótropos do carbono formados por hibridização sp2[3].

\section{1}

\section{Estrutura Eletrônica do Grafeno}

O grafeno é formado por átomos de carbono com elétrons no estado de hibridização sp2. Os orbitais $\sigma$ e $\pi$ dão lugar a bandas eletrônicas independentes 
uma da outra. Diferentemente das ligações $\sigma$, as bandas geradas por ligações $\pi$ são causadas por interações fracas de Van der Waals e precisamente elas são as mais importantes no calculo da dispersão de energia devido à proximidade delas com o nível de Fermi. Para calcular a dispersão das bandas no grafeno é preciso primeiro determinar a célula unitária da rede cristalina, tanto no espaço real como no reciproco. Para isso a rede hexagonal é analisada como duas subredes triangulares A e B, definindo-se a célula unitária como qualquer par de átomos vizinhos não equivalentes como ilustrado na Figura 2.3a.Os vetores unitários a1 e a2 da rede são determinados por:

$$
a_{1}=\frac{a_{c-c}}{2}(3, \sqrt{3}) ; a_{2}=\frac{a_{c-c}}{2}(3,-\sqrt{3})
$$

Sendo $\left[a_{c-c}\right]$ a distância entre átomos vizinhos na rede, $0.142 \mathrm{~nm}$.

(a)

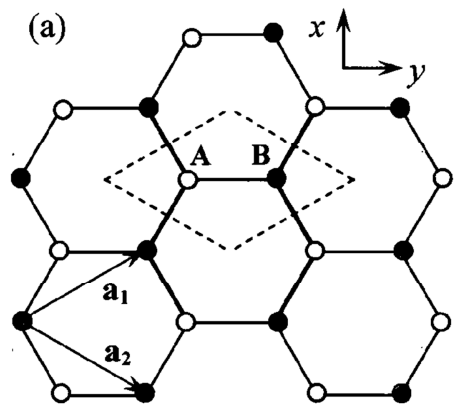

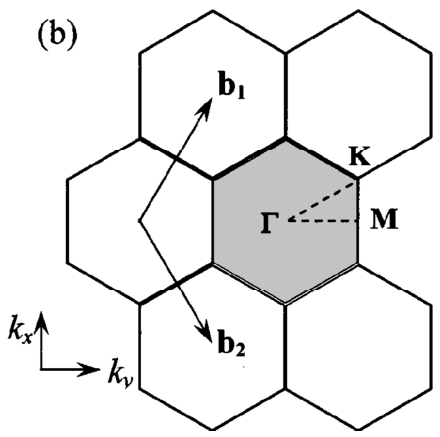

Figura 2.3 Estrutura cristalina do grafeno. a) Célula unitária (losango pontilhado) e vectores primitivos da rede no espaço real, b) Espaço reciproco com seus vetores unitários b1 e b2. A primeira zona de brillouin é mostrada na cor cinza e os pontos de alta simetria nela $(\Gamma, \mathrm{M}$ e K) são representados[4].

A condição de ortogonalidade entre os vetores das redes real e reciproca se define como:

$$
a_{i} b_{j}=2 \pi \delta_{i j} \text { Sendo } \quad \delta_{i j}=\left\{\begin{array}{l}
0, \text { se } i \neq j \\
1, \text { se } i=j
\end{array}\right.
$$

Os vetores da rede recíproca são escritos então como:

$$
b_{1}=\frac{2 \pi}{3 a_{c-c}}(1, \sqrt{3}) ; \quad b_{2}=\frac{2 \pi}{3 a_{c-c}}(1,-\sqrt{3})
$$


A partir destes vetores da rede reciproca é definida a primeira zona de Brillouin, representada na cor cinza na Figura 2.3b.

Dada a natureza fraca das ligações possíveis nos orbitais $\pi$ não hibridizados no grafeno, estes elétrons ficam mais livres e podem ser excitados oticamente desde a banda de valência até a banda de condução. A estrutura eletrônica das bandas de valência e condução podem ser descritas pelo método Tight-Binding baseado na combinação linear de orbitais atômicos $\pi$ considerando apenas os primeiros vizinhos. Para isto deve-se cumprir o teorema de Bloch:

$$
\begin{gathered}
T_{\vec{a}_{i}} \psi=e^{i \vec{k} \cdot \vec{a}_{i}} \psi \\
\Phi_{j}(\vec{k} \cdot \vec{r})=\frac{1}{\sqrt{N}} \sum_{R}^{N} e^{i \vec{k} \cdot \vec{R}} \phi_{j}(\vec{r}-\vec{R}) ; \text { para }(\mathrm{j}=1, . . \mathrm{n})
\end{gathered}
$$

em que $\vec{R}$ é a posição do átomo, $\phi_{j}$ é a função de onda atômica no estado j e n é o número de funções de onda na célula unitária, ou seja, existem n funções de onda no sólido para cada $\mathrm{k}$.

As relações de dispersão de energia podem ser então calculadas[4].Este cálculo se resume a resolver a equação $\operatorname{secular} \operatorname{det}(\widehat{\boldsymbol{H}}-E \widehat{\boldsymbol{S}})=0$, da qual podem se obter os seguintes autovalores:

$$
E(\vec{k})=\frac{\epsilon_{2 p} \pm \gamma_{0} \omega(\vec{k})}{1+s \omega(\vec{k})}
$$

Onde o valor $\gamma_{0}$ se refere ao valor da integral de transferência do primeiro vizinho e $S$ refere-se ao valor da integral de superposição (overlap), calculados segundo:

$$
\gamma_{0}=\left\langle\phi_{A}(\vec{r}-\vec{R})|\widehat{\boldsymbol{H}}| \phi_{B}\left(\vec{r}-\overrightarrow{R^{\prime}}\right)\right\rangle
$$




$$
\begin{aligned}
& S=\left\langle\phi_{A}(\vec{r}-\vec{R}) \mid \phi_{B}\left(\vec{r}-\overrightarrow{R^{\prime}}\right)\right\rangle \\
& \omega(\vec{k})=\sqrt{1+4 \cos \frac{\sqrt{3} k_{x} a}{2} \cos \frac{k_{y} a}{2}+4 \cos \frac{k_{y} a}{2}}
\end{aligned}
$$

sendo $a=\sqrt{3} a_{c-c}=0.246 \mathrm{~nm}$ constante da rede. Os sinais (-) e (+) na equação 2.6 correspondem ás bandas de valência (v) e de condução (c). O parâmetro $\epsilon_{2 p}$ é um ponto arbitrário de referência de energia para o nível de Fermi, relacionado à energia de ligação dos elétrons no orbital 2 p. No modelo de primeiros vizinhos é escolhido igual a $0 \mathrm{eV}$.

A Figura 2.4 representa as curvas de dispersão do grafeno na primeira zona de Brillouin, mostrando as bandas $\pi$ e $\pi^{*}$ de valência e de condução, respectivamente. Observa-se como as curvas de dispersão somente se tocam nos pontos K e K', conhecidos como pontos de Dirac.

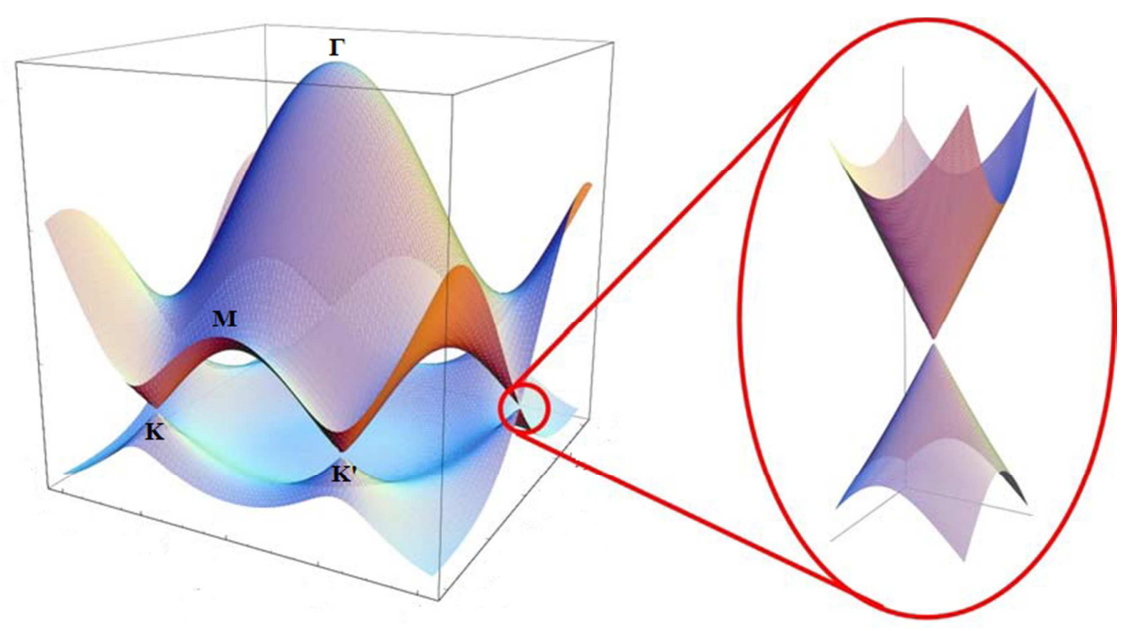

Figura 2.4 Curvas de dispersão do grafeno na primeira zona de Brillouin. No insert, se mostra o comportamento linear da dispersão em torno dos pontos de Dirac[5].

Deste resultado podemos entender então o porquê do grafeno ser chamado de semicondutor de gap zero, dado que as bandas ocupada (inferior) e vazia (superior) não se sobrepõem, mas estão conectadas nos pontos de Dirac. Para as regiões em torno dos pontos $\mathrm{K}$ e com o valor de $S$ perto de 0 , os autovalores de energia dependem linearmente do vetor de ondake aequação 2.6 fica: 


$$
E_{k}= \pm \hbar v_{f} k
$$

Sendo $v_{f}$ a velocidade de Fermi $\left(v_{f} \approx 10^{6} \mathrm{~m} / \mathrm{s}\right)$ dos portadores de carga nessa região. Esta relação linear na proximidade dos pontos de Dirac explica o comportamento balístico dos portadores de carga no grafeno.

\section{2}

\section{Métodos de crescimento}

\subsection{1}

\section{Exfoliação mecânica}

Primeiro método usado na obtenção do material, a exfoliação mecânica consiste na separação de monocamadas de grafeno a partir de fragmentos de grafite pirolítico altamente ordenado (HOPG). $\mathrm{O}$ grupo de pesquisa da universidade de Manchester liderado por Andre Geim serviu-se de uma fita adesiva para separar folhas de grafite cada vez mais finas até ficar apenas uma monocamada. A obtenção do material é bastante simples, mas o tamanho dos filmes de grafeno obtidos desta forma fica na faixa de alguns micrometros[2][6].

O estudo é realizado transferindo o filme para um substrato de Silício com uma camada óxido de silício de espessura cuidadosamente escolhida (tipicamente $300 \mathrm{~nm}$ ). Isto é feito desde que foi observado que o grafeno torna-se visível ao microscópio ótico se colocado no topo deste substrato, devido a um pequeno contraste causado pela interferência com respeito ao substrato limpo. Este arranjo é altamente sensível à quantidade de camadas de grafeno segundo é observado na Figura 2.5. 


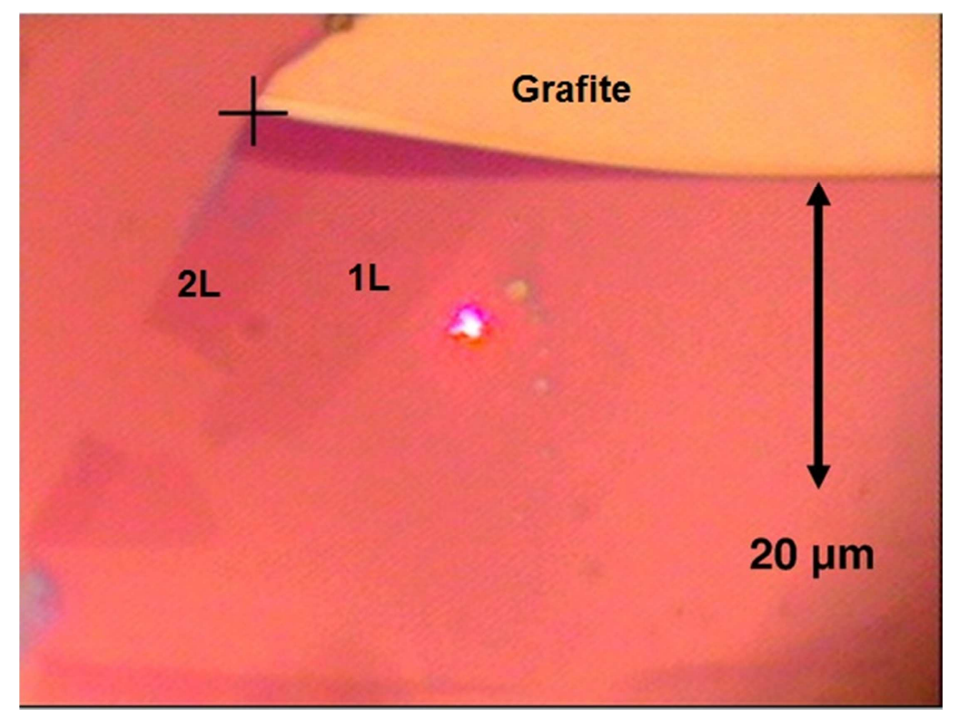

Figura 2.5 Imagem ótica de filme de grafeno obtido por exfoliação mecânica de grafite altamente ordenado e transferido para um substrato de oxido de silício. Observasse a diferencia da cor correspondente a uma monocamada de grafeno e varias camadas.(Adaptado de [7])

Esta transferência só é possível devido a que o grafite interage mais fortemente com a maioria dos outros materiais do que entre as suas próprias camadas. O grafeno obtido por este método ainda hoje é considerado o de melhor qualidade, com propriedades elétricas e mecânicas superiores aos obtidos por outros procedimentos. Ainda assim, a morosidade deste processo o torna industrialmente inviável.

\subsection{2}

\section{Sublimação de carbetos}

Este método usa como precursor carbetos, compostos inorgânicos binários que contêm carbono. O procedimento é o seguinte: Dado o alto ponto de fusão do carbono, o carbeto é aquecido a altas temperaturas num ambiente de pressão controlada, provocando a sublimação do outro elemento além do carbono. Dependendo da receita usada no processo, os átomos de carbono isolados podem se reagrupar para obter diferentes alótropos do carbono: carbono amorfo, nanotubos de carbono ou grafeno. Filmes homogêneos de grafeno de dezenas de micrometros têm sido obtidos a través da sublimação do carbeto de silício numa atmosfera de gás nobre densa que controla o processo[8][9].A atmosfera de gás nobre foi introduzida com o objetivo de controlar a taxa global de sublimação, 
permitindo maiores temperaturas e com isto aumentar o tamanho médio dos grãos no crescimento. A principal vantagem do crescimento por sublimação de carbetos está no fato do crescimento ser feito diretamente no substrato de carbeto, o que facilita sua aplicação na indústria. Já os maiores problemas deste procedimento estão ligados ao controle da uniformidade e espessura do material.

\subsection{3}

\section{Deposição química na fase vapor (CVD)}

A abordagem mais promissora na atualidade para a obtenção de grafeno de qualidade razoável e a baixo custo é a deposição química na fase de vapor (CVD). $\mathrm{Na}$ sua forma mais simples, o procedimento por CVD envolve a decomposição térmica de um gás precursor ou gases na presença de uma superfície catalizadora metálica. A maioria dos substratos usados na literatura correspondem aos metais de transição, principalmente ao Níquel[10][11][12]e o Cobre[13][14][15],ainda quando existem alguns estudos realizados também para o Paládio[16], Rutênio[17]e Irídio[18]. O cobre tornou-se ideal devido principalmente ao seu baixo custo e á baixa solubilidade do carbono nele.

A técnica de crescimento de filmes finos de carbono por CVD vem sendo estudada há mais de 50 anos[19]. Existe por tanto uma ampla variedade de processos de deposição química. Os processos por CVD podem então ser classificados dependendo da pressão de operação do sistema, a temperatura do crescimento, assim como a presença ou não de outras técnicas que podem modificar a dinâmica do sistema, tais como plasma ou feixes de fótons, as quais podem aumentar as taxas de deposição e/ou diminuir as temperaturas de trabalho requerida pelo sistema[20].

O grafeno é obtido a partir do aquecimento do catalizador dentro do sistema de crescimento até a temperatura de trabalho. Depois de um período de tratamento térmico para homogeneizar e remover (redução)os óxidos nativos da superfície do substrato, um vapor precursor contendo carbono é liberado. O composto químico precursor se decompõe nos seus componentes na presença de altas temperaturas e os átomos de carbono se aderem na superfície do catalizador. Os resíduos químicos são descartados do sistema. 
Na Figura 2.6 é possível observar o filme de grafeno sobre um substrato de cobre. As regiões independentes observadas na imagem correspondem aos grãos da superfície do cobre. A natureza do crescimento do filme é irregular, já que o carbono vai se agrupando nos chamados sítios de nucleação e se expande a partir destes em todos os sentidos. Este fato origina a natureza policristalina do grafeno obtido por CVD, já que cada sítio de nucleação gera um monocristal independente.

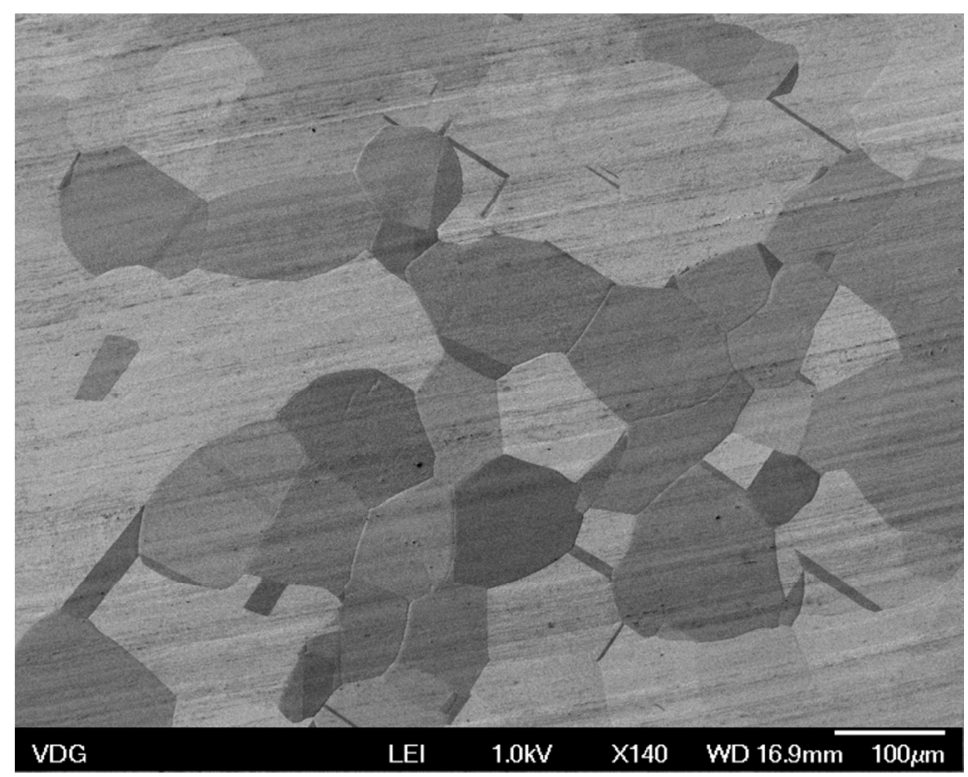

Figura 2.6 Microscopia eletrônica de um filme de grafenoobtido por CVD usando um substrato de cobre como catalizador.

O fato do grafeno crescido por CVD ser policristalino afeta grandemente as suas propriedades elétricas e de transporte, devido á presença de defeitos gerados pelas fronteiras entre os grãos que funcionam como centros espalhadores de portadores de carga. Esta é uma das principais desvantagens da técnica de crescimento por CVD, os defeitos da estrutura cristalina fazem que os valores de mobilidade e condutividade da rede sejam muito menores em comparação aos obtidos pelo método da exfoliação mecânica, embora estudos recentes tenham conseguido diminuir o numero de sítios de nucleação gerado durante o crescimento e obter filmes de grafeno monocristalinos de grande área[21][22]. 
Por outro lado, o fato do crescimento depender somente da superfície do catalizador faz com que seja possível crescer amostras homogêneas de grafeno de quase qualquer forma e tamanhos desejadas[12][13].

Outra desvantagem do grafeno crescido por CVD é que um passo extra é necessário no processo para poder ser usado em aplicações: A transferência do grafeno de cima do metal para um substrato arbitrário (usualmente um substrato de óxido de silício). Além disto, defeitos também são provocados devido às usualmente altas temperaturas de crescimento. Os diferentes coeficientes de expansão térmicas do catalizador e do filme de grafeno podem causar instabilidades mecânicas e defeitos na rede produzidos durante o processo de esfriamento do sistema após o crescimento, tipicamente visíveis na forma de rugas e rachaduras no filme de grafeno observadas na microscopia eletrônica.

\section{3 \\ Fósforo em materiais de carbono}

Em eletrônica de semicondutores tem sido muito pesquisado o conceito de criação de impurezas na estrutura de um material pela introdução de átomos de um grupo próximo na tabela periódica. Isto permite modificar as propriedades eletrônicas de qualquer semicondutor, alterando de forma efetiva o numero de elétrons ou buracos na amostra, segundo desejado[23][24]. Porém, no caso do grafeno um controle otimizado das propriedades eletrônicas por esta via está ainda longe de ser alcançado.

A introdução de átomos dos elementos próximos ao carbono, o boro e o nitrogênio, em estruturas de carbono tem sido muito estudada nos últimos $\operatorname{anos[25][26][27][28][29].~A~incorporação~de~átomos~da~coluna~} 15$ em estruturas de carbono sp2 tem provado ser mais difícil de alcançar, já que eles possuem um raio maior do que o carbono e, portanto, não podem manter uma estrutura planar na rede cristalina[30][31].

O elemento fósforo tem sido muito pouco estudado em estruturas de carbono com hibridização $\mathrm{sp} 2$, sendo muito mais conhecido pela sua incorporação em materiais de diamante e similares[32][33][34][35], devido principalmente à 
configuração tetraédrica preferencial deste elemento. Só recentemente alguns estudos vêm sendo realizados nas áreas de nanotubos de carbono e de grafeno.

O elétron adicional presente na banda de valência do átomo de fósforo com respeito ao carbono parece indicar que as estruturas de carbono que incorporem fósforo apresentariam necessariamente um comportamento de semicondutor do tipo n, com o elétron adicional agindo como o portador de carga. Estudos teóricos realizados sugerem a possibilidade de conseguir modificar as propriedades eletrônicas do grafeno mediante a incorporação de fósforo na sua estrutura, ainda que em pequenas concentrações[36][37].

Alguns estudos teóricos apontam que o átomo de fósforo vai provocar importantes modificações na estrutura cristalina da rede devido ao seu tamanho, ficando ligado por cima do plano da rede e afetando a posição dos átomos de carbono circundantes até o terceiro vizinho, segundo se observa na Figura 2.7[38].

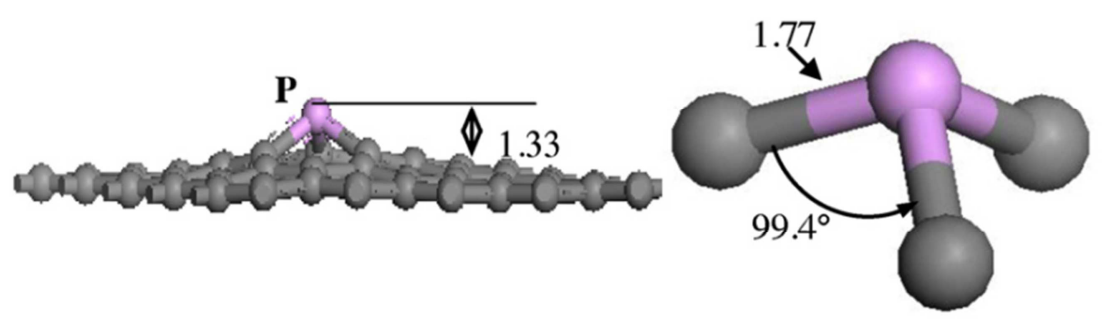

Figura 2.7 Estrutura geométrica otimizada do átomo de fósforo no filme de grafeno[38] (distância em $A^{\circ}$ ).

A alta reatividade química das nanoestruturas de carbono dopado com fósforo as torna promissoras para uma ampla gama de aplicações. Tem sido reportada a proposta de usar nanotubos de carbono[39] e nanolâminas de grafeno[40] como sensor de gás. No primeiro caso foi descoberto que os nanotubos de carbono dopados com fósforo e com fósforo-nitrogênio simultaneamente apresentam afinidade seletiva com respeito a diferentes moléculas gasosas. Portanto, podem ser usados para identificar de forma efetiva a presença de moléculas específicas.

Também as estruturas com fósforo incorporado seriam boas candidatas a serem utilizadas em reações de redução de oxigênio com maior atividade 
eletrocatalítica, mesmo quando comparado com os disponíveis hoje, baseados fundamentalmente em eletrodos de platina.[41][42][43][44]. 


\section{3}

\section{Técnicas de caracterização}

\section{1}

\section{Espectroscopia Raman}

A espectroscopia Raman é uma das técnicas mais poderosas no estudo de matérias baseados no carbono. Trata-se de uma ferramenta de caracterização não destrutiva, rápida e com alta resolução que pode oferecer informação estrutural e eletrônica[45]. O espalhamento da luz em um material pode acontecer de duas formas: elástica ou inelástica. No caso mais comum do espalhamento elástico (Rayleigh), a energia da radiação refletida e idêntica á incidente. O espalhamento inelástico da luz no material é causado pela perda ou ganho de energia da radiação incidente no material. Os fótons incidentes num processo de espalhamento inelástico ou Raman são absorvidos provocando a excitação de elétrons da banda de valência para a banda de condução. O fóton espalhado apresenta maior (AntiStokes) ou menor energia (Stokes) que o fóton incidente. Esta diferença é explicada pela absorção ou criação de um fônon, diminuindo ou aumentando a energia vibracional do material.

$\mathrm{Na}$ figura 3.1 são observados os processos de espalhamento elástico e espalhamento Raman (Stokes e Anti-Stokes).A técnica de espalhamento Raman usualmente fica restrita ao processo Stokes, no qual a energia do fóton espalhado é menor do que o incidente, o que indica um aumento na energia vibracional do material. 


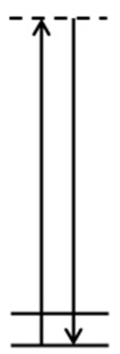

(a)

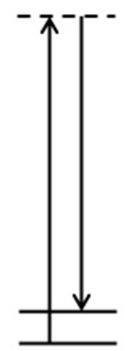

(b)

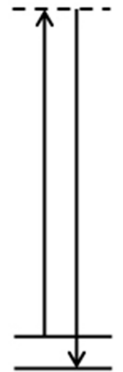

(c)

Figura 3.1: Esquema de níveis de energia para o espalhamento elástico a) e inelástico, Stokes b) e Anti-Stokes c). Os níveis de energia são representados pelas linhas horizontais. Observa-se a perda e ganho de energia nos processos Stokes e AntiStokes, indicado pelas setas verticais indicando os fótons incidentes e espalhados.

Desde um ponto de vista clássico, o espalhamento Raman pode ser descrito pela relação entre o campo elétrico $\vec{E}$ da radiação incidente com o momento dipolo induzido $\overrightarrow{\mathrm{P}}$ no material devido ao modo de vibração presente. Esta relação é dada por:

$$
\overrightarrow{\mathrm{P}}=\alpha \overrightarrow{\mathrm{E}}
$$

Sendo $\alpha$ a polarizabilidade eletrônica. Este parâmetro $\alpha$ é uma propriedade de cada material e está relacionado com a posição dos átomos e a natureza das ligações químicas. Podemos expandir a polarizabilidade em Serie de Taylor em função do parâmetro q que representa a coordenada normal do sistema estudado, da seguinte forma:

$$
\alpha=\alpha_{0}+\left(\frac{\mathrm{d} \alpha}{\mathrm{dq}}\right)_{0} \mathrm{q}+\cdots
$$

Desprezando os termos de ordem superior, q e E podem ser escritos como:

$$
q=q_{0} \cos (\omega t) ; E=E_{0} \cos \left(\omega_{0} t\right)
$$

Sendo $\omega_{0}$ a frequência da radiação incidente e $\omega$ a frequência do modo vibracional da rede. Aplicando algumas identidades trigonométricas e usando estas equações podemos reescrever a expressão para o momento dipolo induzido como:

$$
P=\alpha_{0} E_{0} \cos \left(\omega_{0} t\right)+\frac{q_{0} E_{0}}{2}\left(\frac{d \alpha}{d q}\right)_{0}\left[\cos \left(\omega_{0}+\omega\right) t+\cos \left(\omega_{0}-\omega\right) t\right]
$$


O primeiro termo da equação depende somente da frequência incidente e portanto representa o espalhamento elástico da radiação. Observa-se no segundo termo a presença de dois termos de menor e maior frequência, correspondentes aos fenômenos Stokes e Anti-Stokes, respectivamente. É importante observar que a derivada com respeito a q deve ser diferente do zero, ou seja, que para um deslocamento dos átomos causado pela vibração deve existir uma mudança na polarizabilidade.

A mudança na frequência causada pela criação ou destruição de um fônon pode ser analisada medindo a intensidade da luz para as frequências espalhadas. $\mathrm{O}$ espectro Raman normalmente se reduz a um gráfico de intensidade da luz espalhada vs deslocamento Raman(Raman shift), parâmetro que representa a diferença em energia dos fótons incidentes e espalhados e depende do chamado número de onda $\mathrm{n}$, definido por:

$$
n=1 / \lambda_{0}-1 / \lambda
$$

$\lambda_{0}$ e $\lambda$ correspondem ao comprimento de onda incidente e espalhado. $\mathrm{O}$ deslocamento Raman de um fônon correspondente a uma banda determinadai é dada por:

$$
E_{i}=h v_{i}=h c n_{i}
$$

Sendo $c$ a velocidade da luz e $h$ a constante de Planck.

\subsection{2}

\section{Espectro Raman do grafeno}

A espectroscopia Raman é particularmente efetiva em materiais baseados no carbono com hibridização sp2 devido a grande seção de choque para esse processo, oque permite estudar estados vibracionais característicos de cada material. As relações de dispersão no grafeno podem ser determinadas a partir da representação da frequência dos fônons em função dos pontos de simetria na rede recíproca, obtido a partir do cálculo dos deslocamentos dos átomos. A célula unitária do grafeno esta composta por dois átomos não equivalentes e cada um apresenta três graus de liberdade possíveis. 
A Figura 3.2 mostra o diagrama da dispersão dos fônons para o grafeno com as seis curvas de dispersão referentes aos possíveis deslocamentos dos átomos. Estas curvas se dividem em Acústicas (A) e Óticas (O). As curvas acústicas apresentam valor zero no centro da Zona de Brillouin (ponto $\Gamma$ ) (ver Figura 2.3b). As curvas representam deslocamentos possíveis longitudinais(L) e Transversais (T), no plano da rede (i) ou fora deste (o).

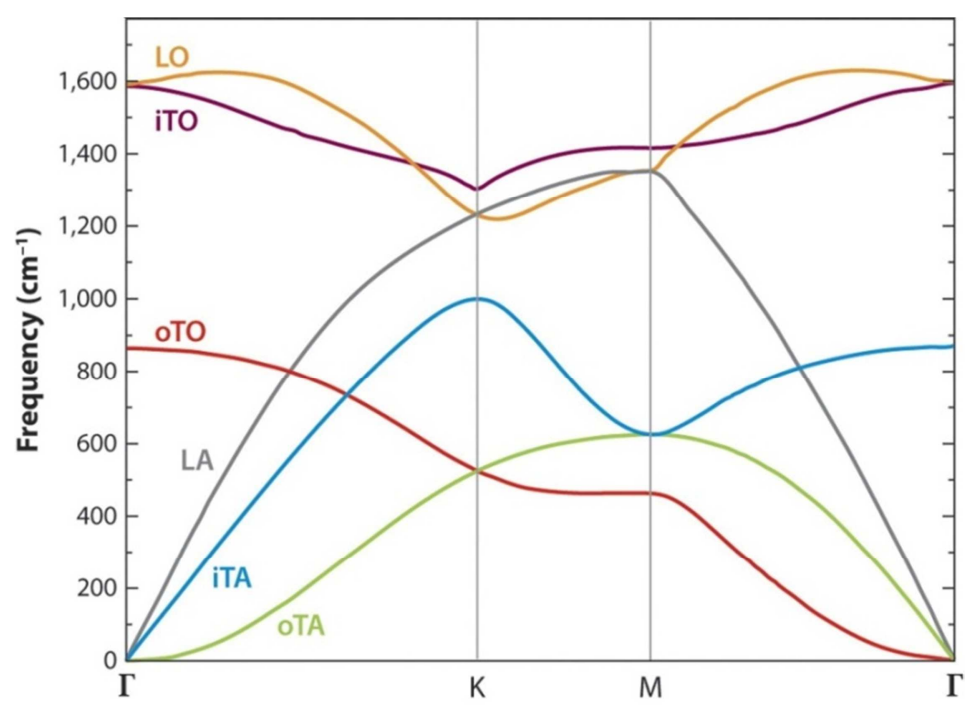

Figura 3.2: Esquema das relações de dispersão dos fônons para o grafeno para os pontos de alta simetria ГMКГ [46].

Na figura 3.3 é possível observar um espectro de grafeno de uma camada com varias bandas características ressaltadas. Dependendo dos processos envolvidos, podem ser analisados em vários grupos:

1. Processos com presença de um ou mais fônons.

2. Processos condicionados pela presença de defeitos na estrutura da rede.

3. Processos inter-vales, no caso em que o elétron é espalhado até um ponto equivalente em outro cone de Dirac; ou intra-vales, onde o espalhamento ocorre dentro do mesmo cone. 


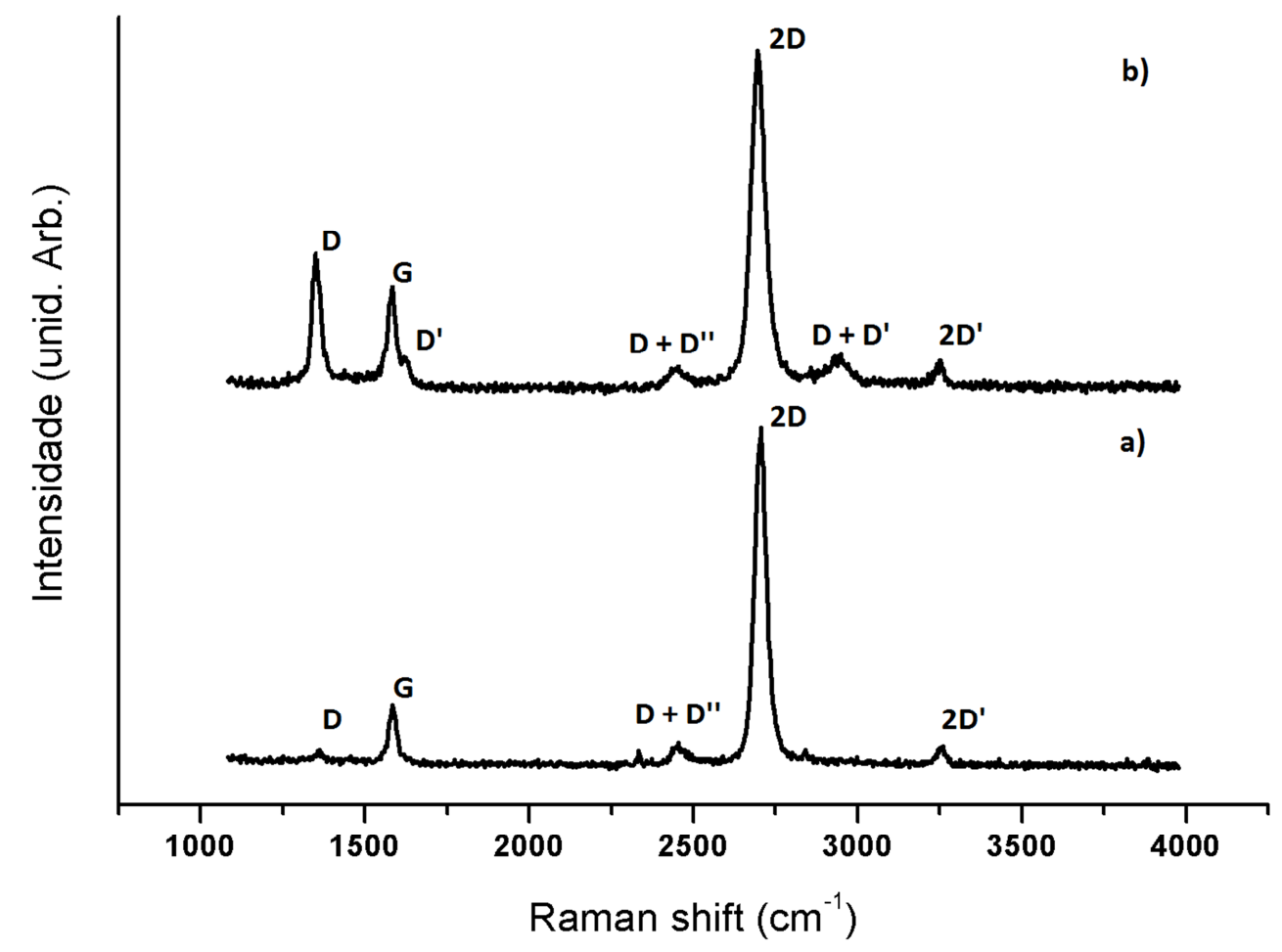

Figura 3.3 Espectro Raman de amostras de grafeno crescido por CVD mostrando as principais bandas características. A) amostra com poucos defeitos. B) amostra defeituosa. Energia do laser $2.62 \mathrm{eV}$, Potência $0.15 \mathrm{~mW}$.

\section{Banda G}

Considerada a banda mais importante do espectro, chamada usualmente de banda grafítica, devido a sua presença em todos os materiais de carbono com hibridação sp2. Localizada ao redor do valor $1580 \mathrm{~cm}^{-1}$, a posição desta banda apresenta pequena dependência da energia do laser incidente, pelo qual é ideal para estudar variações na estrutura da rede. É causada por um processo de primeira ordem, dada a presença de somente um fônon. Esta banda é relacionada à vibração dos átomos de carbono ligados no plano da rede em direções opostas para os dois átomos da célula unitária. A representação do processo é observada na figura.3.4(a). Este processo ocorre em torno ao centro da zona de Brillouin e esta relacionado com as curvas iTO e LO no gráfico da figura 3.2.Normalmente é um processo muito rápido, o qual é evidenciado pela pequena largura do pico a meia altura, do inglês, Full Width at Half-Maximum (FWHM). 


\section{Banda D}

A banda D é causada pela presença de defeitos na estrutura da rede. Esta banda esta localizada em torno de $1350 \mathrm{~cm}^{-1}$. A quebra da simetria e das regras de seleção, na presença de defeitos na rede, provocam a ocorrência de diferentes modos de vibração. Para o caso de grafeno de uma camada, a posição do pico D aumenta linearmente com a energia do laser usada. A intensidade e largura deste pico podem ser usadas para quantificar e classificar tipos de defeitos. A relação de intensidades normalizadas dos picos D e G têm sido muito usada como um indicador de defeitos em diferentes amostras.

\section{Banda 2D}

Esta banda, similar à banda $\mathrm{G}$, é característica de todos os materiais de carbono com hibridação sp2. Por esta causa foi muito tempo considerada como um harmônico superior (overtone) da banda G quando na realidade, segundo o seu nome indica, corresponde a um overtone da banda $\mathrm{D}$, ainda quando não precisa da presença de defeito algum para a sua ativação[6]. Isto é devido a que o processo que da origem á banda 2D é um processo de segunda ordem com a presença de dois fônons. Este processo de dupla ressonância faz com que a banda $2 \mathrm{D}$ seja muito sensível á mudanças na estrutura eletrônica e dos fônons em materiais grafíticos.

\section{Outras bandas}

No espectro de grafeno é possível identificar uma serie de bandas menores que representam ordens superiores de picos já conhecidos, ou combinações de diferentes bandas de primeiro ordem ativadas ou não por defeitos.

Por exemplo, é possível observar bandas com a presença de um fônon e ativadas por defeito como D' $\left(1620 \mathrm{~cm}^{-1}\right)$ ou a banda D" $\left(\sim 1100 \mathrm{~cm}^{-1}\right)$, relacionada a um fenômeno da rama LA [47] ou bandas ativadas por defeitos na presença de dois fônons, como a banda D+D' $\left(\sim 2940 \mathrm{~cm}^{-1}\right)$ e a banda do segundo ordem 2D' $\left(\sim 3300 \mathrm{~cm}^{-1}\right)$.

Na figura 3.4 observam-se exemplos possíveis para a maioria dos processos Raman conhecidos e a qual pico corresponde cada processo. 
a $\quad G$

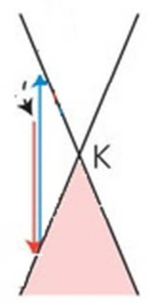

b $D^{\prime}$

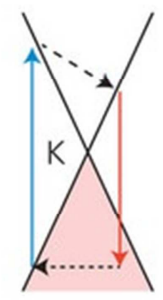

c D'

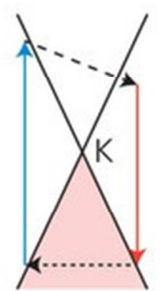

d $D$

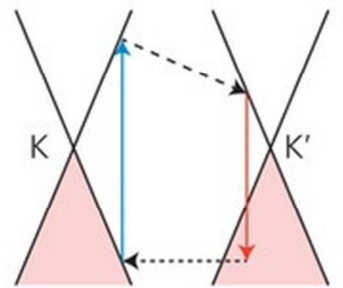

e

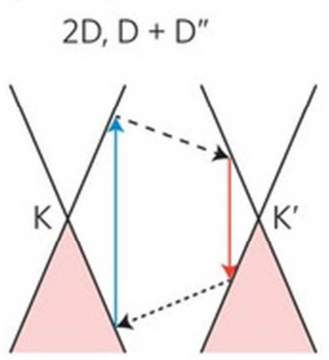

$\mathbf{f}$

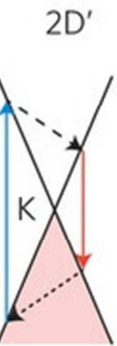

g $\quad D+D^{\prime}$

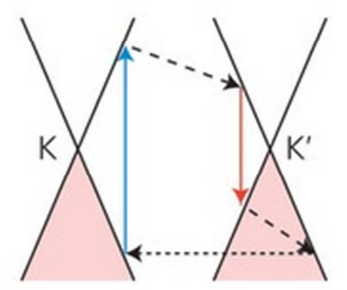

Figura 3.4 Exemplos de processos Raman possíveis e correspondência para cada banda do espectro no grafeno. As setas verticais azuis e vermelhas correspondem aos fótons incidentes e espalhados respetivamente. As linhas com traços correspondem á emissão de fônons e as linhas pontilhadas horizontais correspondem á dispersão de elétrons em defeitos da amostra. a) Banda $G$,(b-d) Processos de primeiro ordem (um fônon) na presença de defeitos, intra-vale (banda D') ou inter-vale (banda D). (e-g) Processos de segundo ordem: 2D, 2D', D+D' e D+D" (Adaptado de [48]).

\section{2}

\section{Instrumentação}

\subsection{1}

\section{Espectroscopia Raman}

O espectrômetro Raman utilizado neste trabalho foi um Raman Confocal (configuração Upright) da NT-MDT, tipo NTEGRA SPECTRA, equipado com um detector CCD (Charge-Coupled Device) com sistema de resfriamento termoelétrico baseado no efeito Peltier (com temperatura de trabalho de $-50^{\circ} \mathrm{C}$ ) e um microscópio ótico com uma única lente objetiva de 100x de aumento e de grande abertura numérica $(0,7)$, utilizada para focalizar o feixe do laser na amostra e para coletar a luz retroespalhada.

O espectrômetro Raman está equipado com um laser de estado sólido na cor azul, com uma energia de $2.62 \mathrm{eV}$ e potência máxima de $50 \mathrm{~mW}$. A figura 3.5 mostra uma fotografia do espectrômetro Raman existente no nosso laboratório e utilizado para fazer as medidas. 


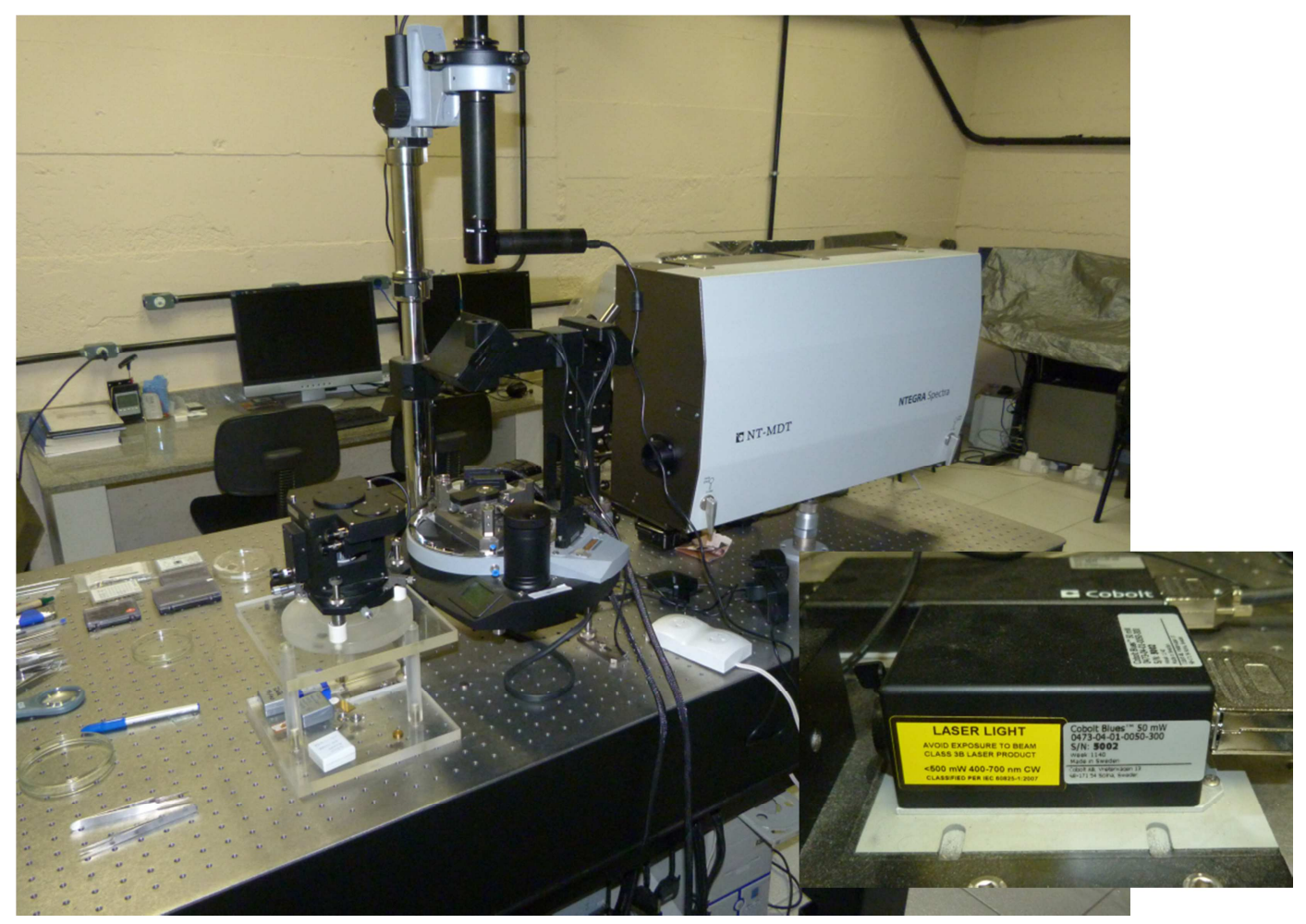

Figura 3.5 Fotografia do espectrômetro Raman instalado no Laboratório de Revestimentos Protetores e Materiais Nanoestruturados. No insert, o Laser de estado sólido utilizado $(\lambda=473 \mathrm{~nm})$.

Este equipamento permite também a realização de medidas de Microscopia de Força Atômica (AFM). Esta técnica consiste em uma cabeça que segura um cantilever que tem uma pequena sonda (ponta) que interage com a superfície atômica. Um laser ilumina o cantilever e um fotodiodo de quatro setores recolhe o sinal refletido nela. $\mathrm{O}$ cantilever vibra a uma frequência fixa que cria um sinal refletido base. Componentes piezoeléctricos são usados então para mover a base de um lado ao outro. A variação na amplitude do sinal refletido pela ponta esta diretamente ligada à variação da superfície da amostra.

A ponta é usualmente feita de silício ou de nitreto de silício, e o raio de sua extremidade esta na escala de vários nanómetros. Na figura 3.6 observa-se um esquema do sistema. 


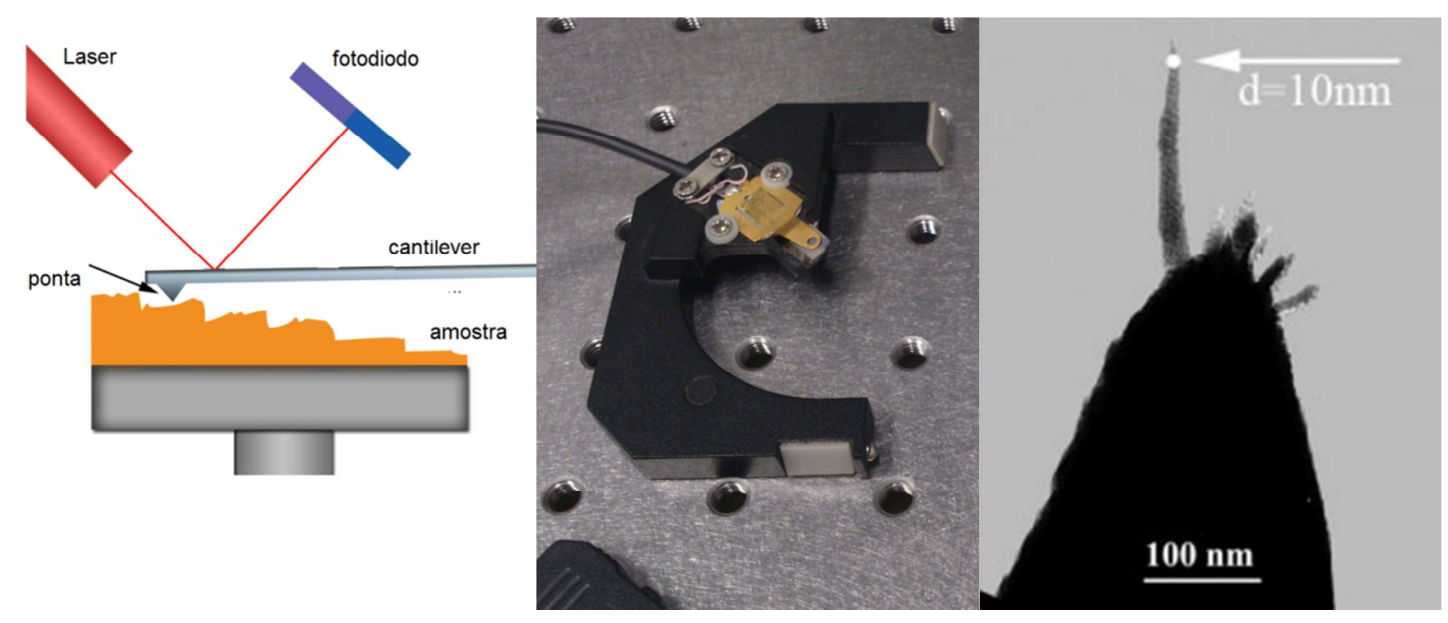

Figura3.6: Desenho de princípio básico do microscópio de força atômica (AFM). Um cantilever, com uma pequena ponta (sonda), move-se ao longo da superfície e experimenta forças atômicas. Laser e fotodiodo são usados para medir as forças. b) Dispositivo de suporte do cantilever. c) Foto da ponta de DLC (NT NSG10_DLC) usada nas medições.

O AFM pode ser operado em vários modos, dependendo da aplicação. Em geral, os possíveis modos de imagem são divididos em modos estático (contato) e uma variedade de modos dinâmicos (não-contato ou "tapping") onde o cantilever é vibrado.

Com essa técnica é possível analisar a superfície do material com alta resolução. O uso mais comum ainda hoje refere-se à análise do perfil da superfície, já que a sensibilidade desta técnica permite detectar variações na altura na faixa de até $1 \mathrm{~nm}$.

A ponta usada nas medidas foi o modelo NT NSG10_DLC, ponta formada pelo cantilever de material de silício e a ponta feita de DLC (Diamond Like Carbon) extrafino, o qual permite atingir resoluções espaciais nas imagens muito altas.

\subsection{2}

\section{Espectroscopia de fotoelétrons induzida por raios X (XPS)}

A espectroscopia por fotoelétrons induzida por raios X (XPS) é uma técnica de análises superficial amplamente usada em física dos materiais, já que permite a detecção detalhada dos elementos químicos presentes numa superfície. Cada elemento químico apresenta elétrons no nível de caroço ligados ao núcleo do 
átomo com uma energia caraterística única, dependente diretamente do seu numero atômico.

A técnica de espetroscopia por fotoelétrons é baseada no efeito fotoelétrico, o qual sugere que se a energia da radiação incidente for suficiente grande, um elétron da camada interna do núcleo é arrancado e a sua energia cinética resultante medida é inversamente proporcional á energia em que se encontrava ligado no momento inicial. Por isto é possível determinar quantitativamente a composição química por elementos de uma amostra conhecendo a energia inicial do feixe de raios $\mathrm{X}$ incidente e detectando a energia cinética dos elétrons arrancados no processo. Além disso, é possível identificar ligações químicas entre elementos, devidas á ocorrência de pequenas mudanças no espectro ao redor dos picos correspondentes aos elementos ligados. Portanto, a técnica de XPS fornece informação não só sobre a composição dos elementos na superfície, mas permite também a obtenção de informação sobre o ambiente químico de cada elemento da amostra estudada.

Outro processo que ocorre na presença de um feixe de raios $\mathrm{X}$ sobre uma superfície é o chamado efeito Auger. A técnica estuda os processos de relaxação do átomo depois de arrancado o elétron da camada interna. Imediatamente apos isto, os elétrons de níveis superiores se reacomodam para cobrir a vacância gerada pelo elétron arrancado, mas a energia criada nesse processo de transição de um nível ao outro provoca em certos casos a ejeção de outro elétron de um nível superior. Um esquema aproximado dos dois processos de excitação do átomo se observa na Figura 3.7.

Devido à natureza do fenômeno usado nestas técnicas, elas podem ser usadas para detectar todos os elementos químicos da tabela periódica com maior ou menor sensibilidade, sempre que o seu número atômico seja igual ou maior que três. O hidrogênio $(Z=1)$ e o Hélio $(Z=2)$ não são detectados por estas técnicas. 


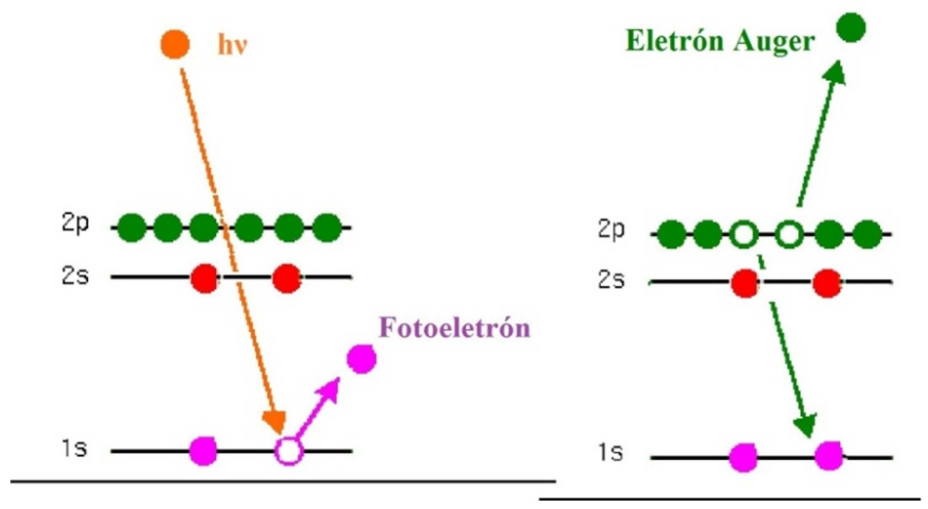

Figura: 3.7 Diagrama para o processo de emissão de XPS (esquerda). Um fóton incidente provoca a ejeção do fotoelétron. Processo secundário de relaxamento (direita), resultando na emissão de um elétron Auger.

Um equipamento de XPS em geral é constituído por uma fonte de raios X, normalmente a partir de magnésio ou alumínio, e um analisador eletrostático de energia de elétrons que permite determinar os elementos a partir da energia constante do feixe incidente. Todo isto precisa ficar dentro de uma câmara em ultra alto vácuo (UHV), já que é preciso garantir a energia dos raios $\mathrm{X}$ no momento da colisão na superfície e reduzir ao máximo possíveis colisões dos elétrons espalhados com átomos do gás residual antes da detecção no analisador, o que provocaria mudanças significativas no espectro.

As medidas foram realizadas com um espectrômetro que conta com uma fonte de raios $\mathrm{X}$ ajustável para alumínio e magnésio e um analisador comercial hemisférico de elétrons VG Thermo Alpha 110. Nas medidas foi usado o feixe com a fonte $\mathrm{K}_{\alpha}$ de magnésio $(h v=1253.6 \mathrm{eV})$, dado que o espectro obtido para a fonte de alumínio produz um pico Auger na zona do pico do carbono 1s. Na Figura 3.8 se observa uma foto do equipamento usado. 


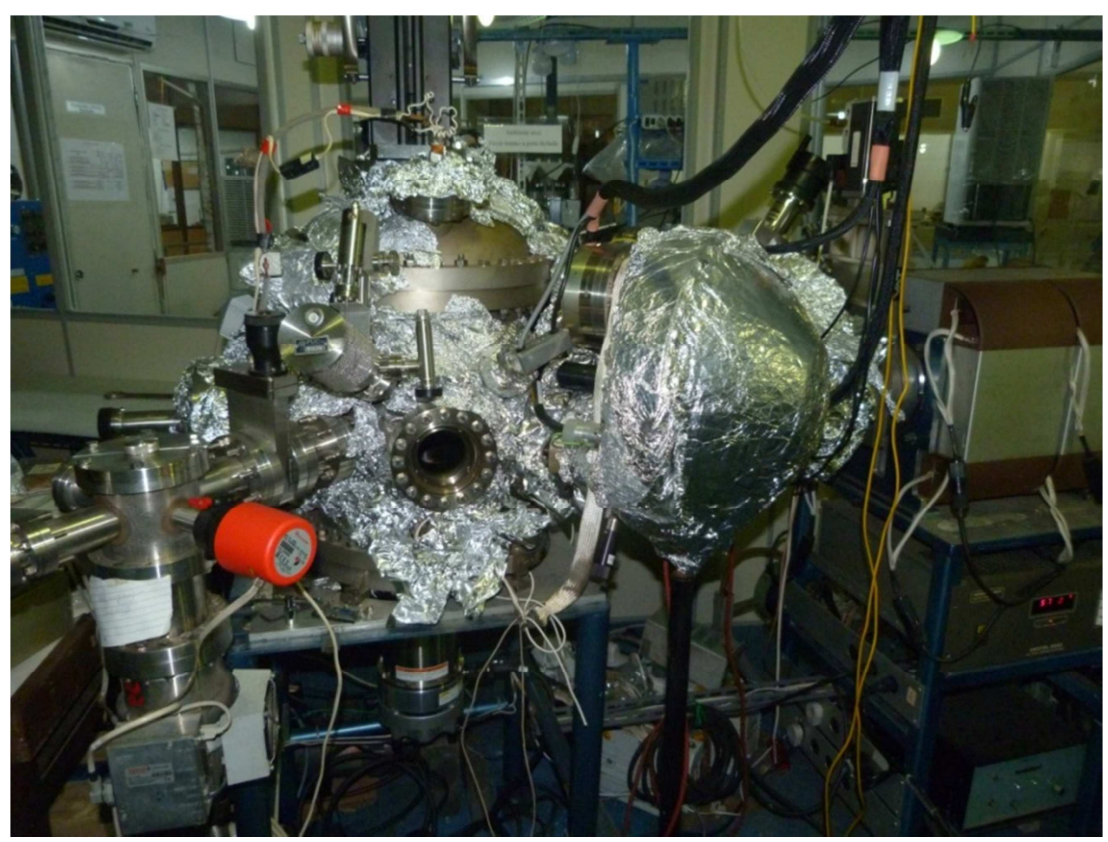

Figura 3.8 Fotografia da câmara do espectrômetro de fotoelétrons induzido por raios-X (XPS) usado nos experimentos e instalado no Laboratório Van de Graaff.

\subsection{3 \\ Microscopia Eletrônica de Varredura (Scanning Electron Microscopy)}

A técnica de microscopia eletrônica de varredura é uma das técnicas mais usadas atualmente na física de materiais, porque permite a obtenção de imagens da superfície de amostras com alta resolução e elevada profundidade de campo.

A técnica consiste na varredura de uma amostra com um feixe focalizado de elétrons de alta energia, que interagem com os átomos na superfície produzindo diferentes sinais que fornecem informação sobre a topografia e composição da amostra.

O sinal dos elétrons secundários e retro espalhados obtido é coletado e amplificado para ser analisado como um sinal elétrico. No modo de detecção básico, imagens de alta resolução são produzidas pelo analise do sinal dos elétrons secundários produzidos pela interação do feixe com a superfície. Os elétrons retroespalhados elasticamente são usados normalmente na identificação de diferentes fases na amostra. Existem outros sinais resultantes da interação do elétron com a superfície, tais como catodo-luminescência, elétrons Auger e raios $\mathrm{X}$. Em especial os raios $\mathrm{X}$ dispersados da amostra podem ser usados em analises 
quantitativas de composição da amostra e para mapeamento de elementos químicos.

Devido ao fato de serem usados feixes de elétrons muito finos neste microscópio, as imagens obtidas com esta técnica apresentam uma grande profundidade de campo, o que resulta vital na caracterização da estrutura da superfície analisada. A resolução das imagens obtidas através desta técnica esta relacionada diretamente à distância na qual se coloque o feixe de elétrons da amostra, já que a focalização ocorre sobre uma área menor. O diâmetro do feixe incidente está então estreitamente ligado à resolução máxima atingida no microscópio; para menor diâmetro maior é a resolução obtida. Atualmente os melhores resultados neste aspecto têm sido alcançados com o uso de canhões de elétrons por emissão de campo (FEG), que produzem feixes com diâmetros de 510 nm e muito baixos níveis de ruído.

O microscópio utilizado nas medições foi o modelo JSM-6701F, da JEOL, com canhão de elétrons com emissão por efeito de campo (FEG) de catodo frio operando em ultra alto vácuo e integrado a uma sofisticada tecnologia digital para a obtenção de alta resolução e imagens de microestruturas de alta qualidade. Este equipamento apresenta dois detectores de elétrons secundários, um superior (SEI) e um inferior (LEI). Uma imagem do microscópio usado se observa na Figura 3.9.

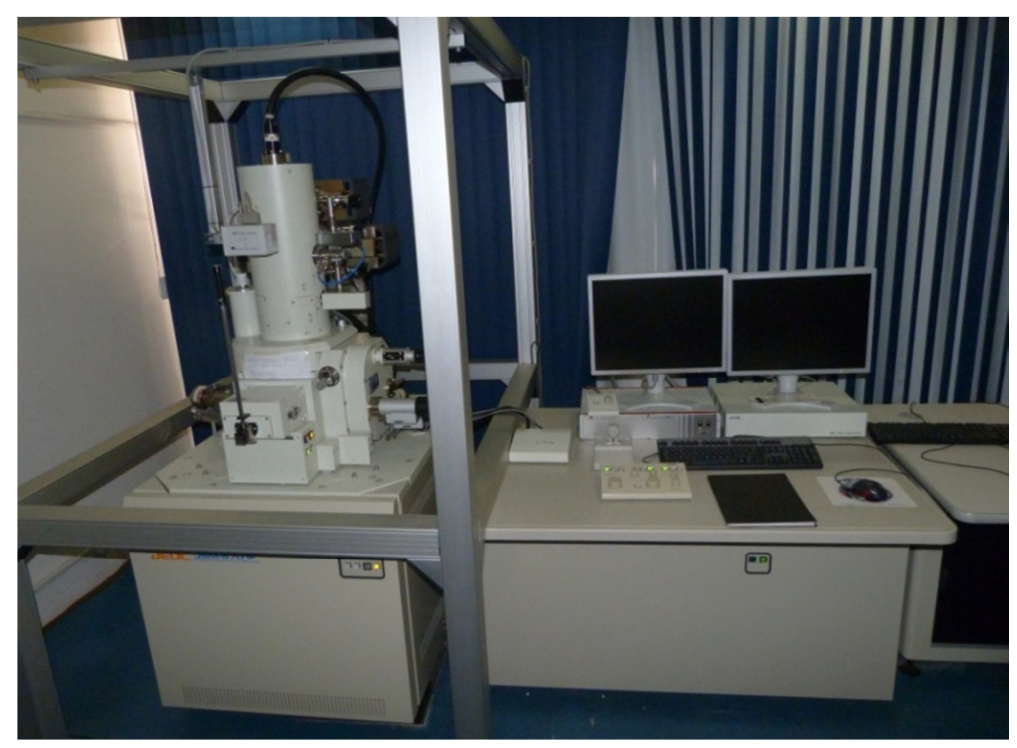

Figura 3.9 Fotografia do microscópio modelo JSM-6701Finstalado no Laboratório de Revestimentos Protetores e Materiais Nanoestruturados. 
Os limites de resolução chegam até $1,0 \mathrm{~nm}$ para uma energia do feixe de $15 \mathrm{kV}$ e até $2.2 \mathrm{~nm}$ para um feixe de $1 \mathrm{kV}$. O rango de magnificação compreende desde 25 vezes até 650000 vezes e a voltagem de trabalho máxima chega até os $30 \mathrm{kV}$. Além disso, o microscópio conta com um sistema de microanálise da energia dispersiva dos raios X (EDS), o qual permite a identificação de padrões característicos de cada elemento para determinar a presença deles ou não na amostra.

\subsection{4}

\section{Microscopia Eletrônica de Transmissão (Transmission Electron Microscopy)}

A técnica de microscopia eletrônica de transmissão constitui uma ferramenta única no estudo de nanoestruturas na atualidade já que permite como poucas a observação detalhada de átomos por observação direta. Usando o mesmo principio básico de funcionamento da Microscopia Eletrônica por Varredura, a Microscopia Eletrônica de Transmissão é baseada no uso de uma fonte focalizada de elétrons a altas energias na obtenção de imagens. As altas energias dos elétrons significam menores comprimentos de onda do feixe, com o qual aumenta muito a resolução máxima que estes equipamentos atingem.

No caso da microscopia por transmissão o feixe de elétrons é emitido em direção a uma amostra ultrafina. Os elétrons são coletados depois de interagir com a amostra. A energia do feixe de elétrons tipicamente usada na microscopia de transmissão é muito maior que a energia do feixe usada para microscopia eletrônica de varredura (duas ordens de grandeza maior). Este fato, junto à espessura muito baixa das amostras requerida nesta técnica inibe a dispersão dos elétrons e permite o passo da quase totalidade destes. Para o modo de imagem típico num microscópio eletrônico de transmissão, em campo claro, a imagem obtida depende diretamente da energia perdida pelo elétron no caminho: regiões escuras denotam maior densidade na amostra ou presença de átomos com números atômicos maiores.

O microscópio usado nas medições foi o modelo da JEOL JEM 2100F. Este equipamento possui uma fonte de elétrons de emissão por efeito de campo (FEG) e uma Câmara CCD (11 Mpixel GATAN Orius Camera), assim como um sistema de análise química que inclui um detector de espectroscopia por energia dispersiva 
de raios $\mathrm{X}(\mathrm{EDS})$ e um detector por perda de energia dos elétrons (EELS). Na Figura 3.10 observasse uma imagem do microscópio usado.

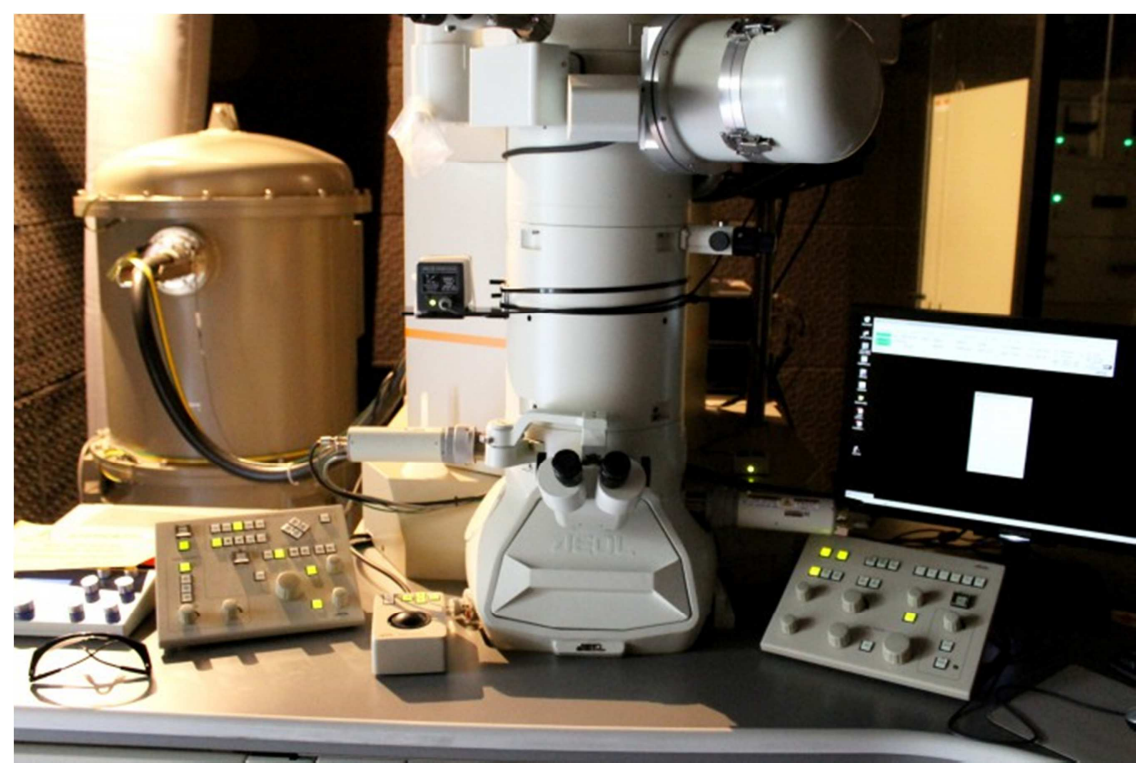

Figura 3.10 Fotografia do microscópio JEM 2100F usado nas medidas por MET. Laboratório de Nanociência e Nanotecnologia (LABNANO), CBPF. 


\section{4}

\section{Resultados e Discussão}

A incorporação de outras espécies na estrutura de filmes de carbono tem sido muito estudada nas ultimas décadas. O método de crescimento por deposição química na fase vapor (CVD) em especial tem se mostrado muito favorável na criação de novos materiais baseados no carbono com propriedades novas focados em numerosas aplicações.

Neste capítulo se utilizou um sistema de crescimento por CVD em alto vácuo (HVCVD) no estudo da incorporação do elemento fósforo na estrutura de um filme de grafeno. Para isto foram aplicadas diferentes técnicas de caracterização tais como espectroscopia Raman, microscopia eletrônica de varredura (MEV), de transmissão (MET), de forca atômica (AFM), assim como espectroscopia de fotoelétrons induzidos por raios X (XPS).

\section{1}

\section{Configurações do experimento}

Todo sistema de crescimento apresenta uma serie de propriedades essenciais que definem a natureza do filme resultante. Os principais parâmetros a serem definidos foram: Precursor de carbono e de fósforo, catalisador a usar e regime de trabalho do sistema (temperatura, pressão, fluxos de entrada no sistema, preparação das amostras). Um esquema do sistema usado é mostrado na Figura 4.1 , onde podem ser reconhecidos os principais componentes.

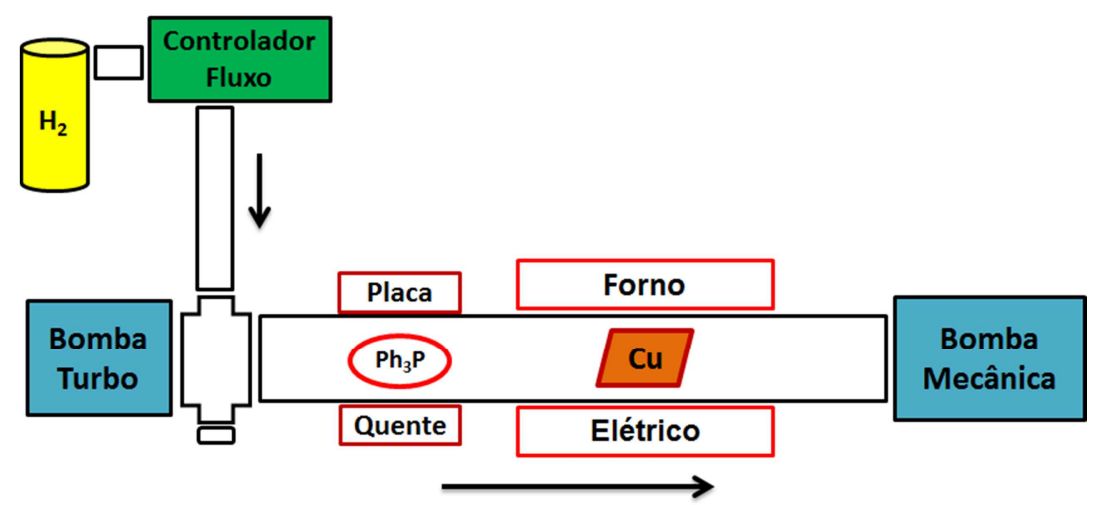

Figura 4.1 Esquema do sistema de crescimento usado no crescimento. 
Nele é identificável a presença de um forno tubular, sistemas de criação de vácuo a ambos os lados (bombas mecânica do tipo scroll e turbomolecular) e diferentes entradas de sustâncias no lado esquerdo do sistema (entrada do fluxo). A dinâmica do crescimento é analisada mais adiante. Uma fotografia do sistema é mostrada na Figura4.2.
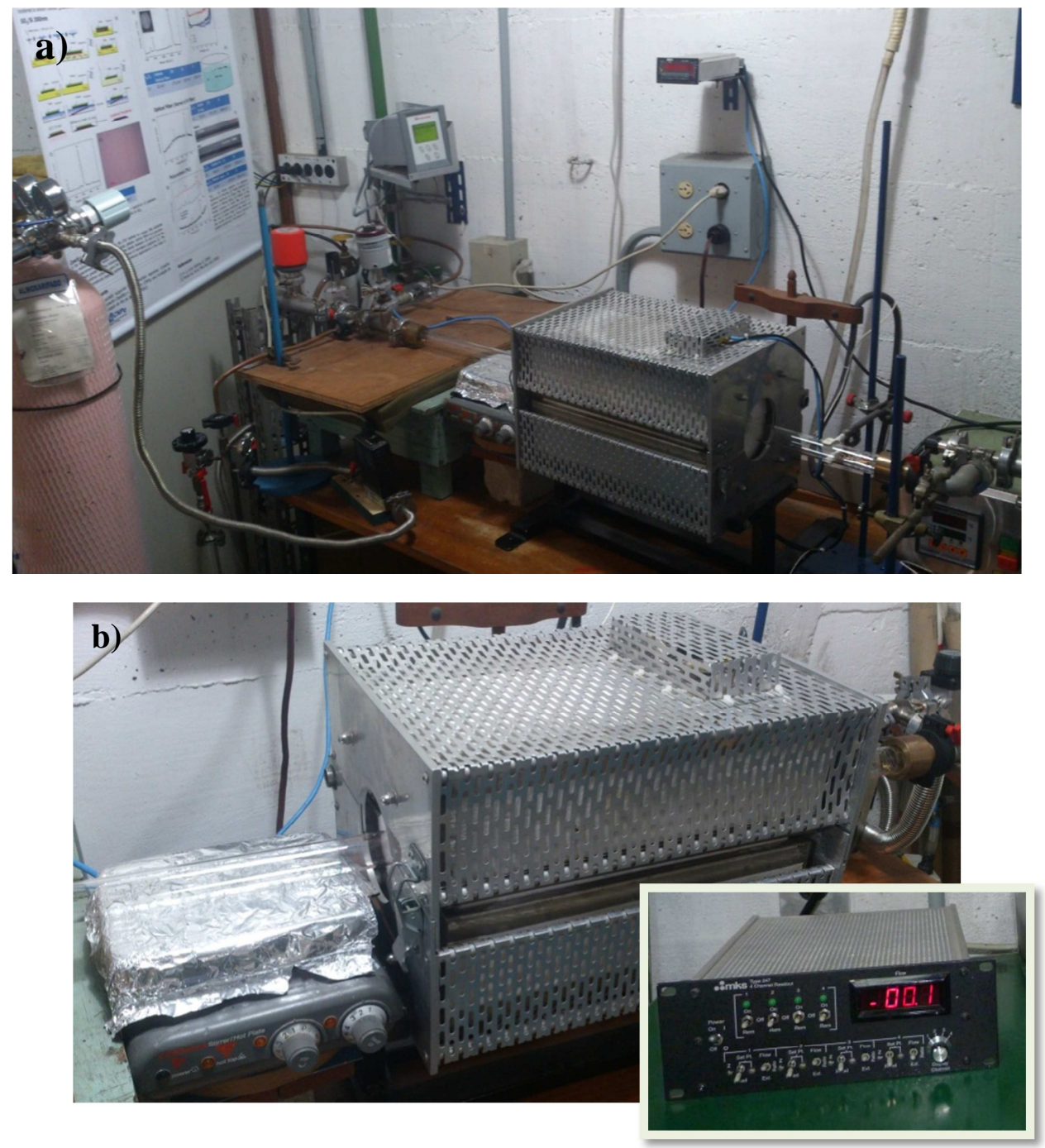

Figura 4.2 Sistema de crescimento por HVCVD instalado no Laboratório Van de Graaff. b) Detalhe do forno e a placa quente usados. No insert, controlador de fluxo de gás usado.

\subsection{1}

\section{Catalisador e precursores}

Neste experimento foram usadas como catalisador folhas de cobre de $25 \mu \mathrm{m}$ de espessura de alta pureza fornecido pela Sigma-Aldrich com pureza de $99.98 \%$. O cobre é amplamente usado como catalisador metálico em sistemas de 
crescimento por CVD de materiais baseados no carbono[49], devido principalmente á baixa solubilidade do carbono nele, o que permite o crescimento uniforme em grandes áreas de grafeno monocamada (Single Layer Graphene).

A preparação do substrato de cobre para o crescimento foi realizada mediante a ultrasonicação sucessiva das amostras de cobre $(1.0 \mathrm{~cm}$ de lado em media), em acetona e álcool isopropílico ao $99.5 \%$. O objetivo disto é tirar possíveis resíduos e homogeneizar a superfície antes do crescimento. Uma foto da folha de cobre usada é mostrada na Figura 4.3.

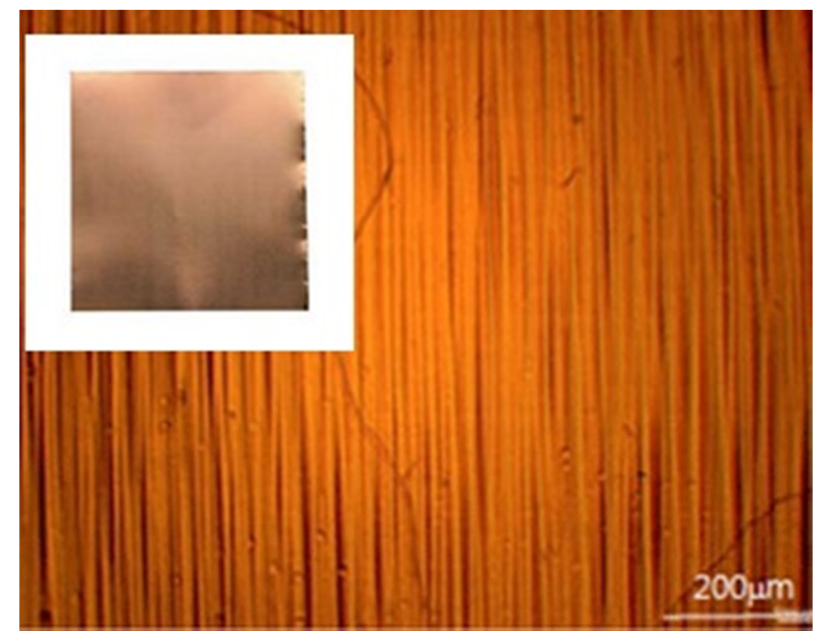

Figura 4.3 Folha de cobre de $25 \mu \mathrm{m}$ de espessura usada nos crescimentos (SigmaAldrich, $99.98 \%$ de pureza). Observam-se as linhas na superfície do cobre na microscopia ótica.

$\mathrm{O}$ precursor escolhido para o crescimento, a Trifenilfosfina $\left(\mathrm{P}\left(\mathrm{C}_{6} \mathrm{H}_{5}\right)_{3}\right)$, combina a presença de átomos de carbono e fósforo na sua estrutura (Figura 4.4a). Aproveitando a baixa temperatura de sublimação do precursor, é possível produzir um fluxo de vapor de Trifenilfosfina na entrada do sistema. Foi usada Trifenilfosfina em pó, em quantidades de 10mg até 40mg (observar Figura 4.4b). A relação de 18:1 entre os átomos de carbono e fósforo na molécula de Trifenilfosfina faz desnecessária a utilização de um processo de crescimento preliminar do filme de grafeno similar ao usualmente realizado na dopagem com nitrogênio[27].

O forno tubular usado apresenta uma zona quente de $22,4 \mathrm{~cm}$ de comprimento e o diâmetro interno do tubo de quartzo usado é de $2,74 \mathrm{~cm}$. As bombas se 
alternam na função de criação de vácuo, sendo a mecânica a usada durante o crescimento.
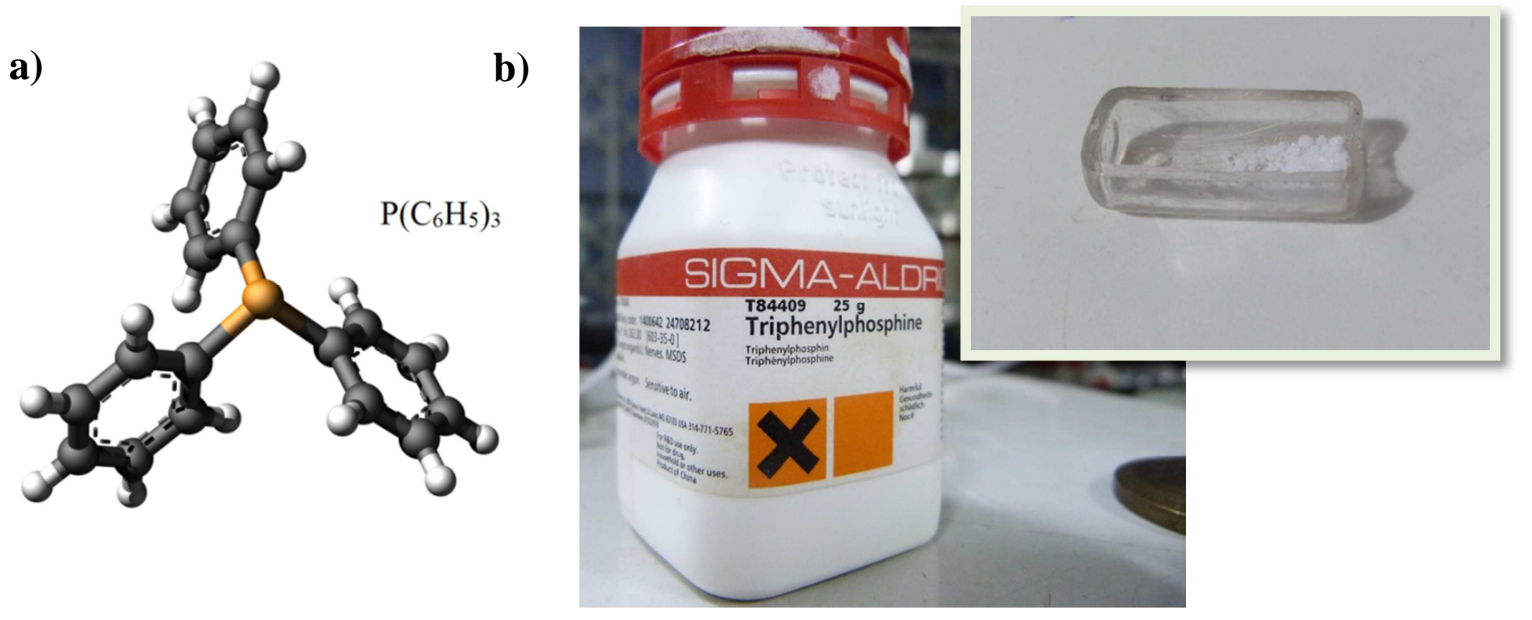

Figura 4.4 Esquema da estrutura da molécula de Trifenilfosfina. O átomo amarelo corresponde ao fósforo, rodeado de três anéis fenil. b) Trifenilfosfina (Sigma Aldrich, 99\% de pureza) usada nos crescimentos. No insert, pó de Trifenilfosfina no cadinho usado no crescimento.

O crescimento por HVCVD foi realizado usando o mesmo procedimento em todos os casos. Após serem limpas, as folhas de cobre são colocadas no centro da zona quente do forno e esquentadas até a temperatura de trabalho, tipicamente $1000{ }^{\circ} \mathrm{C}$, na presença de um fluxo de hidrogênio de $2 \mathrm{sccm}$ (standard cubic centimeters per minute). A pressão do sistema com o fluxo de hidrogênio é aproximadamente 80 mTorr. Este tratamento térmico é mantido durante 20 minutos para garantir a remoção do oxido de cobre da superfície e homogeneizála. No crescimento com o precursor contendo fósforo é colocado um cadinho com o pó de Trifenilfosfina numa placa quente do lado esquerdo do forno. Após o período de tratamento térmico no fluxo de hidrogênio, a placa quente embaixo do cadinho é ligada e o processo de sublimação começa, de forma tal que o processo de crescimento sob o fluxo do vapor demora em media uns 15 minutos. A pressão máxima do vapor de precursor foi de 5 mTorr. Após o crescimento, as amostras são esfriadas rapidamente a uma taxa aproximada de $300{ }^{\circ} \mathrm{C}$ por minuto. $\mathrm{O}$ fluxo de hidrogênio é mantido.

O uso de um precursor sólido causa diversos desafios, maiormente devido a que a sua utilização limita em grande medida o controle do crescimento. Dado que o pó de Trifenilfosfina é colocado dentro do sistema em vácuo antes do começo 
do crescimento, a liberação do vapor ocorre de forma não homogênea. O fluxo do precursor que atravessa o forno só e controlado pela taxa de sublimação. Esta taxa esta diretamente ligada com a taxa de crescimento da temperatura da placa quente.

Além disto, amostras de referencia de grafeno monocamada puro foram crescidas a partir de gás metano $\left(\mathrm{CH}_{4}\right)$, com um fluxo de $20 \mathrm{sccm}$ durante 30 minutos no sistema HVCVD.

\subsection{2}

\section{Processo de transferência}

As amostras obtidas foram submetidas a um processo de transferência em meio úmido para substratos de silício, similar ao proposto por Colombo et al.[50]. Foi depositada uma camada de suporte por centrifugação a $2000 \mathrm{rpm}$ durante 30 segundos na superfície do filme obtido, utilizando um spin coater modelo SCS G3P-8. Foi usada uma solução com uma concentração de $27 \mathrm{mg} / \mathrm{mL}$ de Polimetilmetacrilato (PMMA) (Sigma Aldrich, $\left.\mathrm{M}_{\mathrm{w}}=15000\right)$ em Anisole $\left(\mathrm{C}_{7} \mathrm{H}_{8} \mathrm{O}\right)($ Sigma Aldrich, 99 \%). Logo após foi usada uma solução aquosa de cloreto de Ferro (Sigma Aldrich, 97\%) com uma concentração de $0.13 \mathrm{~g} / \mathrm{mL}$ para remover o catalisador de cobre.

Após a remoção do cobre, a solução resultante é retirada e substituída por agua destilada, trocando-a três vezes no intervalo de uma hora. Posteriormente, o grafeno com o polímero é extraído da água com uma lâmina de silício previamente lavada em acetona e álcool isopropílico aplicando ultrassom em cada caso e secada com um jato de $\mathrm{N}_{2}$. Logo após ser retirado da agua, o filme de carbono depositado sobre o silício é colocado numa placa quente e submetido a uma temperatura de $130{ }^{\circ} \mathrm{C}$ durante 10 minutos. Este passo vaporiza a água remanescente entre o filme e o substrato e melhora a aderência do grafeno no oxido de silício. No passo final o PMMA é removido pela ação de acetona durante quatro horas. Um diagrama simplificado do processo é mostrado na Figura 4.5a. Imagens das amostras durante e após o processo são observadas na Figura 4.5b. 
a)

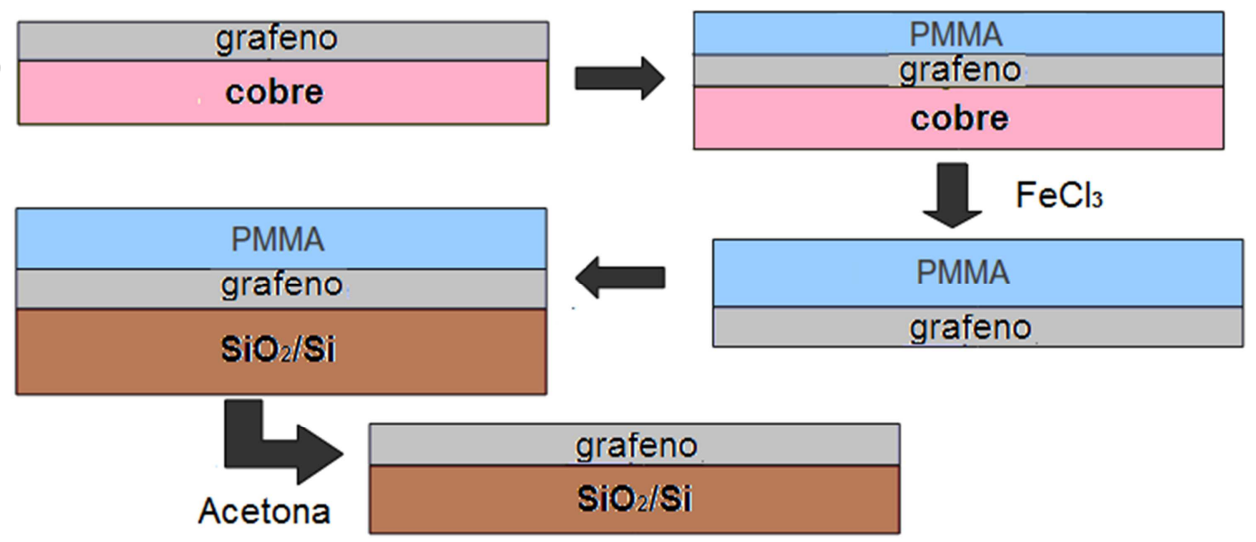

b)
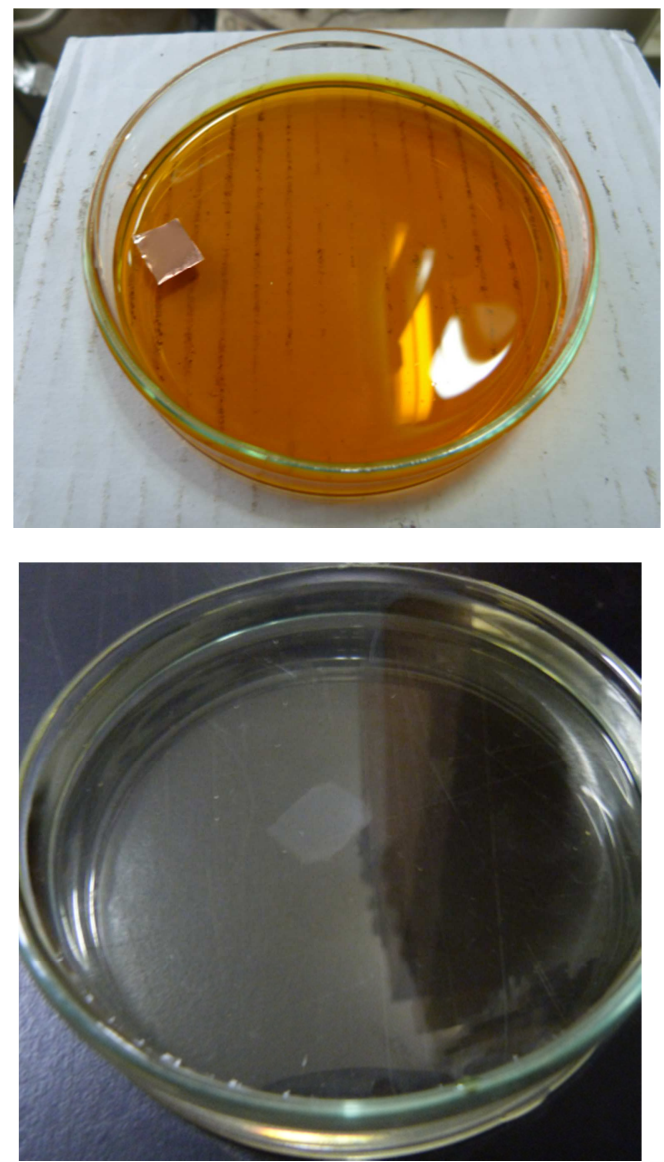
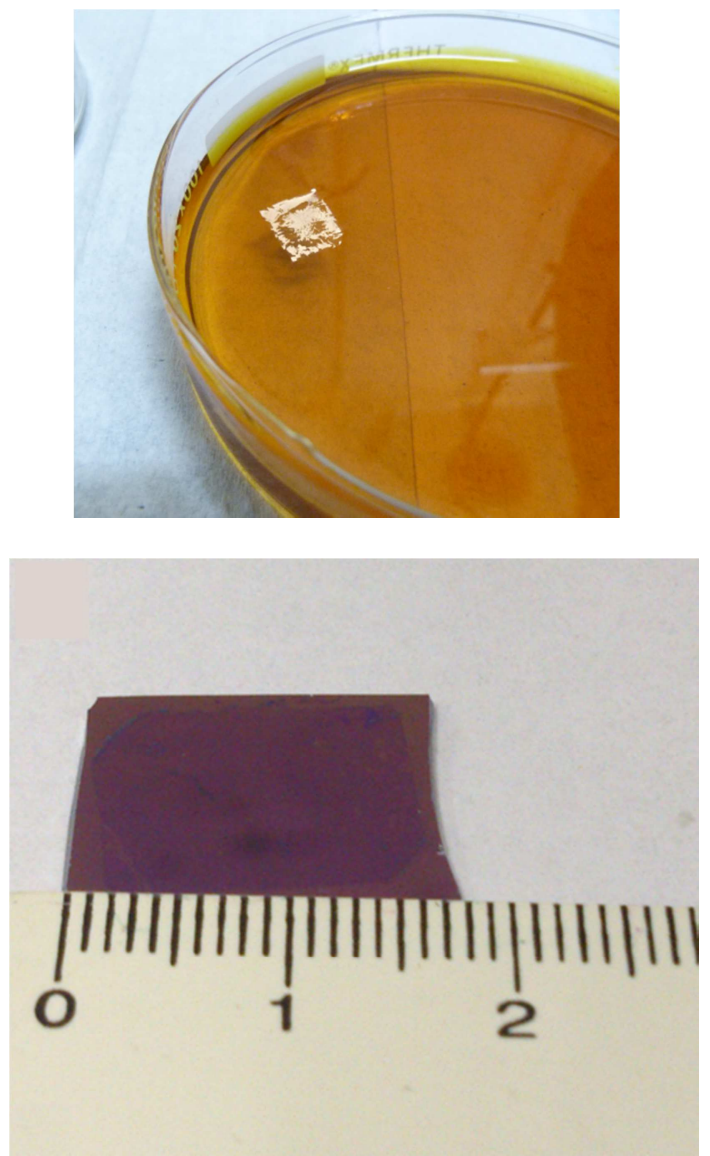

Figura 4.5 Diagrama do processo de transferência utilizado. b) Amostras durante e após o processo de transferência para o substrato de $\mathrm{SiO}_{2} / \mathrm{Si}$ seguindo o procedimento descrito anteriormente.

\section{2}

\section{Caracterização por Microscopia Eletrônica de Varredura (MEV)}

Após cada crescimento, as amostras foram introduzidas no microscópio eletrônico de varredura, modelo JEOL JSM 6701F. As imagens das amostras foram obtidas antes e depois da transferência, em ambos os casos operando a uma 
potencia de $1 \mathrm{kV}$. As imagens mostram claramente a existência de um filme na superfície do substrato em todos os casos.

Na Figura 4.6 se observam imagens obtidas de uma das amostras de referencia crescidas com o precursor de metano, antes e após o processo de transferência para a lâmina de oxido de silício. Na Figura 4.6b é possível identificar as zonas onde a película de carbono está presente, assim como a região na esquerda da imagem correspondente ao substrato de oxido de silício. Além disto, é possível observar na imagem da amostra transferida os remanentes de PMMA na forma de pequenas manchas de contorno irregular de cor branca na superfície.

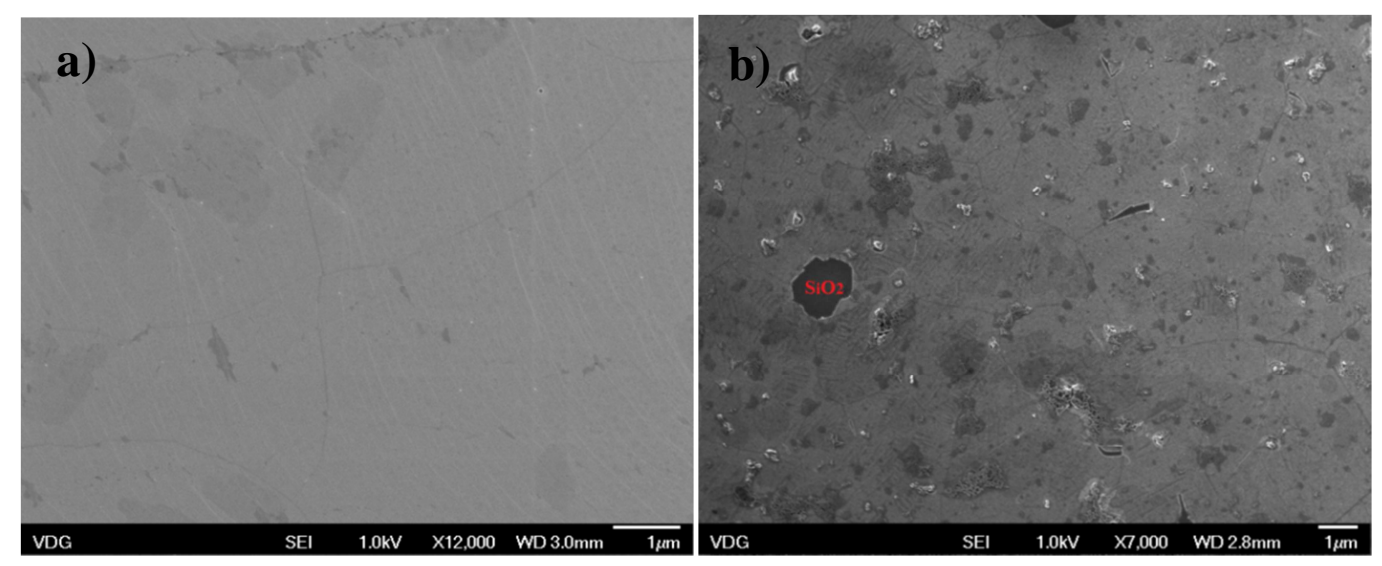

Figura 4.6 Imagem obtida por MEV de uma amostra de grafeno crescido por HVCVD com $20 \mathrm{sccm}$ de pressão de $\mathrm{CH}_{4}$. a) Sobre o substrato de cobre, b) Amostra transferida para o substrato de oxido de silício.

$\mathrm{Na}$ imagem são visíveis também algumas áreas pequenas de um tom mais escuro, usualmente são atribuídas na literatura a regiões no grafeno que apresentam nucleação de multicamadas, causadas por irregularidades no crescimento policristalino por CVD sobre o substrato de cobre[49][51].

Os crescimentos por técnicas de CVD ocorrem a partir da formação de ilhas de nucleação na superfície do catalisador, mas a superfície não uniforme deste provoca que na maioria dos casos o filme exiba zonas irregulares de mais de uma camada. Nesse sentido, a imagem anterior sugere a ocorrência deste fenômeno.

Na imagem da Figura 4.6a também podem ser vistas algumas linhas finas irregulares chamadas wrinkles. A formação destas rugas na superfície do filme 
ocorre tipicamente durante o esfriamento do sistema logo após o crescimento, devido às diferenças entre os coeficientes de expansão térmica do cobre e do filme[14].

As imagens das amostras crescidas com Trifenilfosfina como precursor foram obtidas utilizando o mesmo procedimento. Na Figura 4.7 são mostradas as imagens correspondentes aos quatro casos de estudo.

As imagens obtidas apresentaram pequenas regiões escuras espalhadas na superfície. Além disso, a quantidade e tamanho destas regiões parecem estar ligados à quantidade do precursor introduzida no crescimento: quanto maior a quantidade de precursor utilizada, maior será o diâmetro e o número destas regiões observadas.

Nos três últimos casos da Figura 4.7 se observa também como as regiões escuras nas imagens tendem a se alinhar numa direção especifica. Atribuímos esse comportamento ao fato de que as regiões na estrutura seguem a orientação das linhas presentes na superfície do cobre usado como catalisador. 

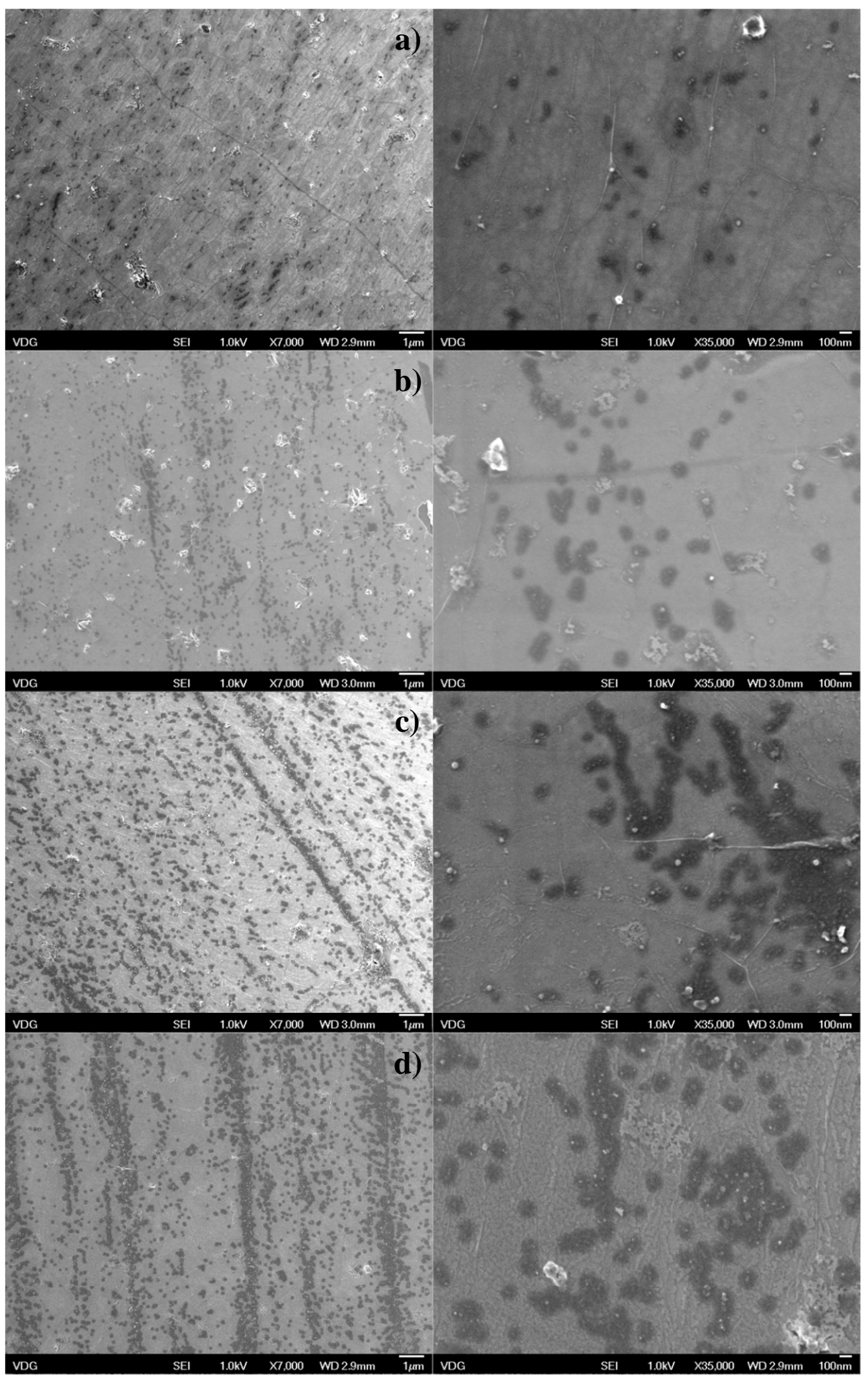

Figura 4.7 Imagens por microscopia eletrônica de varredura dos filmes crescidos usando Trifenilfosfina como precursor e transferidos para lâminas de oxido de silício. As imagens em a), b), c) e d) correspondem ás amostras crescidas com 10, 20, 30 e $40 \mathrm{mg}$ de precursor, respectivamente. Observa-se a presença de pequenas regiões escuras espalhadas nas imagens em todos os casos. 
Foram observadas as amostras antes e depois do processo de transferência para descartar qualquer resíduo ou ligação química induzida no substrato de cobre, como observado na Figura 4.8.

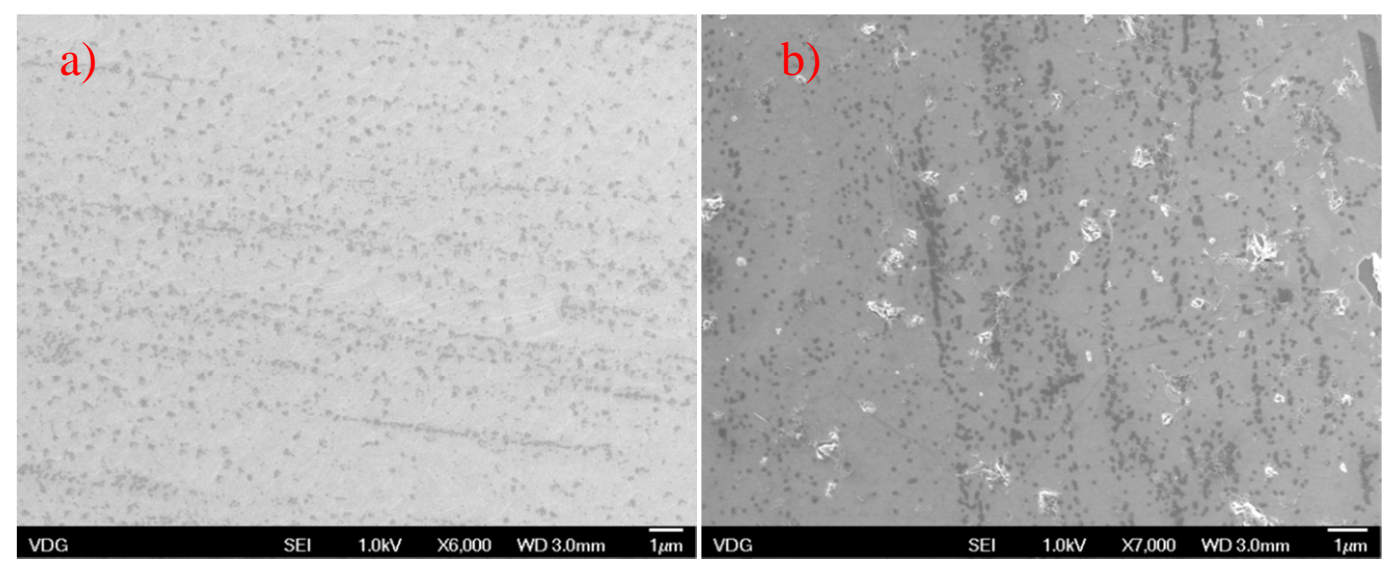

Figura 4.8 Comparação das imagens por microscopia eletrônica de varredura dos filmes crescidos usando $20 \mathrm{mg}$ de Trifenilfosfina como precursor, antes a) e após b) a transferência.

Não foram evidenciadas mudanças significativas nas imagens, comprovandose que a densidade das regiões escuras se mantem aproximadamente constante. Nota-se a presença de resíduos de PMMA como mostrado na Figura 4.8b.

A presença destas regiões para os crescimentos feitos com a Trifenilfosfina e a permanência delas após a transferência sugere a ocorrência de uma mudança estrutural nos filmes de carbono causada pela introdução de átomos de fósforo no experimento.

\section{3}

\section{Caracterização por Microscopia Eletrônica de Transmissão (MET).}

A microscopia de transmissão foi realizada para uma energia do feixe de elétrons calibrada de $100 \mathrm{kV}$. As amostras usadas no analise foram transferidas usando o mesmo procedimento descrito anteriormente, sendo substituído o substrato de silício por uma grade de tipo holeycarbon no processo de transferência. $\mathrm{Na}$ imagem da microscopia por MET na Figura 4.9 é possível observar com mais detalhe a morfologia das amostras crescidas no experimento, neste caso correspondentes ao crescimento com $20 \mathrm{mg}$ de Trifenilfosfina. $\mathrm{Na}$ imagem podem se distinguir as regiões escuras observadas na microscopia por 
MEV e se consegue observar a orientação delas seguindo a direção das linhas do cobre.

Além disto, a microscopia revela que as regiões escuras observadas como entidades únicas e isoladas no $\mathrm{MEV}$, na realidade estão compostas de numerosas zonas escuras menores localizadas muito perto entre si, formando os clusters observados no MEV. Este fato fica ainda mais claro quando observamos a imagem da Figura 4.9b para uma magnificação maior, onde se observa claramente o empilhamento de estas regiões escuras em determinadas regiões da amostra.
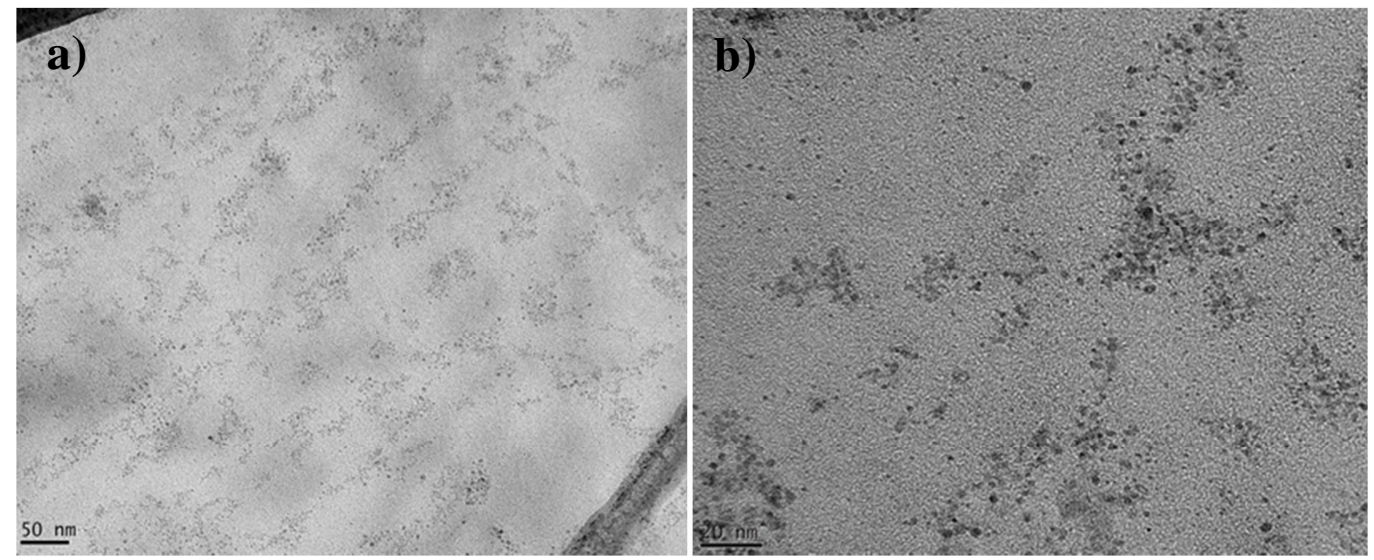

Figura 4.9 Imagens de microscopia eletrônica de transmissão (MET) de grafeno crescido com $20 \mathrm{mg}$ de Trifenilfosfina em modo de imagem de campo claro. b) Ampliação da imagem para a mesma amostra. Microscópio usado: modelo JEOL JEM 2100F, calibrado para uma energia do feixe de elétrons de 100kV.

\section{4}

\section{Caracterização por Microscopia de Força Atômica (AFM)}

As amostras também foram caracterizadas utilizando a técnica de microscopia por força atômica. As amostras transferidas para o substrato de oxido de silício foram medidas e perfis de altura de algumas regiões foram calculados. Na Figura 4.10 se observam imagens de AFM correspondentes a uma amostra crescida com $20 \mathrm{mg}$ de Trifenilfosfina e transferida para um substrato de oxido de silício.

Das imagens obtidas podemos comprovar que as regiões escuras observadas nas microscopias anteriores correspondem a elevações localizadas (pontos claros) sobre o nível da superfície do filme obtido. Isto é confirmado ao observar a reprodução do padrão de linhas observado para as regiões escuras nas imagens por Varredura e Transmissão. 
Em todos os casos foi usado o modo semi-contato do AFM e pontas de carbono DLC (Diamond Like Carbon). O perfil de altura mostrado na Figura 4.10c apresenta uma variação de até uns $15 \mathrm{~nm}$ de altura na amostra de $20 \mathrm{mg}$.

a)

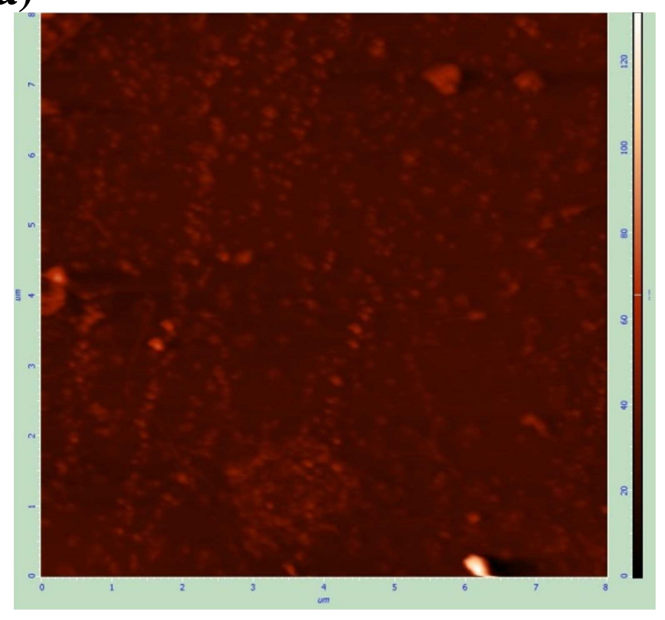

b)

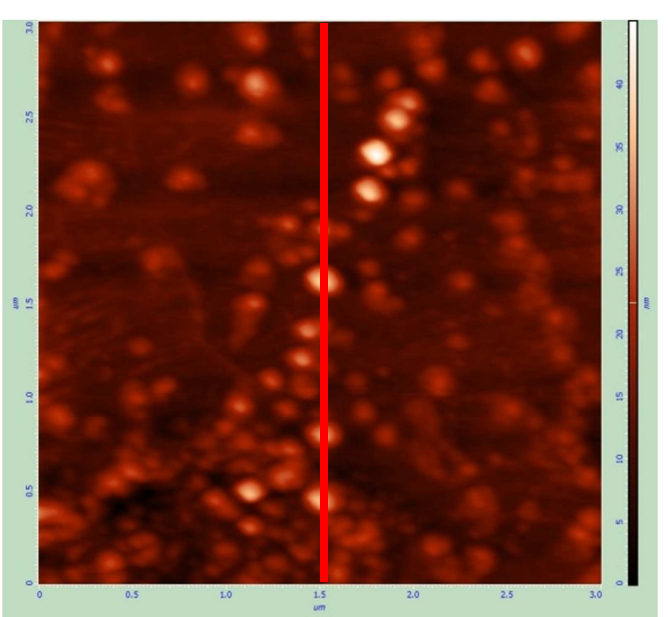

c)

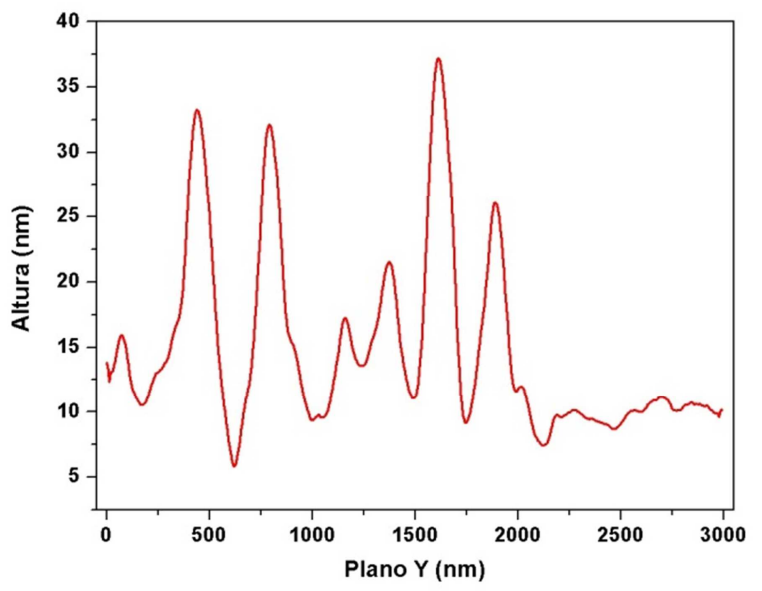

Figura 4.10 Imagens de microscopia de Força Atômica (AFM) de grafeno crescido com $20 \mathrm{mg}$ de Trifenilfosfina (8 $4 \mathrm{~m}$ quadrados). b) Ampliação de $3 \mu \mathrm{m}$ quadrados para a mesma amostra. c) Gráfico do perfil de altura correspondente à linha em (b). (Modo semi-contato. Ponta de carbono DLC)

\section{5}

\section{Caracterização das amostras por Espectroscopia Raman}

As amostras crescidas foram medidas logo após de cada crescimento para verificar a presença de grafeno e testar a qualidade dos filmes obtidos. Com o objetivo de melhorar a qualidade dos filmes também foram feitos crescimentos para diferentes temperaturas do forno mantendo a resto dos parâmetros constantes. Foram testadas três temperaturas de crescimento: $900{ }^{\circ} \mathrm{C}, 950{ }^{\circ} \mathrm{C} \mathrm{e}$ $1000{ }^{\circ} \mathrm{C}$, já que estudos apontam que para crescimentos de grafeno por CVD 
sobre cobre a temperaturas inferiores de $900{ }^{\circ} \mathrm{C}$ a quantidade de defeitos e do número de sítios de nucleação do grafeno varia dependendo da orientação cristalográfica do substrato na superfície, sendo esta variação mais importante que efeitos de rugosidades da superfície do catalisador. Para temperaturas maiores a quantidade de defeitos e sítios de nucleação é invariante.[52]

As amostras obtidas sobre o substrato de cobre foram colocadas no espectrômetro Raman e comparadas. Na Figura 4.11 se observa como para temperaturas menores do crescimento a qualidade do material obtido diminui. Este comportamento se manteve para diferentes quantidades de precursor, pelo qual foi escolhida a temperatura de $1000{ }^{\circ} \mathrm{C}$ como a mais indicada e usada nos crescimentos sucessivos.

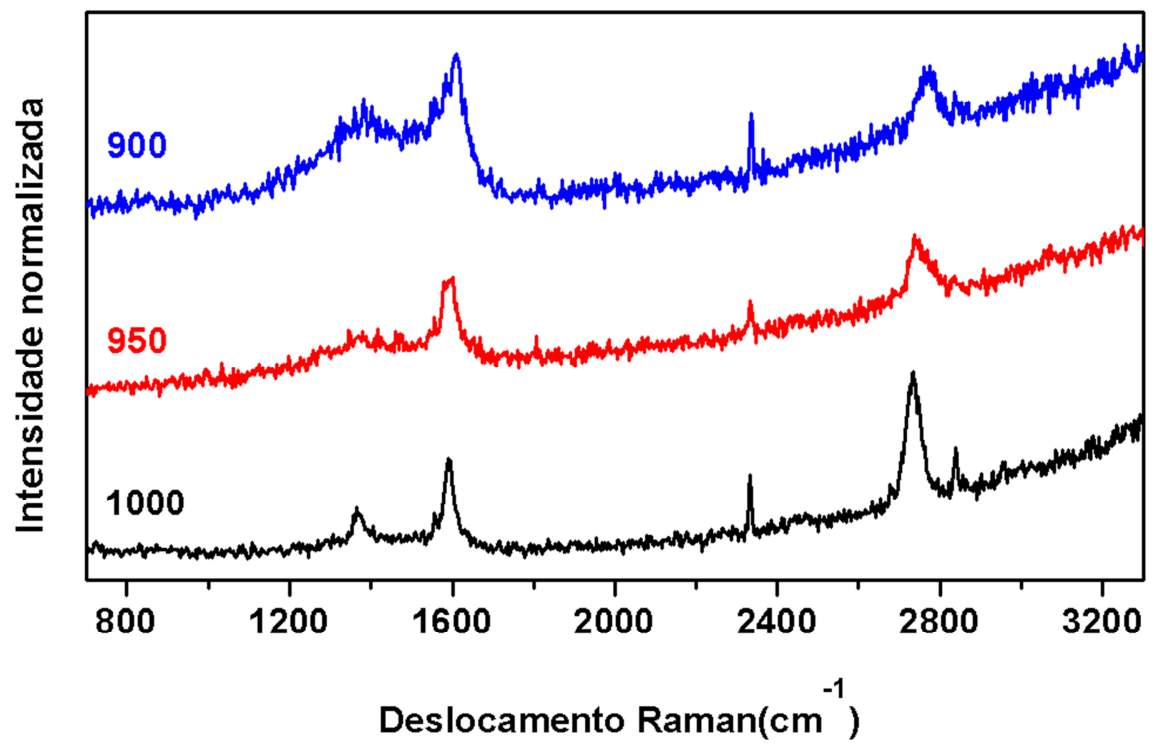

Figura 4.11Espectros Raman normalizados de grafeno obtido para diferentes temperaturas de crescimento. Amostras medidas sobre substrato de cobre obtidas com $20 \mathrm{mg}$ de Trifenilfosfina como precursor.(Energia do laser $2.62 \mathrm{eV}$, potência do laser 0.15 $\mathrm{mW}$, resolução espectral de $3 \mathrm{~cm}^{-1}$ ).

As amostras crescidas para $1000{ }^{\circ} \mathrm{C}$ e diferentes quantidades de precursor foram transferidas segundo o método descrito neste capítulo. Logo após disto as amostras crescidas com Trifenilfosfina foram novamente medidas, além da amostra padrão crescida com um gás de metano como precursor. Em todos os casos foi identificada a presença de grafeno. 
Na Figura 4.12 são mostrados espectros medidos em cada uma das amostras usando um laser com comprimento de onda de 473nm (2.62 eV de energia).
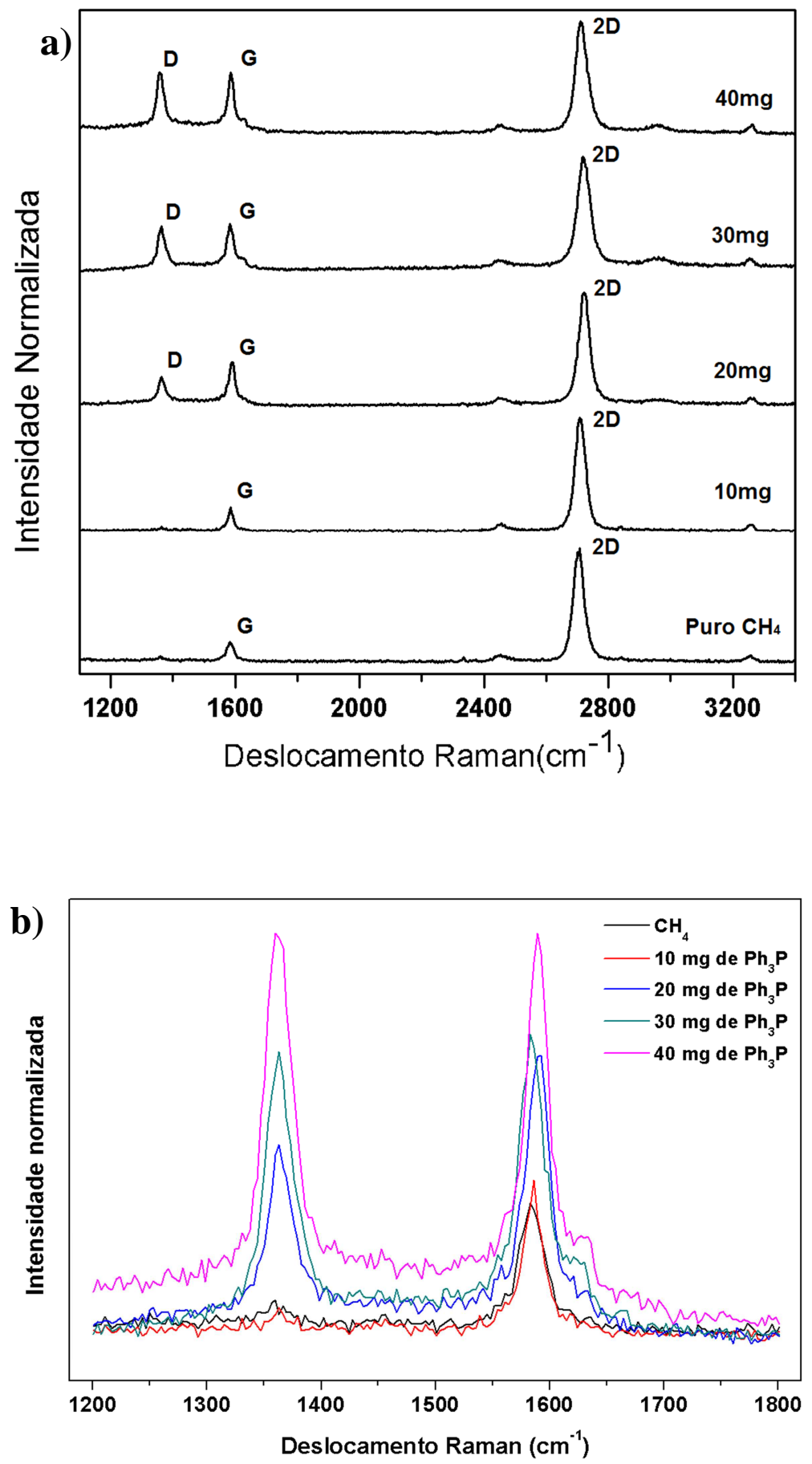

Figura 4.12 Espectros Raman normalizados de filmes de grafeno crescidos por HVCVD para os quatro casos em que foi usada a Trifenilfosfina sólida, assim como no caso de referência crescido com gás metano. b) Bandas $D$ e $G$ dos espectros mostrados em a). (Energia do laser $2.62 \mathrm{eV}$, potência do laser $0.15 \mathrm{~mW}$, resolução espectral de $3 \mathrm{~cm}^{-1}$ ). 
Nas medições realizadas em pontos aleatórios de cada amostra foi comprovada a existência de inomogeneidades nos espectros medidos. No caso da amostra de referencia crescida com $\mathrm{CH}_{4}$, não foram observadas irregularidades significativas nas medidas realizadas.

Da Figura 4.12 se pode ver que em todos os espectros mostrados foi conseguida a obtenção de grafeno, identificável pela relação entre as intensidades das bandas $2 \mathrm{D}$ e $\mathrm{G}\left(\mathrm{I}_{2 \mathrm{D}} / \mathrm{I}_{\mathrm{G}}\right)$ e a largura a meia altura (Full Width at Half Maximum) pequena da banda 2D $\left(35-40 \mathrm{~cm}^{-1}\right)$. Para os crescimentos com maior quantidade de precursor foram obtidas amostras mais defeituosas, indicado pelo aumento da intensidade da banda $\mathrm{D}$ e a aparição de bandas associadas a defeitos como a banda D' $\left(\sim 1620 \mathrm{~cm}^{-1}\right)$.

Das imagens na Figura 4.7 observadas anteriormente é evidente que o aumento da área e o número das zonas escuras para maiores quantidades de precursor requerem um estudo mais aprofundado sobre as variações do espectro Raman na presença destas regiões. Para isto foram realizadas medidas de espectros Raman ao longo de linhas que cobrissem as diferentes regiões observadas no MEV. As linhas em todos os casos foram feitas com $10 \mu \mathrm{m}$ de comprimento e $1 \mu \mathrm{m}$ de passo. Nas Figuras 4.13 até 4.16 são mostrados apenas os espectros representativos das variações dos espectros Raman em cada caso. 


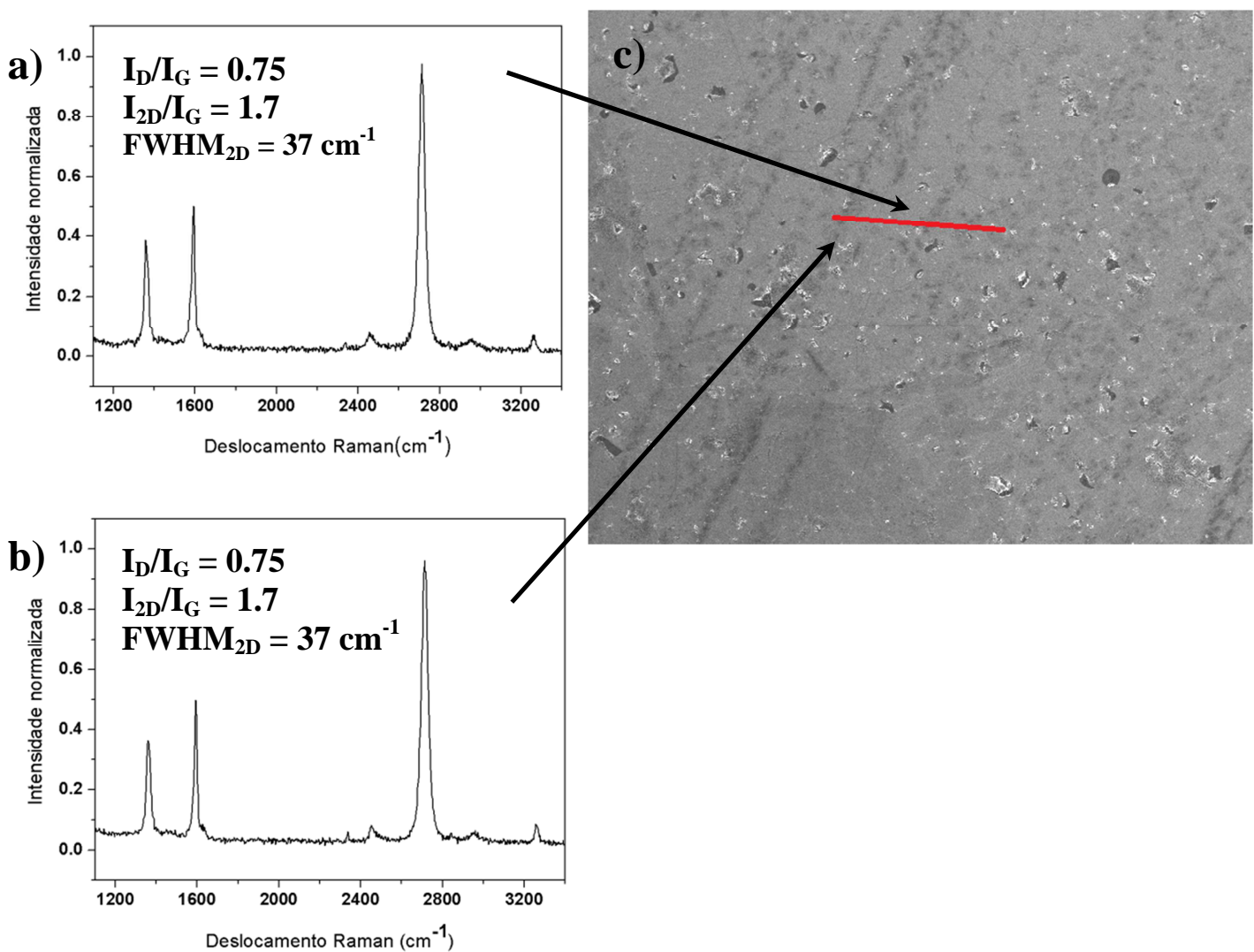

Figura 4.13 Espectros Raman normalizados em diferentes regiões da amostra crescida com $10 \mathrm{mg}$ de Trifenilfosfina, correspondendo a a) regiões sem irregularidades, b) regiões irregulares escuras, c) imagem de MEV da linha medida. As localizações aproximadas das medidas na amostra correspondem às pontas das setas. (Energia do laser $2.62 \mathrm{eV}$, potência do laser $0.15 \mathrm{~mW}$, resolução espectral de $3 \mathrm{~cm}^{-1}$ ).

Nas figuras se observa a localização aproximada das linhas de espectros medidos no Raman. Foram escolhidos dois espectros Raman específicos em cada linha medida, de forma que mostrem as variações na estrutura observadas nas imagens da microscopia. Os parâmetros mostrados para cada espectro foram calculados usando um ajuste para uma curva lorentziana e removendo o fundo. Da Figura 4.13 é evidente que não existem variações significativas no espectro na linha de estudo no caso do crescimento com $10 \mathrm{mg}$ de precursor. Já nos outros casos foram observadas mudanças. 


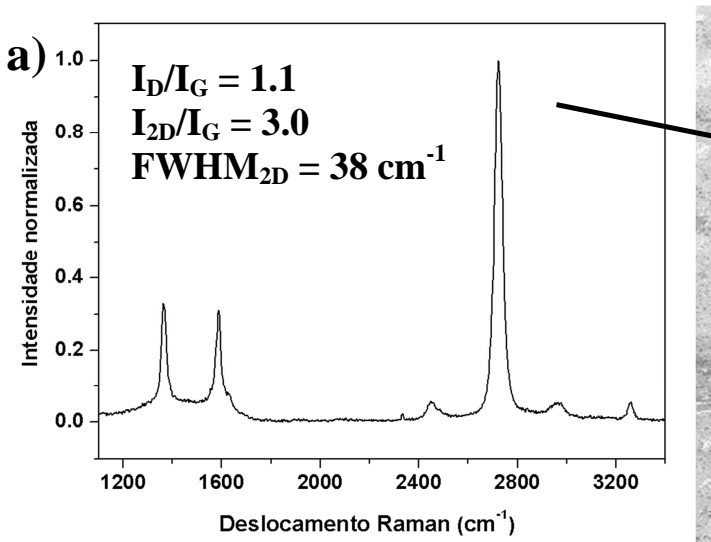

c)

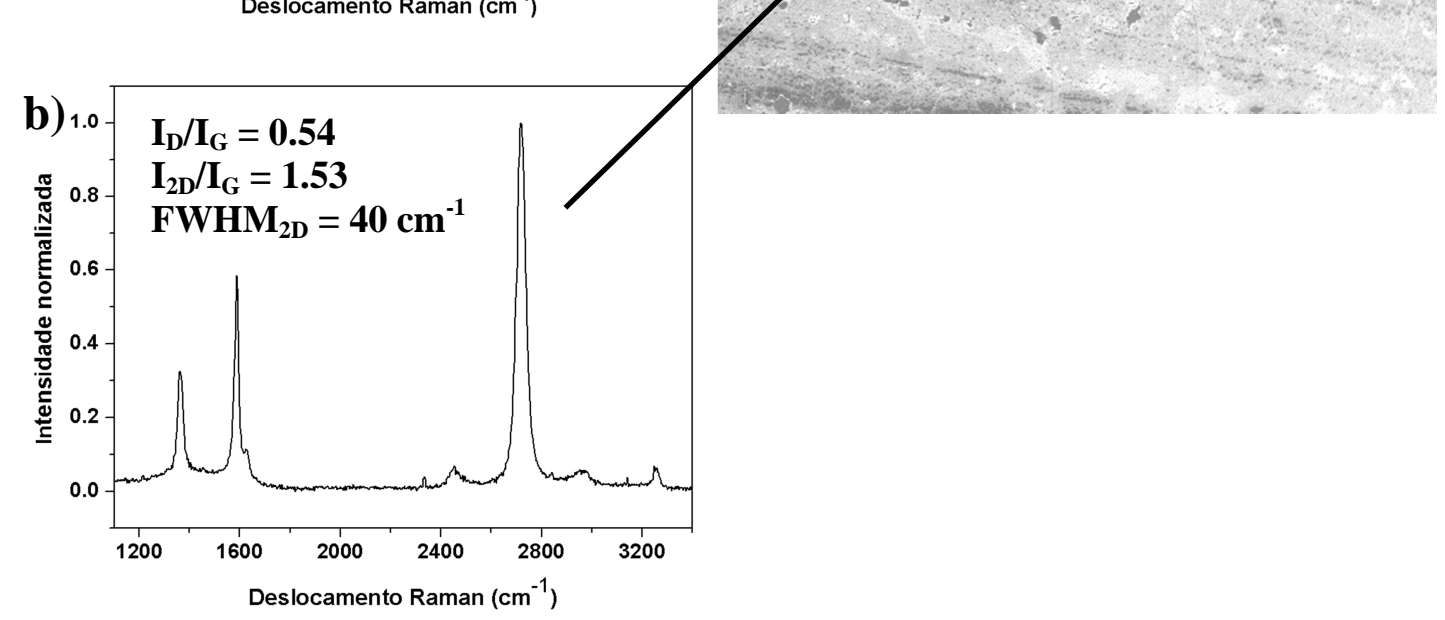

Figura 4.14 Espectros Raman normalizados em diferentes regiões da amostra crescida com $20 \mathrm{mg}$ de Trifenilfosfina, correspondendo a a) regiões sem irregularidades, b) regiões irregulares escuras, c) imagem de MEV da linha medida. As localizações aproximadas das medidas na amostra correspondem às pontas das setas. (Energia do laser $2.62 \mathrm{eV}$, potência do laser $0,15 \mathrm{~mW}$, resolução espectral de $3 \mathrm{~cm}^{-1}$ ). 


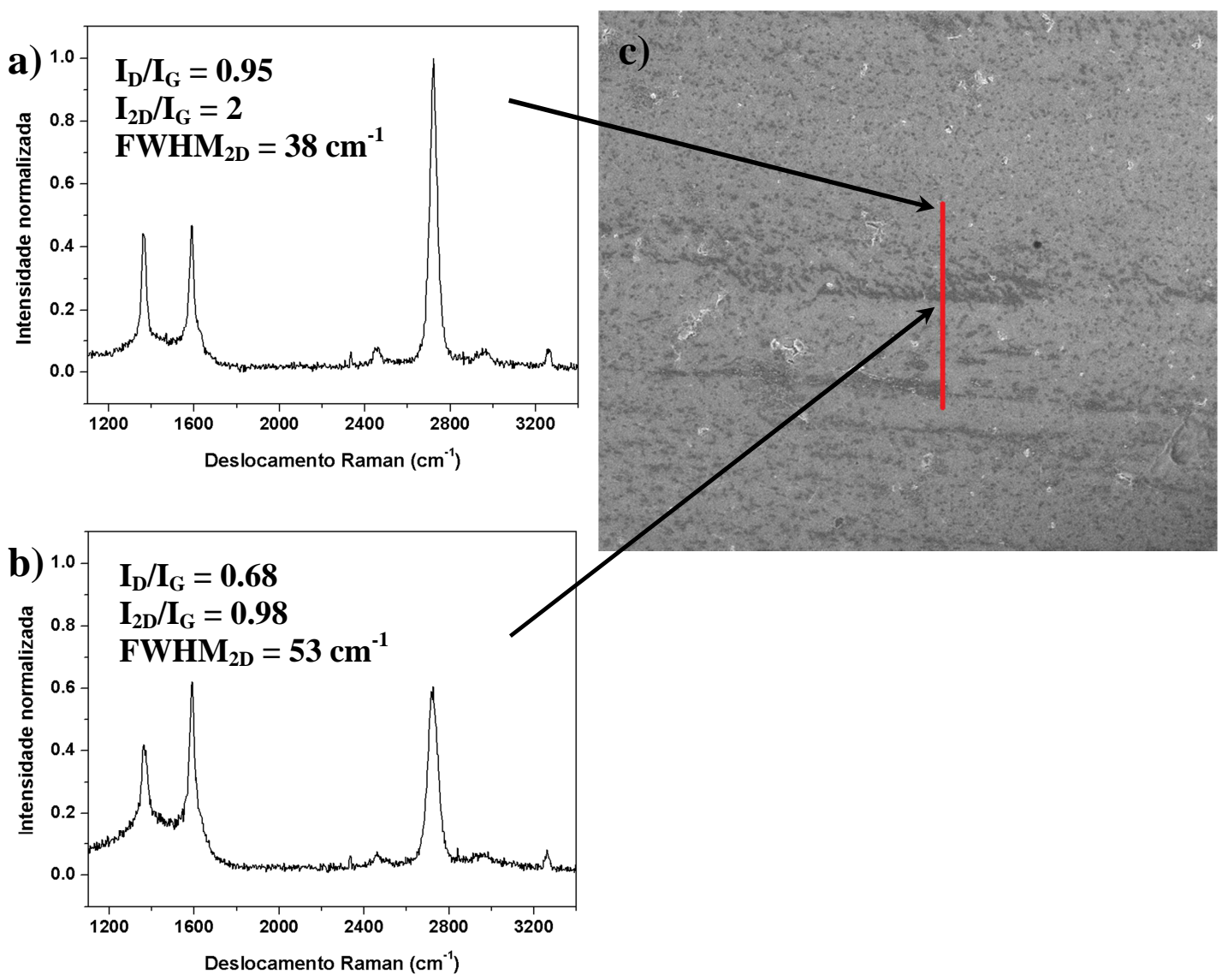

Figura 4.15 Espectros Raman normalizados em diferentes regiões da amostra crescida com $30 \mathrm{mg}$ de Trifenilfosfina, correspondendo a a) regiões sem irregularidades, b) regiões irregulares escuras, c) imagem de MEV da linha medida. As localizações aproximadas das medidas na amostra correspondem às pontas das setas. (Energia do laser $2.62 \mathrm{eV}$, potência do laser $0.15 \mathrm{~mW}$, resolução espectral de $3 \mathrm{~cm}^{-1}$ ).

Nos três últimos casos se observa uma diminuição na relação entre as intensidades das bandas 2D e G. Não foram observadas diferenças significativas nas intensidades da banda $\mathrm{G}$ entre as amostras crescidas, o que significa que as variações da relação $\mathrm{I}_{2 \mathrm{D}} / \mathrm{I}_{\mathrm{G}}$ ocorrem fundamentalmente por câmbios na intensidade da banda 2D. A variação desta banda pode ocorrer por vários motivos. A existência de zonas de multicamadas no grafeno e a divisão dos modos de vibração subsequente provocam a diminuição da intensidade da banda $2 \mathrm{D}$ e um aumento da sua largura [6]. A dopagem do filme grafeno também pode causar uma variação na intensidade da banda $2 \mathrm{D}$ e portanto da relação $\mathrm{I}_{2 \mathrm{D}} / \mathrm{I}_{\mathrm{G}}[53]$. 

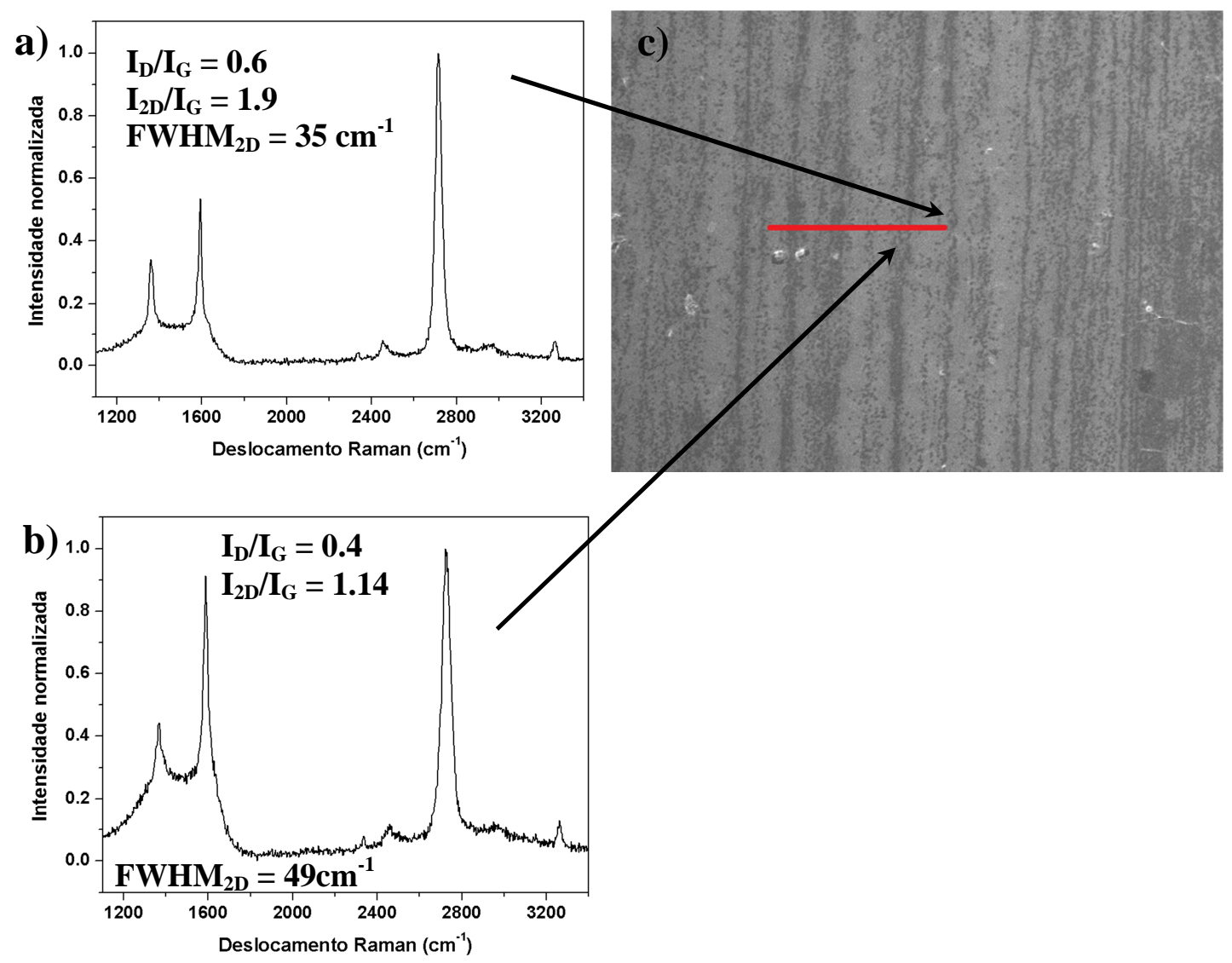

Figura 4.16 Espectros Raman normalizados em diferentes regiões da amostra crescida com $40 \mathrm{mg}$ de Trifenilfosfina, correspondendo a a) regiões sem irregularidades, b) regiões irregulares escuras, c) imagem de MEV da linha medida. As localizações aproximadas das medidas na amostra correspondem às pontas das setas. (Energia do laser $2.62 \mathrm{eV}$, potência do laser $0.15 \mathrm{~mW}$, resolução espectral de $3 \mathrm{~cm}^{-1}$ ).

Por outro lado, se observa que a relação entre as intensidades das bandas D e $\mathrm{G}\left(\mathrm{I}_{\mathrm{D}} / \mathrm{I}_{\mathrm{G}}\right)$ é maior em torno das regiões irregulares escuras que acima destas. Isto poderia estar acontecendo devido a que foi comprovado que zonas com alto índice de defeitos no grafeno não obedecem a relação de grafitização proposta por Tuinstra e Koenig[54] que estabelece uma relação proporcional entre a relação $\mathrm{I}_{\mathrm{D}} / \mathrm{I}_{\mathrm{G}}$ e a quantidade de defeitos presentes numa amostra. Estes estudos apontam que a partir de uma determinada densidade de defeitos se inverte o comportamento e a relação $\mathrm{I}_{\mathrm{D}} / \mathrm{I}_{\mathrm{G}}$ diminui[55][56]. Para os crescimentos realizados com maior quantidade de precursor se observa formação localizada de carbono amorfo, indicada pelo aumento da largura das bandas D e G, principalmente nas regiões escuras observadas na microscopia. 
Foi realizada uma analise estatística da posição da banda $\mathrm{G}$, usando um mínimo de 15 pontos em cada amostra para crescimentos com quantidades de precursor diferentes. Foi usado o caso do crescimento com metano como referência. Na Figura 4.17 se observa que para uma mesma potência do laser a banda $G$ se desloca ligeiramente para maiores frequências, atingindo um deslocamento máximo de $3 \mathrm{~cm}^{-1}$ para a amostra crescida com $30 \mathrm{mg}$ de Trifenilfosfina. Pequenos deslocamentos para maiores frequências da banda $G$ têm sido relacionados com a existência de dopagem no grafeno [53], mas este fenômeno também tem sido relacionado com altos níveis de defeitos [57].

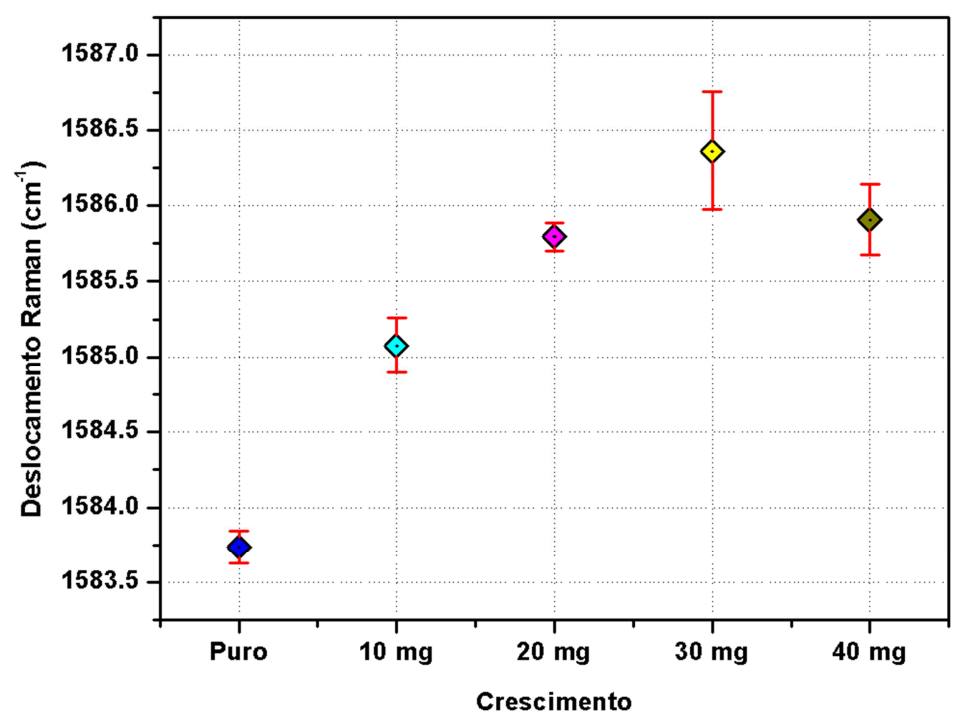

Figura 4.17 Posição da banda $G$ para o grafeno crescido com massas de precursor diferentes. As barras de erro mostram a variação da posição para diferentes pontos em cada amostra.(Energia do laser $2.62 \mathrm{eV}$, potência do laser $0.14 \mathrm{~mW}$, resolução espectral de $1 \mathrm{~cm}^{-1}$ ).

\section{6}

\section{Espectroscopia por fotoelétrons induzidos por raios X (XPS)}

Os filmes de carbono obtidos no procedimento foram analisados com um espectrômetro de fotoelétrons induzidos por raios X para identificar a presença de fósforo ou não na estrutura da amostra. Para isto foi usado uma fonte $K_{\alpha}$ de magnésio $(h v=1253.6 \mathrm{eV})$ e um analisador comercial hemisférico de elétrons VG Thermo Alpha 110. As amostras transferidas sobre o silício foram medidas numa posição rasante com respeito ao feixe de raios X. Foram feitos espectros de baixa resolução (survey) com $1 \mathrm{eV}$ de passo para identificar elementos nas amostras. 
Na Figura 4.18 observa-se um espectro completo de uma amostra crescida com 20 mg de Trifenilfosfina, onde podem ser identificadas as bandas de carbono (C1s) e oxigênio (O1s) para valores na posição de $284.5 \mathrm{eV}$ e $532.3 \mathrm{eV}$, respectivamente.

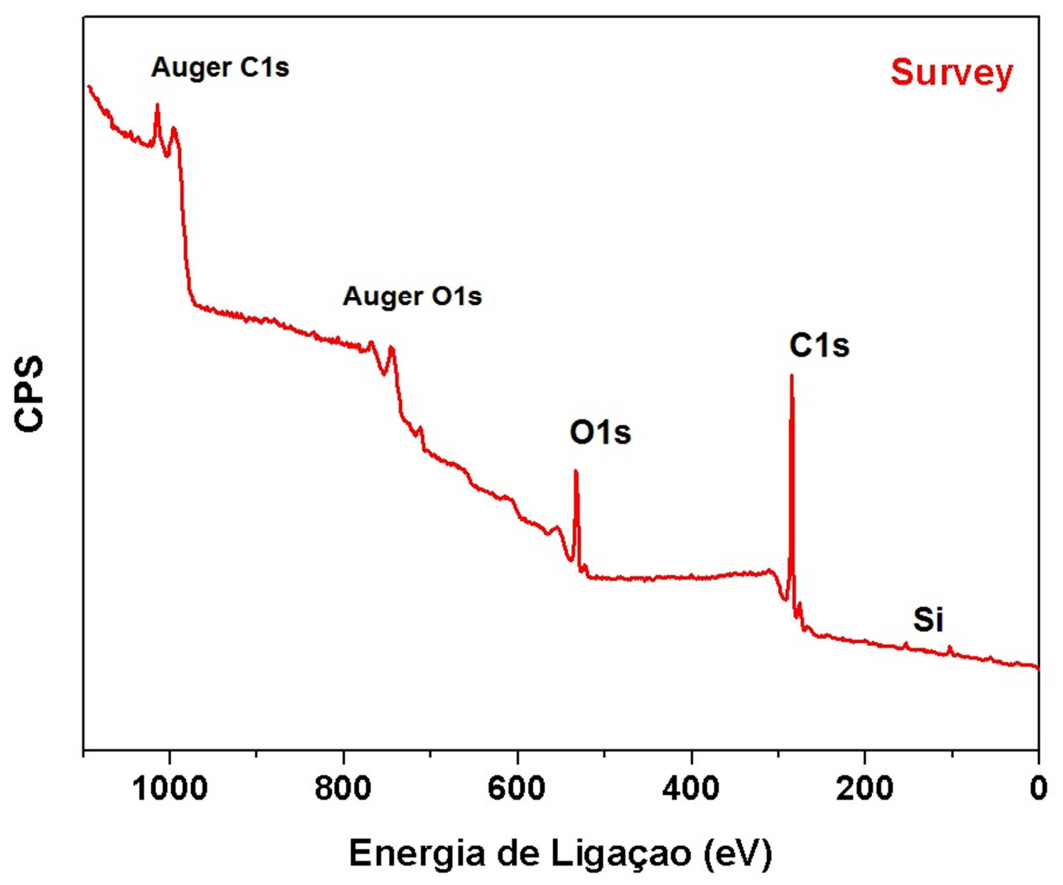

Figura 4.18 Espectro completo (survey) do grafeno crescido com $20 \mathrm{mg}$ de Trifenilfosfina e transferido para o substrato de oxido de silício. $(h v=1253.6 \mathrm{eV})(1 \mathrm{eV}$ de passo)

Além disto, são facilmente reconhecíveis as bandas Auger do Carbono e do Oxigênio para os valores da posição de 990 eV e 750 eV aproximadamente. As pequenas bandas correspondentes ao oxido de Silício ( $2 \mathrm{p}$ e $2 \mathrm{~s})$ do substrato são observadas nas posições $102 \mathrm{eV}$ e $154 \mathrm{eV}$ aproximadamente. Neste espectro não é possível identificar nenhum pico relacionado com a presença do fósforo.

$\mathrm{Na}$ análise das bandas correspondentes a cada elemento foi usado o software CasaXPS, desenvolvido para a análise de espectros de XPS [58][59][60]. Foram utilizadas no ajuste curvas de tipo Voight [61] que combinam Lorentzianas e Gaussianas e o fundo foi calculado usando curvas Shirley. Em todos os casos a posição do pico de carbono C1s foi corrigida para $284.5 \mathrm{eV}$.

Análises localizados foram realizados para as bandas de cada elemento presente na amostra com um passo de $0.1 \mathrm{eV}$. Em todos os casos a energia de 
passagem foi estabelecida em $20 \mathrm{eV}$. A Figura 4.19 mostra um espectro de XPS correspondente ao pico de carbono $\mathrm{C} 1 \mathrm{~s}$ de uma amostra crescida com $20 \mathrm{mg}$ de Trifenilfosfina. Além do pico C1s localizado no valor de $284.5 \mathrm{eV}$, é claramente visível o efeito das ligações carbono-oxigênio pela presença de picos menores nas posições $286.1 \mathrm{eV}$ e $288.7 \mathrm{eV}$.

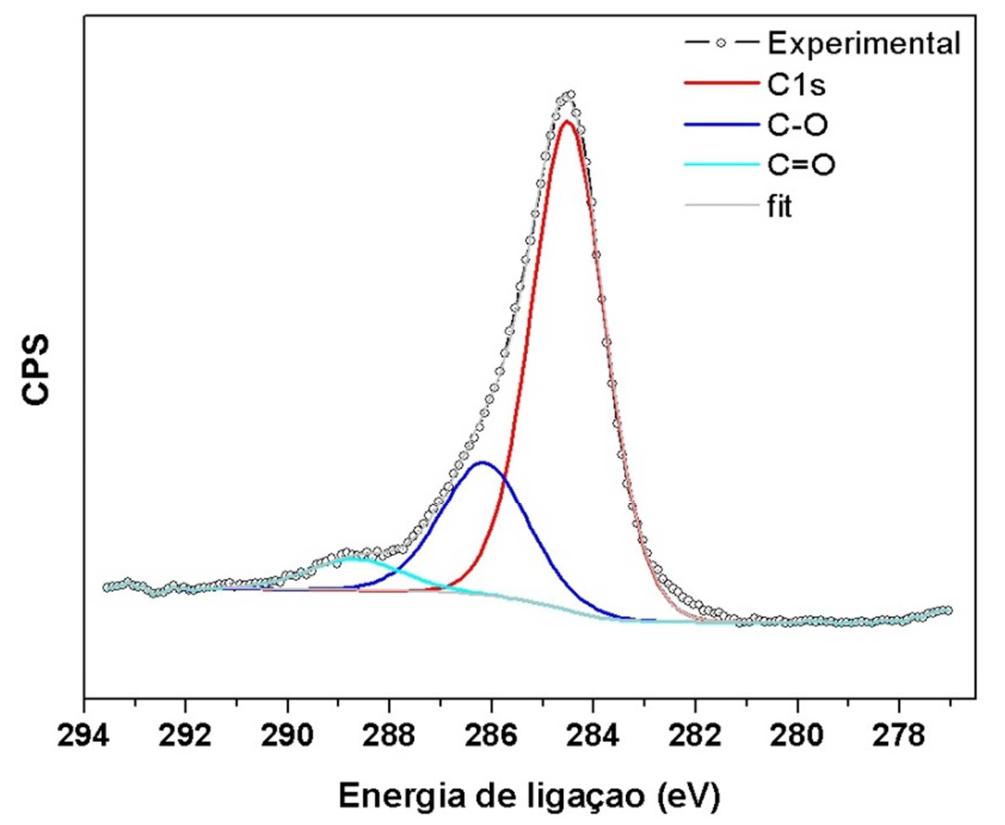

Figura 4.19 Espectro de XPS do Carbono C1s do grafeno crescido com $20 \mathrm{mg}$ de Trifenilfosfina. $O$ ajuste revela a presença de picos relacionados com o oxigênio ligado ao carbono presente na amostra. $(h v=1253.6 \mathrm{eV})(0.1 \mathrm{eV}$ de passo $)$

Não se observa neste caso nenhuma evidencia da presença de fósforo no sistema, o que se explicaria se o conteúdo deste elemento na amostra fosse pequeno segundo esperado. A presença destes picos menores correspondentes ao oxigênio ligado ao carbono pode ser atribuída fundamentalmente aos resíduos de PMMA na superfície da amostra [62].

A região do espectro XPS correspondente ao fósforo foi medida também em cada caso estudado. O ajuste foi realizado partindo da configuração do pico de fósforo P2p, formado por um dupleto que corresponde aos componentes $\mathrm{P} \_2 \mathrm{p} 3 / 2$ e P_2p1/2 com aproximadamente $0.84 \mathrm{eV}$ de diferencia entre eles. Na Figura 4.20 é mostrado o espectro do pico P2p para o crescimento com $20 \mathrm{mg}$ de precursor. 


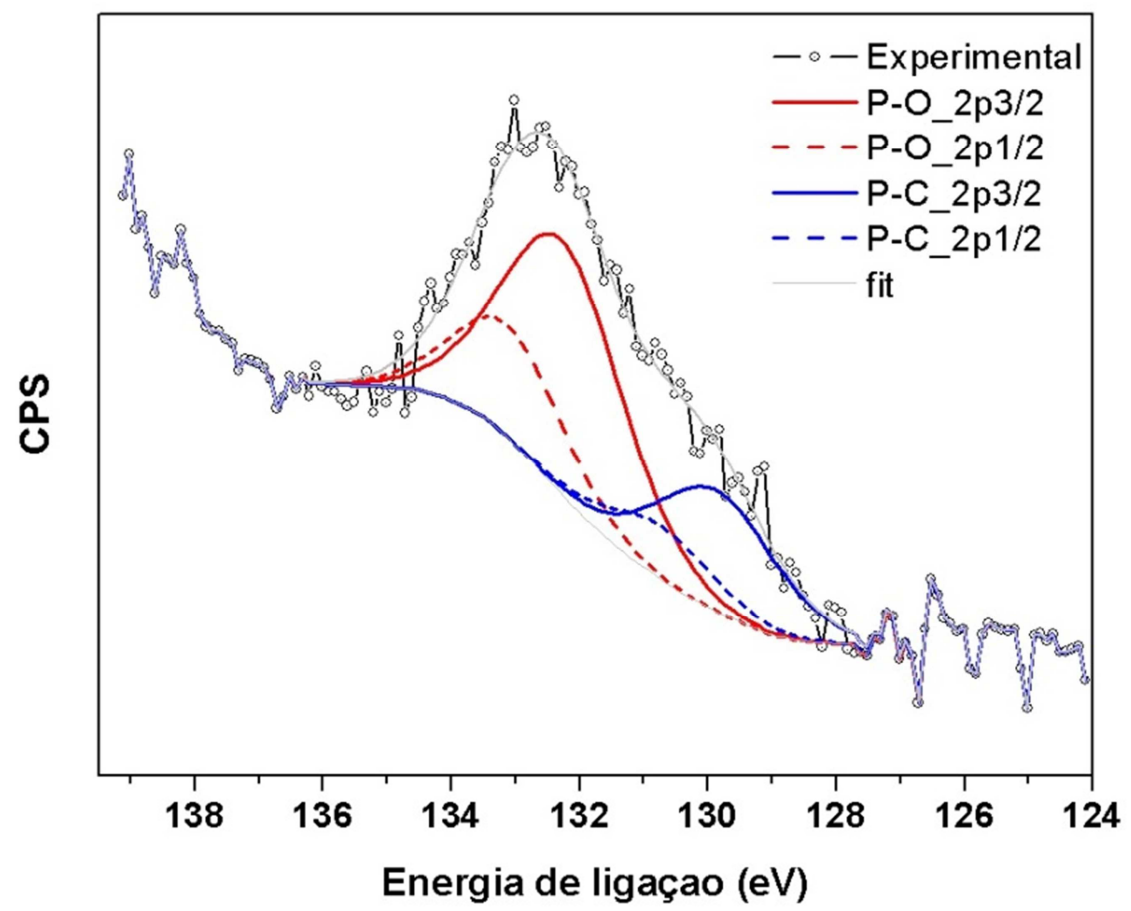

Figura 4.20 Espectro de XPS do Fósforo P2p do grafeno crescido com $20 \mathrm{mg}$ de Trifenilfosfina. $\mathrm{O}$ ajuste revela a presença de dois dupletos. ( $h v=1253.6 \mathrm{eV})(0.1 \mathrm{eV}$ de passo)

O espectro medido mostra um pico largo que pode ser ajustado em dois dupletos bem definidos. O dupleto mais importante, nas posições entre $132.7 \mathrm{e}$ $133.5 \mathrm{eV}$, é associado neste caso à ligações fósforo-oxigênio. A posição desses picos está em bom acordo com trabalhos prévios realizados sobre dopagem com fósforo em materiais à base de carbono [63]. O dupleto menor foi ajustado para as posições de $130.2 \mathrm{eV}$ e $131 \mathrm{eV}$, valores estes associados na literatura à ligação fósforo-carbono [41][64][65]. Estas medições sugerem a incorporação de fósforo no grafeno durante o crescimento.

A concentração relativa de fósforo na amostra foi estimada pela relação entre a suma das áreas correspondentes ao fósforo $\left(\mathbf{A}_{\mathbf{P}}\right)$ e a suma das áreas correspondentes ao pico do carbono $\mathrm{C} 1 \mathrm{~s}$ e ao fósforo $\left(\mathbf{A}_{\mathbf{P}}+\mathbf{A}_{\mathbf{C 1 s}}\right)$. De forma similar, o fósforo ligado ao carbono é estimado usando só as áreas correspondentes ao dupleto de fósforo ligado ao carbono. O pico do oxigênio contém uma contribuição importante por causa da camada de óxido de silício no substrato, o que impede uma avaliação correta da sua presença no filme de grafeno. Na Tabela 4.1 são mostrados os valores calculados para cada caso. O erro 
calculado é o desvio de uma média, produto da subtração de diferentes fundos nos respectivos picos. Foram tomadas em conta na estimativa as correspondentes eficiências de detecção de cada elemento e as secções efetivas de fotoionização. Para o caso do crescimento com $10 \mathrm{mg}$ de Trifenilfosfina o conteúdo de fósforo obtido foi muito pequeno e ligado ao oxigênio somente.

Tabela 4.1 Concentrações relativas estimadas de Fósforo total e Fósforo-Carbono para os casos analisados.

\begin{tabular}{|l|c|c|}
\hline Amostras & $\begin{array}{l}\text { Fósforo Total relativo } \\
(\%)\end{array}$ & $\begin{array}{l}\text { Fósforo-Carbono } \\
\text { relativo (\%) }\end{array}$ \\
\hline 10mg de $\mathbf{P}\left(\mathbf{C}_{6} \mathbf{H}_{5}\right)_{3}$ & $0.12 \pm 0,01$ & 0 \\
\hline 20mg de $\mathbf{P}\left(\mathbf{C}_{6} \mathbf{H}_{5}\right)_{3}$ & $0.61 \pm 0.02$ & $0.14 \pm 0,01$ \\
\hline 30mg de $\mathbf{P}\left(\mathbf{C}_{6} \mathbf{H}_{5}\right)_{3}$ & $0.62 \pm 0.03$ & $0.09 \pm 0.02$ \\
\hline 40mg de $\mathbf{P}\left(\mathbf{C}_{6} \mathbf{H}_{5}\right)_{3}$ & $0.68 \pm 0,05$ & $0.09 \pm 0,02$ \\
\hline
\end{tabular}

As medições realizadas para todos os casos de estudo comprovaram a incorporação de fósforo no crescimento, e foi estabelecido que uma parte dessa quantidade esta associada com ligações fósforo-carbono. Como esperado a relação entre fósforo e carbono é constante já que é sempre usado o mesmo precursor. A única exceção é quando foi utilizada a menor quantidade de precursor. O fato de não se ver o pico fósforo-carbono é explicado pelo limite de detecção da técnica XPS. 


\section{5 \\ Conclusões e perspectivas}

Neste trabalho foram obtidos filmes de grafeno usando um precursor sólido, a Trifenilfosfina, num processo de deposição química na fase vapor em alto vácuo (HVCVD). A microscopia eletrônica de Varredura permitiu observar a presença de pequenas regiões irregulares na superfície das amostras crescidas, não sendo assim para amostras obtidas usando o gás metano como precursor. Estas regiões foram observadas na microscopia antes e após o processo de transferência, sugerindo uma modificação na morfologia do filme obtido usando Trifenilfosfina como precursor no crescimento. Foi descoberto também que a área e o número destas regiões nas amostras estão diretamente ligadas à quantidade de precursor usada no crescimento.

Posteriores imagens obtidas por microscopia eletrônica de transmissão revelaram que as regiões observadas por MEV estão constituídas por zonas muito menores empilhadas muito perto umas das outras em forma de clusters localizados em determinadas zonas das amostras. Em alguns casos foi possível observar a orientação destes clusters seguindo a direção das linhas do substrato de cobre. Foi usada também a microscopia por força atômica para descobrir que estas regiões observadas por MEV sobressaem da amostra, os perfis de altura também foram obtidos.

A espectroscopia Raman foi usada para determinar a temperatura de trabalho adequada no sistema de crescimento. Foi comprovada a presença de grafeno em todas as amostras obtidas, mas foi observado que, em geral, a quantidade de defeitos nas amostras aumenta com o aumento da massa do precursor usado no crescimento. Foram observadas variações significativas nos espectros obtidos para as regiões escuras antes mencionadas e o resto do filme do grafeno. Independentemente da amostra, os espectros Raman obtidos medindo sobre as regiões escuras apresentaram menor intensidade da banda 2D e maior largura a meia altura que os espectros medidos sobre o resto do filme. A banda D apresentou valores de máxima intensidade na proximidade das regiões escuras 
observadas, mas voltou a diminuir ao medir diretamente sobre estas. A diminuição da intensidade da banda D sobre estas regiões escuras pode ser atribuída à presença de dano estrutural na rede cristalina, na presença de alta densidade de defeitos. Foi feita também uma analise estatística da posição da banda $\mathrm{G}$ nas amostras crescidas. Foi comprovado um shift Raman da posição da banda $G$ na direção de maior frequência, o qual esta de acordo com efeitos associados a incorporação de heteroátomos na estrutura do grafeno.

As medidas realizadas por XPS permitiram comprovar a incorporação de fósforo no filme crescido em cada caso. Maiores quantidades de precursor no crescimento corresponderam a uma maior quantidade de fósforo incorporado no filme. As medidas mostraram que o pico $2 p$ do fósforo pode ser dividido em dois dupletos, um deles atribuído a ligações P-O e o outro a ligações P-C. As posições destes dois dupletos ficaram de acordo com a literatura considerada.

\section{1 Perspectivas}

No futuro são necessários estudos adicionais para definir a natureza das áreas irregulares observadas na microscopia e verdadeiramente compreender a incorporação de fósforo no grafeno.

É imperativo achar alguma maneira de melhorar o controle do fluxo de precursor no crescimento através do controle da taxa de sublimação do precursor.

Uma técnica que poderia resultar muito útil neste caso poderia ser a microscopia por tunelamento, porque seria possível determinar com certeza se o fósforo incorporado esta confinado nas regiões escuras ou se também alguma pequena parte deste esta substituindo átomos de carbono diretamente na rede.

Seria importante também realizar medições de mobilidade e reatividade das amostras obtidas, com o objetivo de comparar e estudar como foram modificadas as propriedades do grafeno em comparação com o grafeno puro. 


\section{Referências bibliográficas}

[1] E. Fradkin, "Critical behavior of disordered degenerate semiconductors. I. Models, symmetries, and formalism," Phys. Rev. $B$, vol. 33, no. 5, 1986.

[2] K. S. Novoselov, a K. Geim, S. V Morozov, D. Jiang, Y. Zhang, S. V Dubonos, I. V Grigorieva, and a a Firsov, "Electric field effect in atomically thin carbon films.," Science, vol. 306, no. 5696, pp. 6669, Oct. 2004.

[3] a K. Geim and K. S. Novoselov, "The rise of graphene.," Nat. Mater., vol. 6, no. 3, pp. 183-91, Mar. 2007.

[4] R. Saito, G. Dresselhaus, and M. Dresselahus, Physical Properties of Carbon Nanotubes. 1998, p. 272.

[5] a. H. Castro Neto, N. M. R. Peres, K. S. Novoselov, and a. K. Geim, "The electronic properties of graphene," Rev. Mod. Phys., vol. 81, no. 1, pp. 109-162, Jan. 2009.

[6] a. C. Ferrari, J. C. Meyer, V. Scardaci, C. Casiraghi, M. Lazzeri, F. Mauri, S. Piscanec, D. Jiang, K. S. Novoselov, S. Roth, and a. K. Geim, "Raman Spectrum of Graphene and Graphene Layers," Phys. Rev. Lett., vol. 97, no. 18, p. 187401, Oct. 2006.

[7] M. Castriota, E. Cazzanelli, D. Pacilè, L. Papagno, Ç. O. Girit, J. C. Meyer, A. Zettl, M. Giarola, and G. Mariotto, "Spatial dependence of Raman frequencies in ordered and disordered monolayer graphene," Diam. Relat. Mater., vol. 19, no. 5-6, pp. 608-613, May 2010.

[8] K. V Emtsev, A. Bostwick, K. Horn, J. Jobst, G. L. Kellogg, L. Ley, J. L. McChesney, T. Ohta, S. a Reshanov, J. Röhrl, E. Rotenberg, A. K. Schmid, D. Waldmann, H. B. Weber, and T. Seyller, "Towards wafer-size graphene layers by atmospheric pressure graphitization of silicon carbide.," Nat. Mater., vol. 8, no. 3, pp. 203-7, Mar. 2009.

[9] K. The and K. Furthermore, "How silicon leaves the scene," vol. 8, no. March, pp. 171-172, 2009.

[10] H. J. Park, J. Meyer, S. Roth, and V. Skákalová, "Growth and properties of few-layer graphene prepared by chemical vapor deposition," Carbon N. Y., vol. 48, no. 4, pp. 1088-1094, Apr. 2010.

[11] Y. W. Y. Wang, C. M. C. Miao, B. H. B. Huang, J. Z. J. Zhu, W. L. W. Liu, Y. P. Y. Park, Y. X. Y. Xie, and J. C. S. Woo, "Scalable 
Synthesis of Graphene on Patterned Ni and Transfer," IEEE Trans. Electron Devices, vol. 57, 2010.

[12] A. Reina, X. Jia, J. Ho, D. Nezich, H. Son, V. Bulovic, M. S. Dresselhaus, and J. Kong, "Large area, few-layer graphene films on arbitrary substrates by chemical vapor deposition.," Nano Lett., vol. 9, no. 1, pp. 30-5, Jan. 2009.

[13] I. Vlassiouk, P. Fulvio, H. Meyer, N. Lavrik, S. Dai, P. Datskos, and S. Smirnov, "Large scale atmospheric pressure chemical vapor deposition of graphene," Carbon N. Y., vol. 54, pp. 58-67, Apr. 2013.

[14] X. Li, W. Cai, J. An, S. Kim, J. Nah, D. Yang, R. Piner, A. Velamakanni, I. Jung, E. Tutuc, S. K. Banerjee, L. Colombo, and R. S. Ruoff, "Large-area synthesis of high-quality and uniform graphene films on copper foils.," Science, vol. 324, no. 5932, pp. 1312-4, Jun. 2009.

[15] J. K. Wassei, M. Mecklenburg, J. a Torres, J. D. Fowler, B. C. Regan, R. B. Kaner, and B. H. Weiller, "Chemical vapor deposition of graphene on copper from methane, ethane and propane: evidence for bilayer selectivity.," Small, vol. 8, no. 9, pp. 1415-22, May 2012.

[16] S.-Y. Kwon, C. V Ciobanu, V. Petrova, V. B. Shenoy, J. Bareño, V. Gambin, I. Petrov, and S. Kodambaka, "Growth of semiconducting graphene on palladium.," Nano Lett., vol. 9, no. 12, pp. 3985-90, Dec. 2009.

[17] P. W. Sutter, J.-I. Flege, and E. A. Sutter, "Epitaxial graphene on ruthenium.," Nat. Mater., vol. 7, pp. 406-411, 2008.

[18] J. Coraux, A. T. N'Diaye, M. Engler, C. Busse, D. Wall, N. Buckanie, F.-J. M. zu Heringdorf, R. van Gastel, B. Poelsema, and T. Michely, "Growth of graphene on Ir(111)," New Journal of Physics, vol. 11. p. 039801, 2009.

[19] B. C. BANERJEE, T. J. HIRT, and P. L. WALKER, "Pyrolytic Carbon Formation from Carbon Suboxide," Nature, vol. 192, no. 4801, pp. 450-451, Nov. 1961.

[20] H. O. Pierson, Handbook of Chemical Vapor Deposition (CVD). 1999, pp. 464-485.

[21] X. Li, C. W. Magnuson, A. Venugopal, R. M. Tromp, J. B. Hannon, E. M. Vogel, L. Colombo, and R. S. Ruo, "Large-Area Graphene Single Crystals Grown by Low-Pressure,” pp. 3-6, 2011. 
[22] Q. Yu, L. a Jauregui, W. Wu, R. Colby, J. Tian, Z. Su, H. Cao, Z. Liu, D. Pandey, D. Wei, T. F. Chung, P. Peng, N. P. Guisinger, E. a Stach, J. Bao, S.-S. Pei, and Y. P. Chen, "Control and characterization of individual grains and grain boundaries in graphene grown by chemical vapour deposition.," Nat. Mater., vol. 10, no. 6, pp. 443-9, Jun. 2011.

[23] D. Wei, Y. Liu, Y. Wang, H. Zhang, L. Huang, and G. Yu, "Synthesis of $\mathrm{N}$-doped graphene by chemical vapor deposition and its electrical properties.," Nano Lett., vol. 9, no. 5, pp. 1752-8, May 2009.

[24] R. Lv and M. Terrones, "Towards new graphene materials: Doped graphene sheets and nanoribbons," Mater. Lett., vol. 78, pp. 209218, Jul. 2012.

[25] N. Li, Z. Wang, K. Zhao, Z. Shi, Z. Gu, and S. Xu, "Large scale synthesis of $\mathrm{N}$-doped multi-layered graphene sheets by simple arcdischarge method," Carbon N. Y., vol. 48, no. 1, pp. 255-259, Jan. 2010.

[26] Y. Wang, Y. Shao, D. W. Matson, J. Li, and Y. Lin, "Nitrogen-doped graphene and its application in electrochemical biosensing.," $A C S$ Nano, vol. 4, pp. 1790-1798, 2010.

[27] R. Lv, Q. Li, A. R. Botello-Méndez, T. Hayashi, B. Wang, A. Berkdemir, Q. Hao, A. L. Elías, R. Cruz-Silva, H. R. Gutiérrez, Y. A. Kim, H. Muramatsu, J. Zhu, M. Endo, H. Terrones, J.-C. Charlier, M. Pan, and M. Terrones, "Nitrogen-doped graphene: beyond single substitution and enhanced molecular sensing.," Sci. Rep., vol. 2, p. 586, Jan. 2012.

[28] Z.-H. Sheng, H.-L. Gao, W.-J. Bao, F.-B. Wang, and X.-H. Xia, "Synthesis of boron doped graphene for oxygen reduction reaction in fuel cells," J. Mater. Chem., vol. 22, no. 2, p. 390, 2012.

[29] L. S. Panchakarla, K. S. Subrahmanyam, S. K. Saha, A. Govindaraj, H. R. Krishnamurthy, U. V. Waghmare, and C. N. R. Rao, "Synthesis, Structure, and Properties of Boron- and Nitrogen-Doped Graphene," Adv. Mater., vol. 560012, p. NA-NA, Aug. 2009.

[30] P. a. Denis, "Band gap opening of monolayer and bilayer graphene doped with aluminium, silicon, phosphorus, and sulfur," Chem. Phys. Lett., vol. 492, no. 4-6, pp. 251-257, Jun. 2010.

[31] A. G. Garcia, S. E. Baltazar, A. H. R. Castro, J. F. P. Robles, and A. Rubio, "Influence of $S$ and P Doping in a Graphene Sheet," J. Comput. Theor. Nanosci., vol. 5, no. 11, pp. 2221-2229, Nov. 2008.

[32] T. Citj, "R [[ LAT | D / TER | ALS Growth and characterization of phosphorus doped n-type diamond thin films," pp. 0-4, 1998. 
[33] S. Koizumi, T. Teraji, and H. Kanda, "Phosphorus-doped chemical vapor deposition of diamond," Diam. Relat. Mater., vol. 9, no. 3-6, pp. 935-940, Apr. 2000.

[34] A. Kraft, G. Gmbh, and K. Str, "Doped Diamond: A Compact Review on a New , Versatile Electrode Material," vol. 2, pp. 355-385, 2007.

[35] H. Sternschulte, K. Thonke, R. Sauer, and S. Koizumi, "Optical evidence for 630-meV phosphorus donor in synthetic diamond," Phys. Rev. B, vol. 59, no. 20, pp. 12924-12927, May 1999.

[36] P. a. Denis, "Concentration dependence of the band gaps of phosphorus and sulfur doped graphene," Comput. Mater. Sci., vol. 67, pp. 203-206, Feb. 2013.

[37] P. a. Denis, "When noncovalent interactions are stronger than covalent bonds: Bilayer graphene doped with second row atoms, aluminum, silicon, phosphorus and sulfur," Chem. Phys. Lett., vol. 508, no. 1-3, pp. 95-101, May 2011.

[38] H. Wang, H. Wang, Y. Chen, Y. Liu, J. Zhao, Q. Cai, and X. Wang, "Phosphorus-doped graphene and $(8,0)$ carbon nanotube: Structural, electronic, magnetic properties, and chemical reactivity," Appl. Surf. Sci., vol. 273, no. 2, pp. 302-309, May 2013.

[39] E. Cruz-Silva, F. Lopez-Urias, E. Munoz-Sandoval, B. G. Sumpter, H. Terrones, J.-C. Charlier, V. Meunier, and M. Terrones, "Phosphorus and phosphorus-nitrogen doped carbon nanotubes for ultrasensitive and selective molecular detection.," Nanoscale, vol. 3, no. 3, pp. 1008-13, Mar. 2011.

[40] F. Niu, L.-M. Tao, Y.-C. Deng, Q.-H. Wang, and W.-G. Song, "Phosphorus doped graphene nanosheets for room temperature NH3 sensing," New J. Chem., pp. 1-4, 2014.

[41] D. Yu, Y. Xue, and L. Dai, "Vertically Aligned Carbon Nanotube Arrays Co-doped with Phosphorus and Nitrogen as Efficient MetalFree Electrocatalysts for Oxygen Reduction," J. Phys. Chem. Lett., vol. 3, pp. 2863-2870, 2012.

[42] C. Zhang, N. Mahmood, H. Yin, F. Liu, and Y. Hou, "Synthesis of Phosphorus-Doped Graphene and its Multifunctional Applications for Oxygen Reduction Reaction and Lithium Ion Batteries," pp. 1-6, 2013.

[43] C. H. Choi, M. W. Chung, S. H. Park, and S. I. Woo, "Additional doping of phosphorus and/or sulfur into nitrogen-doped carbon for efficient oxygen reduction reaction in acidic media.," Phys. Chem. Chem. Phys., vol. 15, no. 6, pp. 1802-5, Feb. 2013. 
[44] Z.-W. Liu, F. Peng, H.-J. Wang, H. Yu, W.-X. Zheng, and J. Yang, "Phosphorus-Doped Graphite Layers with High Electrocatalytic Activity for the $\mathrm{O} 2$ Reduction in an Alkaline Medium," Angew. Chemie, vol. 123, no. 14, pp. 3315-3319, Mar. 2011.

[45] A. C. Ferrari, "Raman spectroscopy of graphene and graphite: Disorder, electron-phonon coupling, doping and nonadiabatic effects," Solid State Commun., vol. 143, no. 1-2, pp. 47-57, Jul. 2007.

[46] M. S. Dresselhaus, A. Jorio, and R. Saito, "Characterizing Graphene, Graphite, and Carbon Nanotubes by Raman Spectroscopy," Annu. Rev. Condens. Matter Phys., vol. 1, no. 1, pp. 89-108, Aug. 2010.

[47] P. Venezuela, M. Lazzeri, and F. Mauri, "Theory of double-resonant Raman spectra in graphene: intensity and line shape of defectinduced and two-phonon bands," Phys. Rev. B, vol. 8, pp. 035433, jul. 2011.

[48] A. C. Ferrari and D. M. Basko, "Raman spectroscopy as a versatile tool for studying the properties of graphene.," Nat. Nanotechnol., vol. 8, no. 4, pp. 235-46, Apr. 2013.

[49] C. Mattevi, H. Kim, and M. Chhowalla, "A review of chemical vapour deposition of graphene on copper," J. Mater. Chem., vol. 21, no. 10, p. 3324, 2011.

[50] X. Li, Y. Zhu, W. Cai, M. Borysiak, B. Han, D. Chen, R. D. Piner, L. Colombo, and R. S. Ruoff, "Transfer of large-area graphene films for high-performance transparent conductive electrodes.," Nano Lett., vol. 9, no. 12, pp. 4359-63, Dec. 2009.

[51] G. H. Han, F. Güneş, J. J. Bae, E. S. Kim, S. J. Chae, H.-J. Shin, J.Y. Choi, D. Pribat, and Y. H. Lee, "Influence of copper morphology in forming nucleation seeds for graphene growth.," Nano Lett., vol. 11, pp. 4144-8, 2011.

[52] J. D. Wood, S. W. Schmucker, A. S. Lyons, E. Pop, and J. W. Lyding, "Effects of Polycrystalline Cu Substrate on Graphene Growth by Chemical Vapor Deposition," Nano Lett., vol. 11, pp. 4547-4554, 2011.

[53] a Das, S. Pisana, B. Chakraborty, S. Piscanec, S. K. Saha, U. V Waghmare, K. S. Novoselov, H. R. Krishnamurthy, a K. Geim, a C. Ferrari, and a K. Sood, "Monitoring dopants by Raman scattering in an electrochemically top-gated graphene transistor.," Nat. Nanotechnol., vol. 3, no. 4, pp. 210-5, Apr. 2008. 
[54] F. Tuinstra, "Raman Spectrum of Graphite," J. Chem. Phys., vol. 53, no. 3, p. 1126, 1970.

[55] M. S. Dresselhaus, a Jorio, a G. Souza Filho, and R. Saito, "Defect characterization in graphene and carbon nanotubes using Raman spectroscopy.," Philos. Trans. A. Math. Phys. Eng. Sci., vol. 368, no. 1932, pp. 5355-77, Dec. 2010.

[56] A. Jorio, E. H. M. Ferreira, F. Stavale, C. A. Achete, R. B. Capaz, M. V. O. Moutinho, A. Lombardo, T. S. Kulmala, and A. C. Ferrari, "Quantifying Defects in Graphene via Raman Spectroscopy at Different Excitation Energies," pp. 3190-3196, 2011.

[57] C. Deng, S. Member, W. Lin, S. Eimer, D. Ravelosona, C. Chappert, and W. Zhao, "Raman Spectroscopy Study of Low Energy He + Ion Irradiation Effect in Graphene Transferred onto SiO 2 *," pp. 903906, 2013.

[58] K. Axis, "Peak Fitting in XPS," Bioengineering, pp. 1-29, 2006.

[59] M. C. Biesinger, B. P. Payne, A. P. Grosvenor, L. W. M. Lau, A. R. Gerson, and R. S. C. Smart, "Resolving surface chemical states in XPS analysis of first row transition metals, oxides and hydroxides: $\mathrm{Cr}, \mathrm{Mn}, \mathrm{Fe}$, Co and Ni," Appl. Surf. Sci., vol. 257, no. 7, pp. 27172730, Jan. 2011.

[60] J. Yan, T. Wei, W. Qiao, B. Shao, Q. Zhao, L. Zhang, and Z. Fan, "Rapid microwave-assisted synthesis of graphene nanosheet/Co3O4 composite for supercapacitors," Electrochimica Acta, vol. 55. pp. 6973-6978, 2010.

[61] I. Nacional, D. I. Nucleares, A. P. No, and C. Escandón, "An expression for an approximation of the Voigt profile I Y ," vol. 300, pp. 159-163, 1991.

[62] J. W. Suk, W. H. Lee, J. Lee, H. Chou, R. D. Piner, Y. Hao, D. Akinwande, and R. S. Ruo, "Enhancement of the Electrical Properties of Graphene Grown by Chemical Vapor Deposition via Controlling the E ff ects of Polymer Residue," 2013.

[63] E. Cruz-Silva, D. A. Cullen, L. Gu, J. M. Romo-Herrera, E. MuñozSandoval, F. López-Urías, B. G. Sumpter, V. Meunier, J. Charlier, D. J. Smith, H. Terrones, and M. Terrones, "Heterodoped nanotubes: theory, synthesis, and characterization of phosphorus-nitrogen doped multiwalled carbon nanotubes.," ACS Nano, vol. 2, no. 3, pp. 441-8, Mar. 2008.

[64] D. G. Larrude, M. E. H. Maia da Costa, F. H. Monteiro, a. L. Pinto, and F. L. Freire, "Characterization of phosphorus-doped multiwalled carbon nanotubes," J. Appl. Phys., vol. 111, no. 6, p. 064315, 2012. 
[65] J. N. Hart, P. W. May, N. L. Allan, K. R. Hallam, F. Claeyssens, G. M. Fuge, M. Ruda, and P. J. Heard, "Towards new binary compounds: Synthesis of amorphous phosphorus carbide by pulsed laser deposition," J. Solid State Chem., vol. 198, pp. 466-474, Feb. 2013. 